\title{
Input-parallel Output-series DC-DC Boost Converter with a Wide Input Voltage Range, for Fuel Cell Vehicles
}

\author{
Ping Wang, Lei Zhou, Yun Zhang, IEEE, Member, Jing Li, IEEE, Member, and Mark Sumner, Senior Member, \\ IEEE
}

\begin{abstract}
An input-parallel, output-series DC-DC Boost converter with a wide input voltage range is proposed in this paper. An interleaved structure is adopted in the input side of this converter to reduce input current ripple. Two capacitors are connected in series on the output side to achieve a high voltage-gain. The operating principles and steady-state characteristics of the converter are presented and analyzed in this paper. A $400 \mathrm{~V} / 1.6 \mathrm{~kW}$ prototype has been created which demonstrates that a wide range of voltage-gain can be achieved by this converter and it is shown that the maximum efficiency of the converter is $96.62 \%$, and minimum efficiency is $94.14 \%$ The experimental results validate the feasibility of the proposed topology and its suitability for fuel cell vehicles.
\end{abstract}

KEY WORDS: Input-parallel output-series; Wide voltage-gain range; Current ripple; Voltage stress; Fuel cell vehicles.

\section{INTRODUCTION}

Traditional fossil fuel resources are depleting quickly, but their continued use contributes to increasing pollution [1]-[3]. Development of clean energy systems is essential. Photovoltaic power generation, wind power generation and fuel cell power generation are important clean energy technologies [4]-[6]. With regard to transport, clean-energy vehicles which include fuel cell vehicles, pure electric vehicles, and hybrid energy source vehicles can be considered one of the most essential applications for clean-energy [7]-[8]. Fuel cell vehicles can provide clean propulsion power with zero emission, as well as higher energy utilization [9]. However, the use of fuel cells brings challenges, particularly with their low output voltage and high output current [10]. The main DC link bus of fuel cell vehicles has a high voltage level $(400 \mathrm{~V})$, making it difficult to directly match voltages between the fuel cell stack and the main DC link bus. The fuel cell also has a "soft" output characteristic [11] - its output voltage varies with load - and it must be interfaced to the main DC link bus through a step-up DC-DC converter with a wide range of voltage-gain. In addition the input current ripple of the converter for fuel cells must be low enough to prevent accelerated reduction of the life time of the fuel cell [12].

The conventional DC-DC Boost converter is employed due to its simple structure, but it suffers from disadvantages including limited voltage-gain due to parasitic parameters and the extreme duty cycle, and high voltage stress for its power semiconductors. The conventional interleaved Boost DC-DC converter can obtain low input current ripple, but this converter still has certain disadvantages including limited voltage-gain and high voltage stress for power semiconductors. The voltage stress for power semiconductors in the three-level DC-DC Boost converter in [13] can be reduced by half, but its voltage-gain is still limited. What's more, the output and input sides of this converter are connected by a diode; the potential difference between the two sides is a high frequency PWM voltage, which may result in additional maintenance requirements and increased EMI. The output and input sides of the Boost three-level DC-DC converter in [14] share a common ground, but the voltage-gain of this converter is still restricted. In addition, this converter requires a complicated control scheme to balance the flying-capacitor voltage. The multilevel DC-DC Boost converter in [15] obtains a high voltage-gain, and low voltage stress for the power semiconductors. However, this converter is too complex for automotive applications and requires reductions in cost and size. The converter proposed in [16] uses a $\mathrm{Z}$ source network to achieve a higher voltage-gain, but the output and the input sides do not share a common ground, which may result in 
maintenance safety issues and additional EMI. The Quasi-Z source network is applied to the conventional Boost DC-DC converter in [17]. This converter, with high voltage gain also has a high voltage stress for the power semiconductors. The converter in [18] which applied a switched-inductor structure, can achieve a high voltage-gain, but a diode in the converter suffers high voltage stress. Non-isolated DC-DC converters with coupled inductors can obtain a high voltage-gain, low voltage stress for power semiconductors and high efficiency. There are many types of DC-DC converters with coupled inductors discussed in [19]-[22]. The converter with coupled inductors in [19] can obtain a high voltage-gain and low voltage stress for power semiconductors, but it suffers high ripple of input current. Interleaved boost converters with coupled inductors discussed in [20] have advantages of high voltage-gain and low input current ripple. However, these converters have high voltage stress for power semiconductors. Stacked high step-up coupled-inductor boost converters discussed in [21] can obtained a very high voltage-gain and low voltage stress for power semiconductors, but the input current ripple of these converters are higher. The interleaved boost converters with winding-cross-coupling mentioned in [21] obtain a high voltage-gain, low voltage stress for power semiconductors and low input current ripple. The Cascaded boost converters [22] can also obtain a high voltage-gain, but these converters have high input current ripple. In addition, their efficiencies are the product of the efficiency of each stage.

Some of the DC-DC converters described do not provide low input current ripple, high voltage-gain, and low voltage stress for power semiconductors at the same time. In this paper, an input-parallel output-series DC-DC Boost converter with a wide input voltage range is proposed as a solution. Compared with the conventional interleaved DC-DC Boost converter and the three-level DC-DC Boost converter, this converter has advantages including low input current ripple, low voltage stress for power semiconductors, and high voltage-gain. In addition, the potential difference between the output and the input sides of this converter is a capacitor voltage rather than a high frequency PWM voltage. This paper is organized as follows: in Section II, the topology of the input-parallel output-series Boost DC-DC converter is presented. The operating principles of the converter topology are discussed in Section III. In Section IV, the steady-state characteristics of the converter are analyzed. The experimental results and analysis are given in Section $V$. Finally, the conclusions are presented in Section VI.

\section{TOPOLOGY OF PROPOSED CONVERTER}

The proposed input-parallel output-series DC-DC Boost converter is shown in Fig. 1. The conventional DC-DC Boost converter topology can be formed by inductor $L_{1}$, power switch $Q_{1}$, diode $D_{1}$ and capacitor $C_{2}$. Similarly, inductor $L_{2}$, power switch $Q_{2}$, and capacitors $C_{1}$ and $C_{3}$ constitute a Boost DC-DC converter whose output voltage polarity is opposite to the input voltage polarity. These two converters are connected in parallel at the input side and in series at the output side: this arrangement forms the input-parallel output-series DC-DC Boost converter.

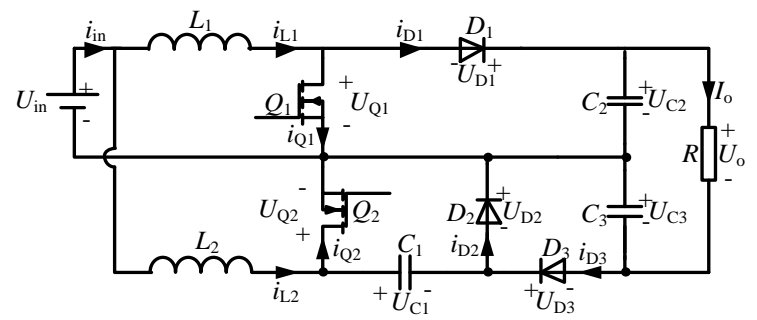

Fig. 1 The topology of the input-parallel output-series DC-DC Boost converter.

The topology of the converter comprises 2 inductors, 2 active power switches and 3 diodes. It is assumed that $L_{1}=L_{2}, C_{1}=C_{2}=C_{3}, U_{\text {in }}$ is the input voltage, and $i_{\text {in }}$ is the input current. $i_{\mathrm{L} 1}$ and $i_{\mathrm{L} 2}$ are the currents flowing through $L_{1}$ and $L_{2}$ respectively. The currents of $Q_{1}, Q_{2}, D_{1}, D_{2}$, and $D_{3}$ are $i_{\mathrm{Q} 1}, i_{\mathrm{Q} 2}, i_{\mathrm{D} 1}, i_{\mathrm{D} 2}$, and $i_{\mathrm{D} 3}$ respectively. In addition, $U_{\mathrm{D} 1}, U_{\mathrm{D} 2}, U_{\mathrm{D} 3}, U_{\mathrm{C} 1}, U_{\mathrm{C} 2}$, and $U_{\mathrm{C} 3}$ are the voltage stress of $D_{1}, D_{2}, D_{3}, C_{1}, C_{2}$, and $C_{3}$ respectively. $U_{\mathrm{o}}$ is the output voltage, and $I_{\mathrm{o}}$ is the output current. An interleaved structure is adopted in the input side of this converter to reduce input current ripple. In addition, the two capacitors at the output side are connected in series to obtain a high voltage-gain. 


\section{OPERATING PRINCIPLES}

In order to analyze the steady-state characteristics of the proposed converter, the operation conditions are assumed to be as follows: (a) all the power semiconductors and energy storage components are ideal, which means the on-state resistances of power semiconductors, the forward voltage drop of the diodes, and the equivalent series resistances (ESRs) of the inductors and capacitors are ignored. (b) all the capacitances are large enough such that each capacitor voltage can be treated as constant. An interleaved structure is used in the input side of this converter. In this case, the relationship between $d_{1}$ and $d_{2}$ can be written as $d_{1}=d_{2}=d$, where $d_{1}$ and $d_{2}$ are the duty cycles of $Q_{1}$ and $Q_{2}$ respectively. The phase difference between the gate driving signals of $Q_{1}$ and $Q_{2}$ is $180^{\circ}$.

According to the operation of $Q_{1}$ and $Q_{2}$, when the proposed converter operates in the continuous conduction mode (CCM), there are four switching states described as " $S_{1} S_{2} "$ in a switching period, $S_{1} S_{2}=\{00,01,10,11\}$. In addition, the sequence of the switching states in a switching period is related to the duty cycle ranges of $Q_{1}$ and $Q_{2}$. Sequence $I$ "10-00-01-00-10" appears within the range of $0<d<0.5$, while Sequence II "11-10-11-01-11" is obtained within the range of $0.5<d<1$.

When the proposed converter operated in the discontinuous conduction mode (DCM), there are seven switching states in each switching period, $S_{1} S_{2}=\{01,10$, $\left.11,10_{\mathrm{D}}, 01_{\mathrm{D}}, 00_{\mathrm{D} 1}, 00_{\mathrm{D} 2}\right\} . " 10_{\mathrm{D}}$ " represents the conditions of $Q_{1}$ is turned on, $Q_{2}$ is turned off, and $i_{\mathrm{L} 2}=0$. " $01_{\mathrm{D}}$ " means that $Q_{1}$ is turned off, $Q_{2}$ is turned on, and $i_{\mathrm{L} 1}=0$. "00 $\mathrm{D} 1$ " represents that $Q_{1}$ and $Q_{2}$ are turned off, and $i_{\mathrm{L} 1}=0$. "00 2 " means that $Q_{1}$ and $Q_{2}$ are turned off, and $i_{\mathrm{L} 2}=0$. In addition, Sequence $I$ "10-10 $\mathrm{D}-00_{\mathrm{D} 2}-01-01_{\mathrm{D}}-00_{\mathrm{D} 1}-10 "$ appears within the range of $0<d<0.5$, while Sequence II "11-10-10D-11-01-01 $-11 "$ can be obtained within the range of $0.5<d<1$. Tab. 1 shows the on-off states of power semiconductors in each switching state. Energy flow paths in each switching state of the converter are shown

in

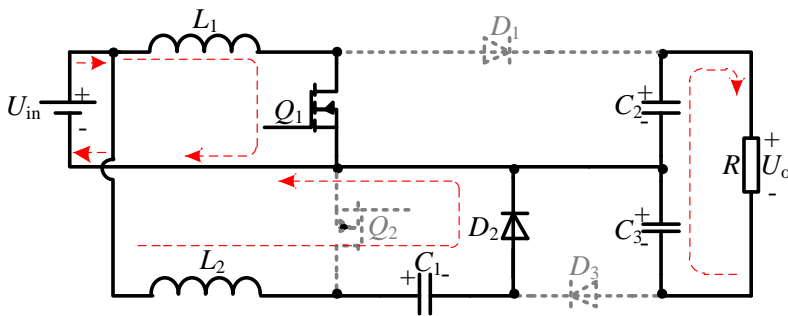

(a) $S_{1} S_{2}=10$

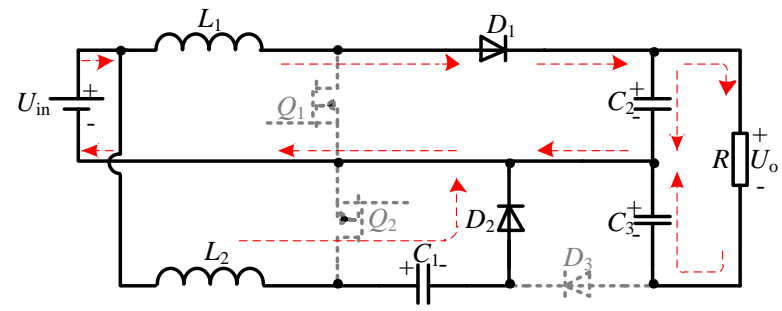

(b) $S_{1} S_{2}=00$

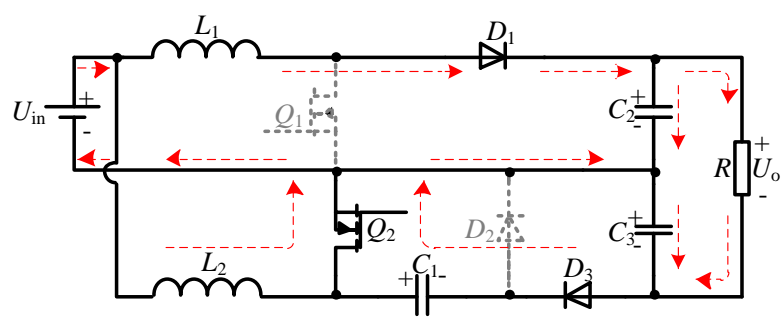

(c) $S_{1} S_{2}=01$

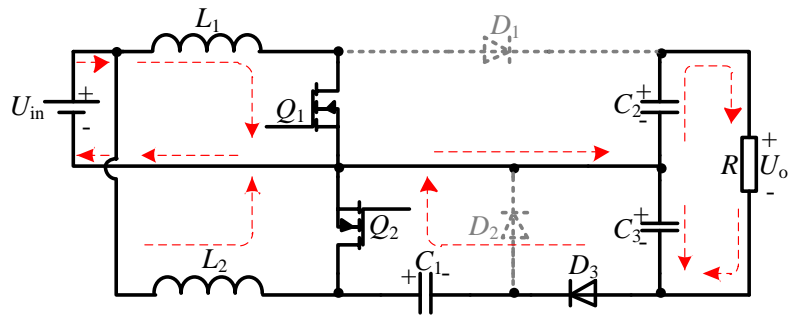

(d) $S_{1} S_{2}=11$

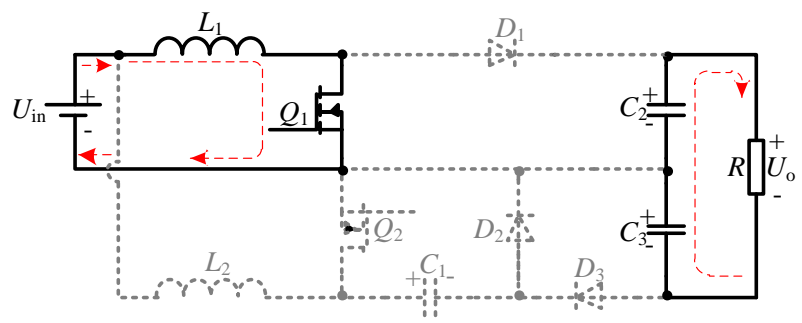

(e) $S_{1} S_{2}=10_{\mathrm{D}}(\mathrm{DCM})$

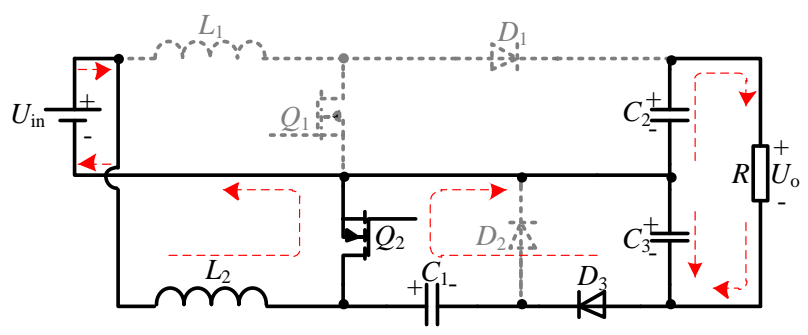

(f) $S_{1} S_{2}=01_{\mathrm{D}}(\mathrm{DCM})$ 


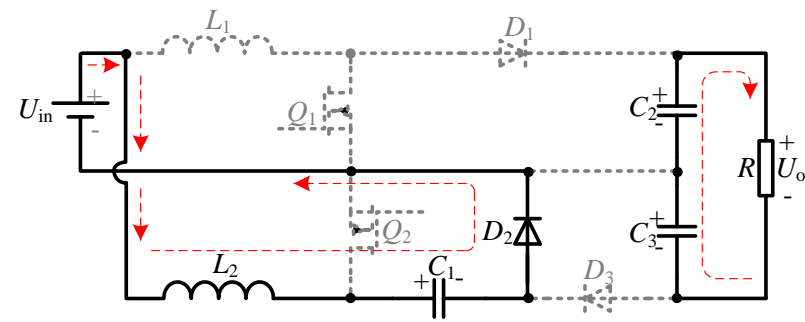

(g) $S_{1} S_{2}=00_{\mathrm{D} 1}(\mathrm{DCM})$

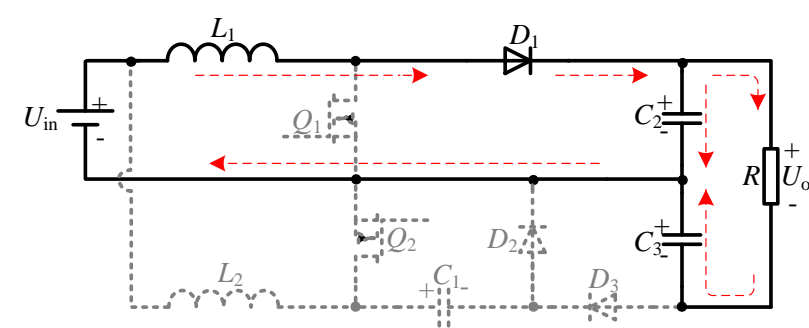

(h) $S_{1} S_{2}=00_{\mathrm{D} 2}$ (DCM)

Fig. 2. The main waveforms for the proposed converter are given in Fig. 3.

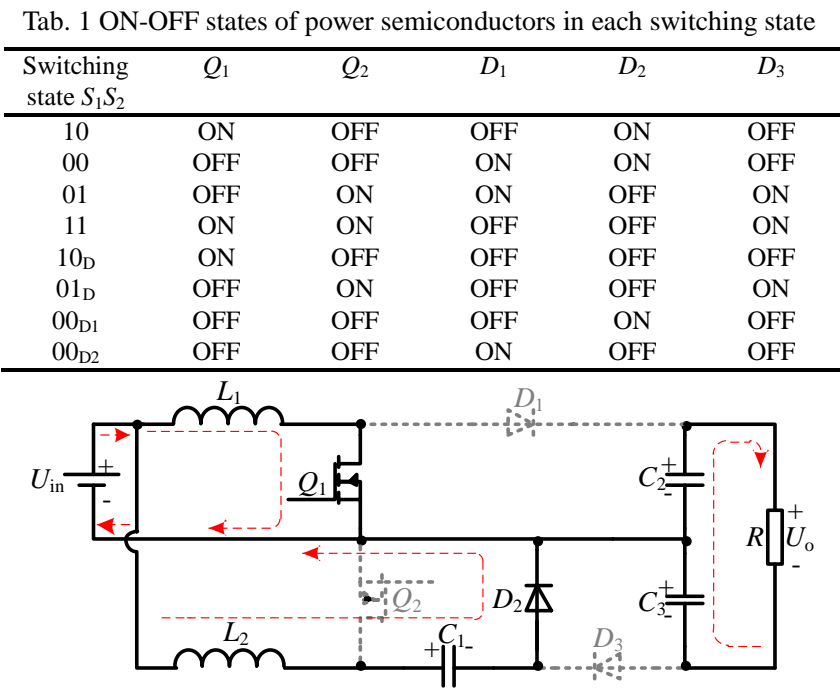

(a) $S_{1} S_{2}=10$

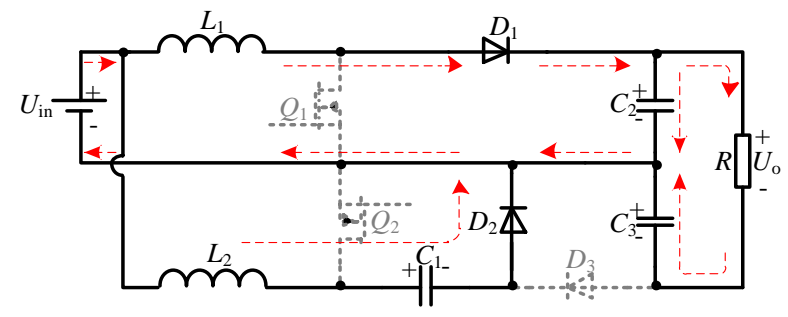

(b) $S_{1} S_{2}=00$

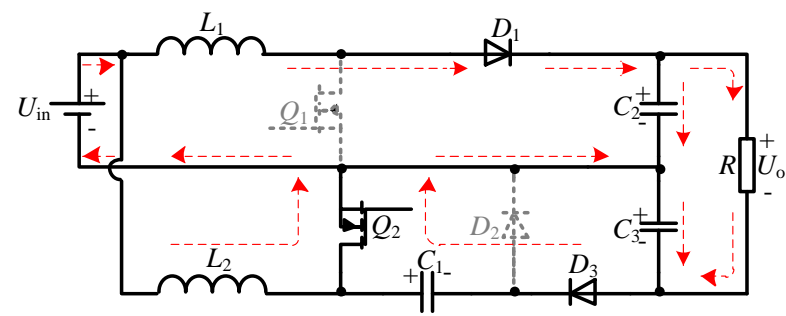

(c) $S_{1} S_{2}=01$

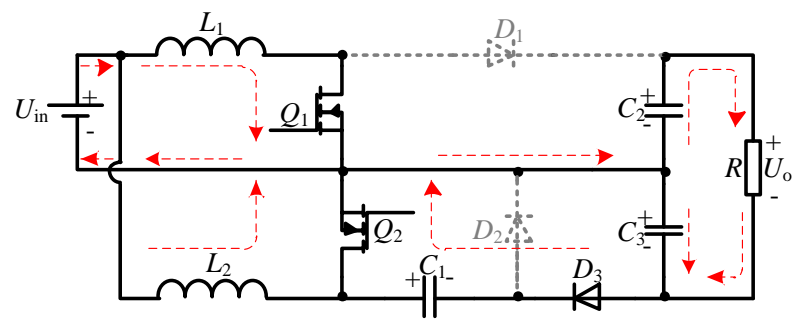

(d) $S_{1} S_{2}=11$

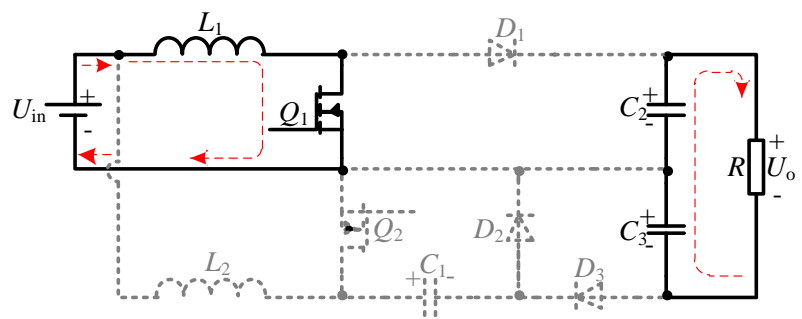

(e) $S_{1} S_{2}=10_{\mathrm{D}}(\mathrm{DCM})$

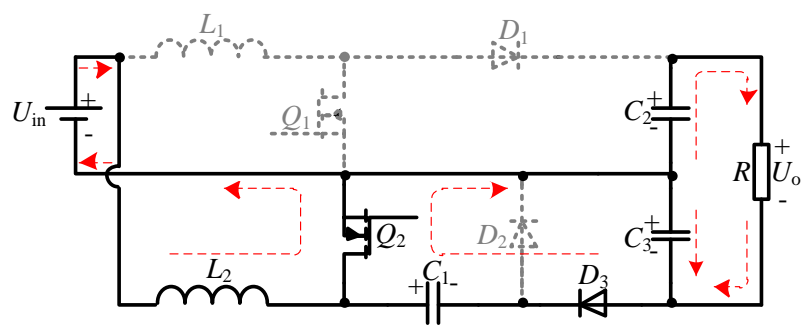

(f) $S_{1} S_{2}=01_{\mathrm{D}}(\mathrm{DCM})$

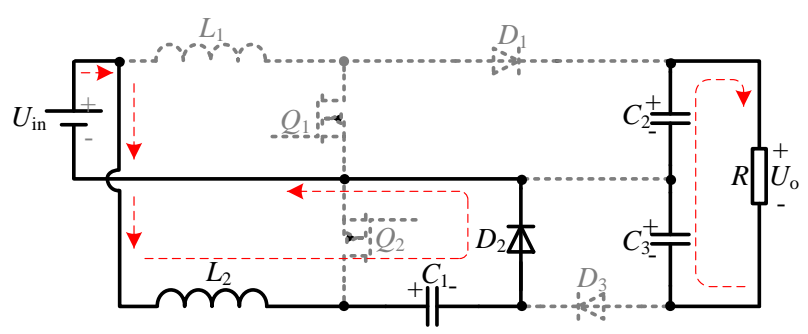

(g) $S_{1} S_{2}=00_{\mathrm{D} 1}(\mathrm{DCM})$

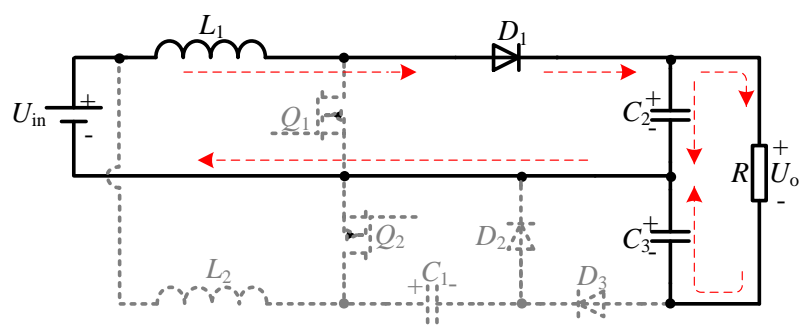

(h) $S_{1} S_{2}=00_{\mathrm{D} 2}(\mathrm{DCM})$

Fig. 2 Energy flow paths in each switching state. 


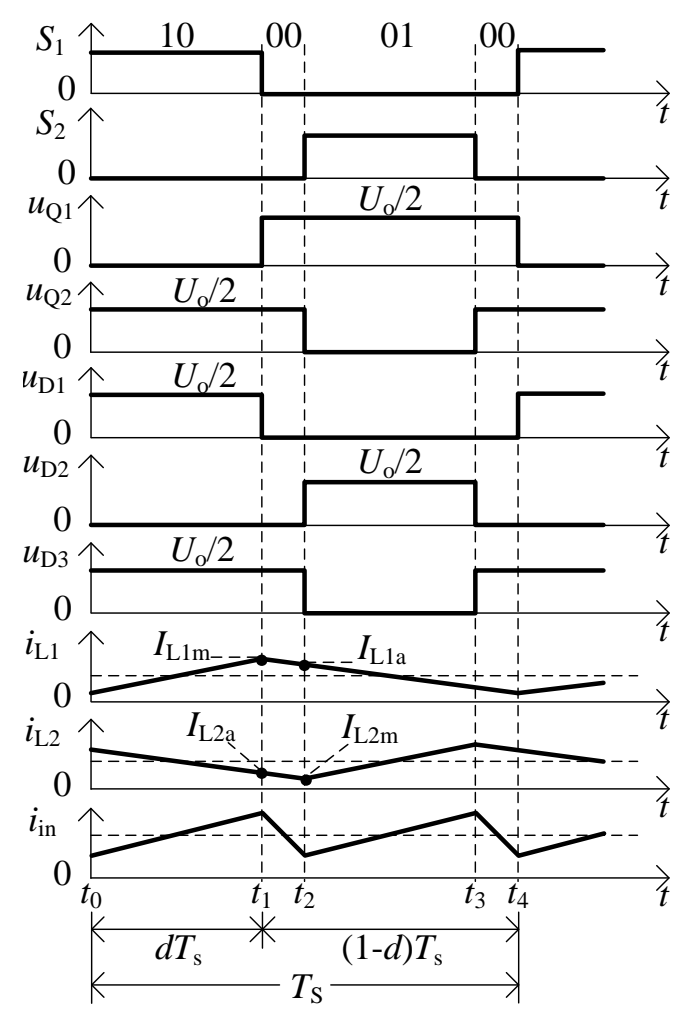

(a) The main waveforms in the range of $0<d<0.5$ (CCM)

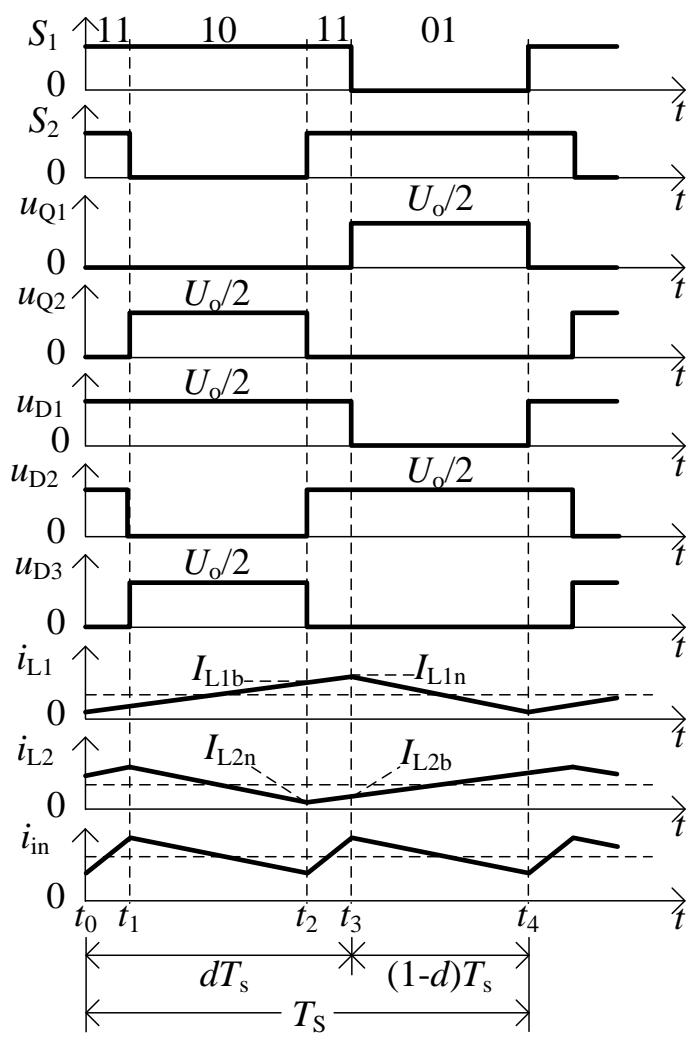

(b) The main waveforms in the range of $0.5<d<1$ (CCM)

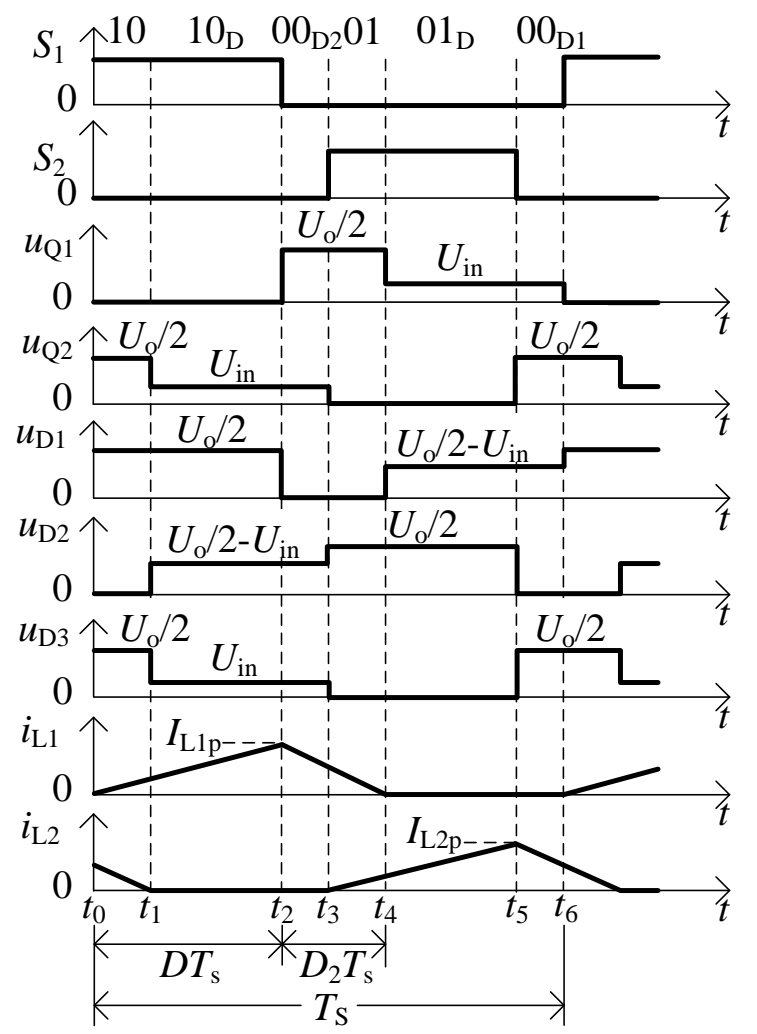

(c) The main waveforms in the range of $0<d<0.5$ (DCM)

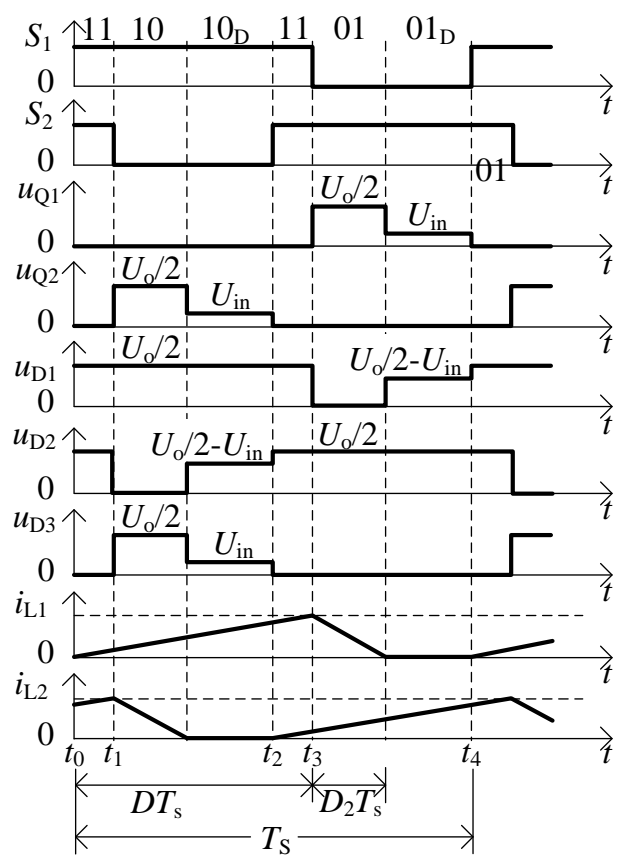

(d) The main waveforms in the range of $0.5<d<1$ (DCM)

Fig. 3 The main waveforms for the proposed converter.

\section{A. CCM operation}

When $S_{1} S_{2}=10$ : power switch $Q_{1}$ is turned on and $Q_{2}$ is turned off. Diodes $D_{1}$ and $D_{3}$ are turned off, while $D_{2}$ is turned on. The energy flow path in this switching state is shown 


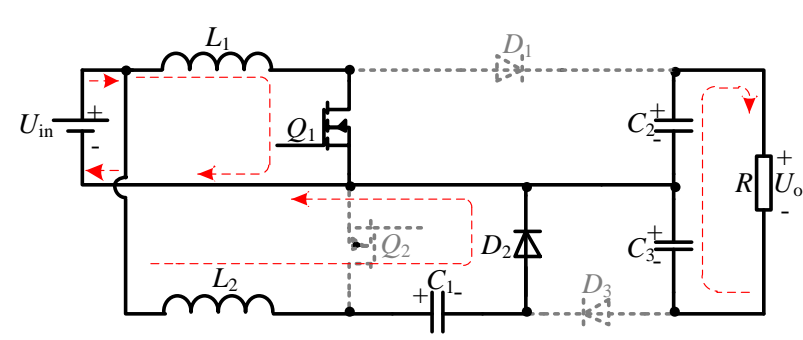

(a) $S_{1} S_{2}=10$

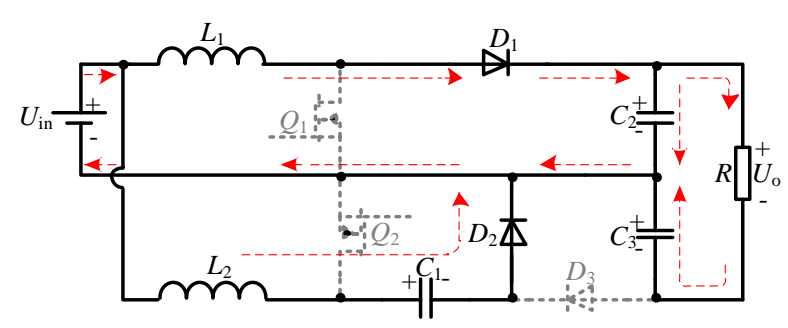

(b) $S_{1} S_{2}=00$

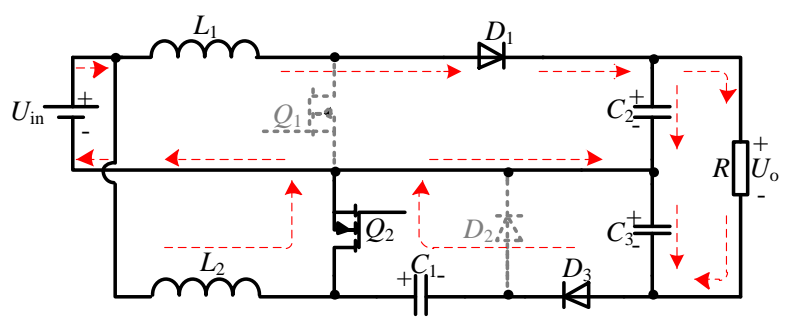

(c) $S_{1} S_{2}=01$

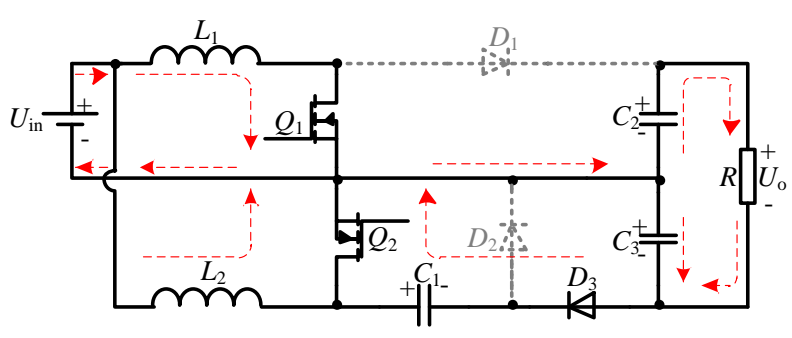

(d) $S_{1} S_{2}=11$

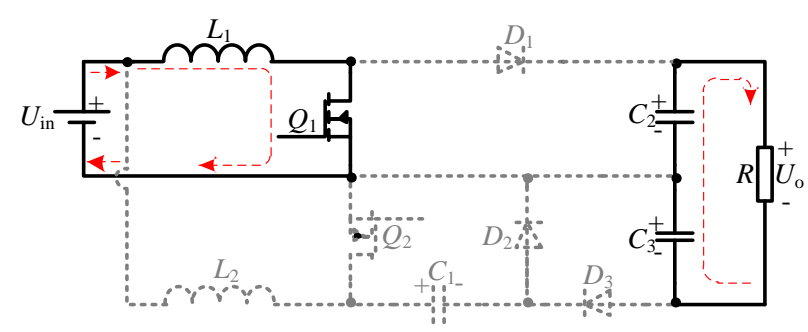

(e) $S_{1} S_{2}=10_{\mathrm{D}}(\mathrm{DCM})$

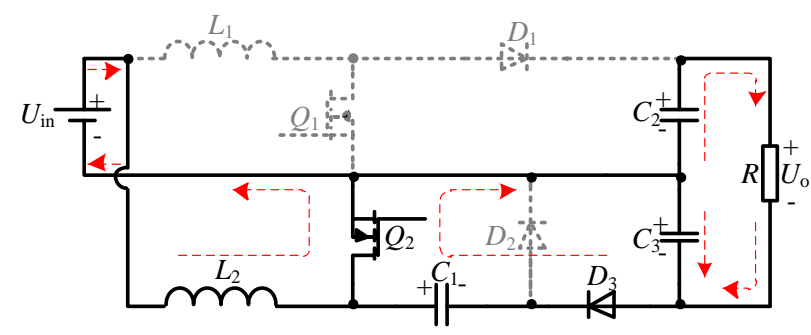

(f) $S_{1} S_{2}=01_{\mathrm{D}}(\mathrm{DCM})$

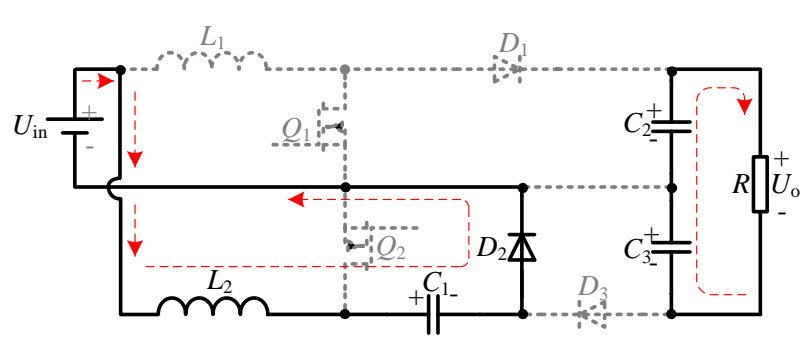

(g) $S_{1} S_{2}=00_{\mathrm{D} 1}$ (DCM)

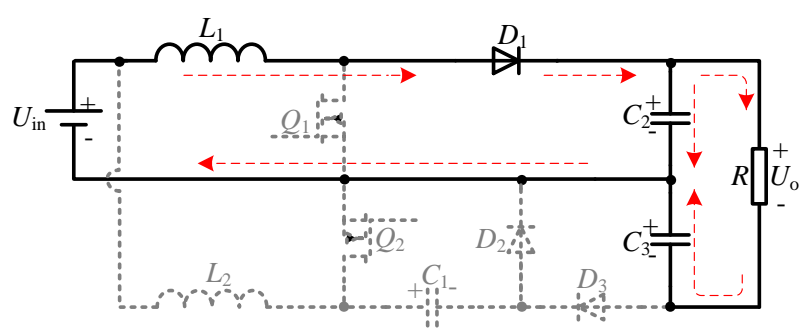

(h) $S_{1} S_{2}=00_{\mathrm{D} 2}(\mathrm{DCM})$

Fig. 2(a). Inductor $L_{1}$ is being charged by the DC source, while $L_{2}$ is discharging. At the same time, $C_{1}$ is being charged by inductor $L_{2}$, while $C_{2}$ and $C_{3}$ are discharging. Capacitors $C_{2}$ and $C_{3}$ are connected in series to transfer energy to the load.

When $S_{1} S_{2}=00$ : power switches $Q_{1}$ and $Q_{2}$ are turned off. Diodes $D_{1}$ and $D_{2}$ are turned on, while $D_{3}$ is turned off. The energy flow path in this switching state is shown in

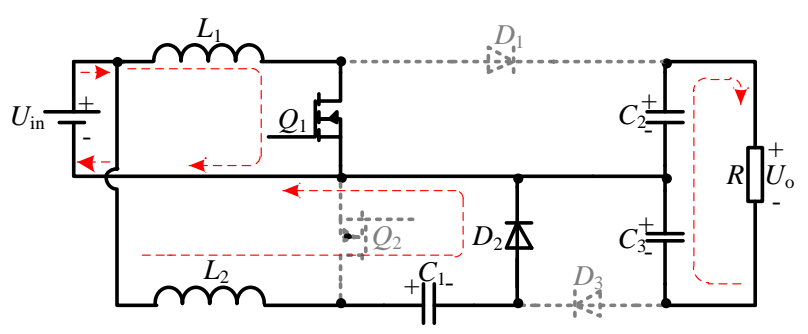

(a) $S_{1} S_{2}=10$

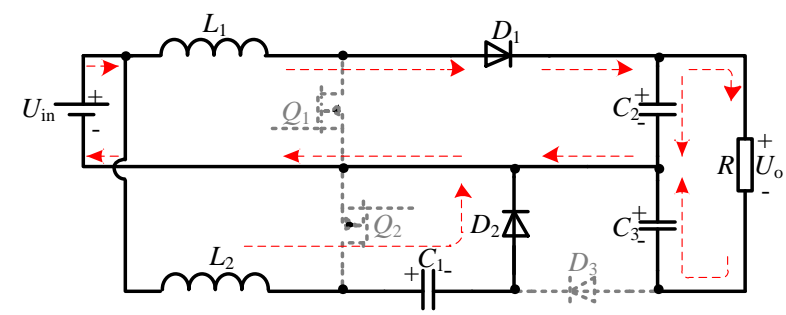

(b) $S_{1} S_{2}=00$

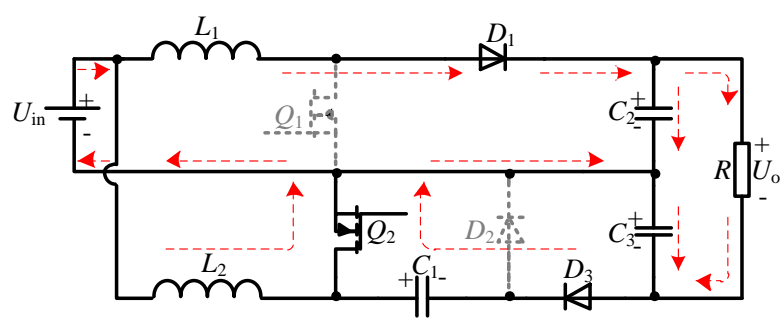


(c) $S_{1} S_{2}=01$

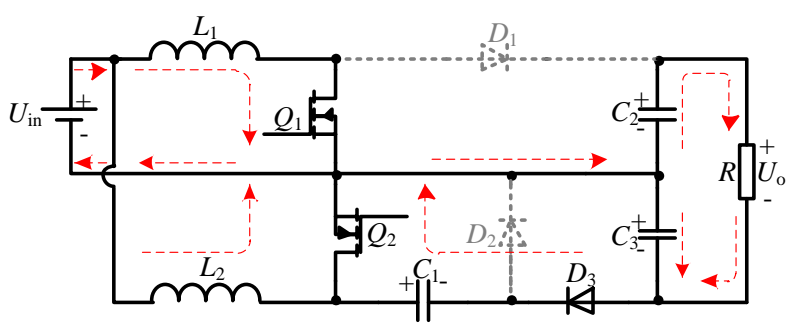

(d) $S_{1} S_{2}=11$

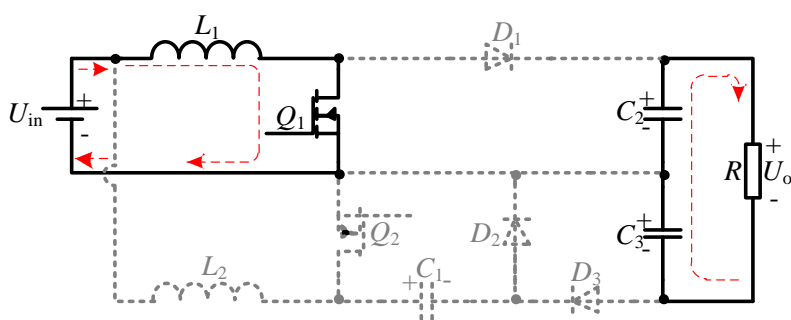

(e) $S_{1} S_{2}=10_{\mathrm{D}}(\mathrm{DCM})$

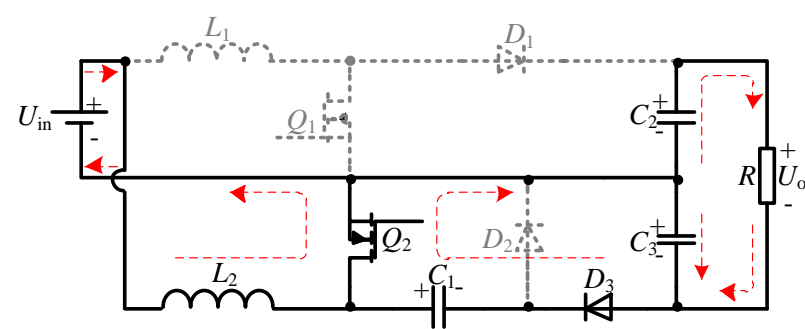

(f) $S_{1} S_{2}=01_{\mathrm{D}}(\mathrm{DCM})$

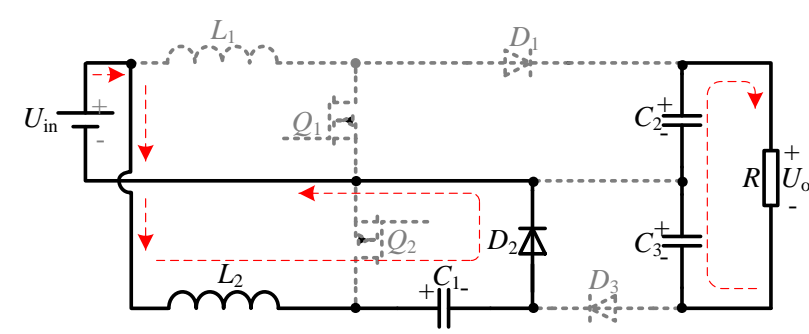

(g) $S_{1} S_{2}=00_{\mathrm{D} 1}$ (DCM)

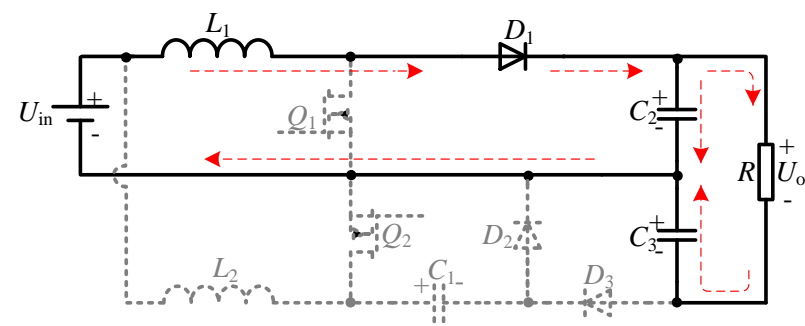

(h) $S_{1} S_{2}=00_{\mathrm{D} 2}(\mathrm{DCM})$

Fig. 2(b). Inductors $L_{1}$ and $L_{2}$ are discharging. At the same time, $C_{1}$ is charging from inductor $L_{2}$, while $C_{3}$ is discharging. The DC source, $L_{1}$ and $C_{3}$ transfer energy to the load.

When $S_{1} S_{2}=01$ : power switch $Q_{1}$ is turned off and $Q_{2}$ is turned on. Diodes $D_{1}$ and $D_{3}$ are turned on, while $D_{2}$ is turned off. The energy flow path in this switching state is shown

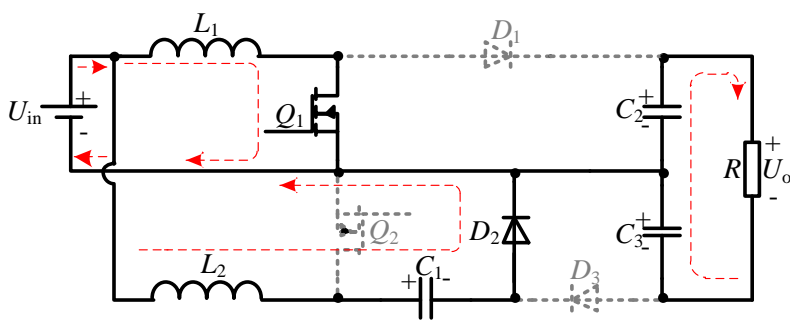

(a) $S_{1} S_{2}=10$

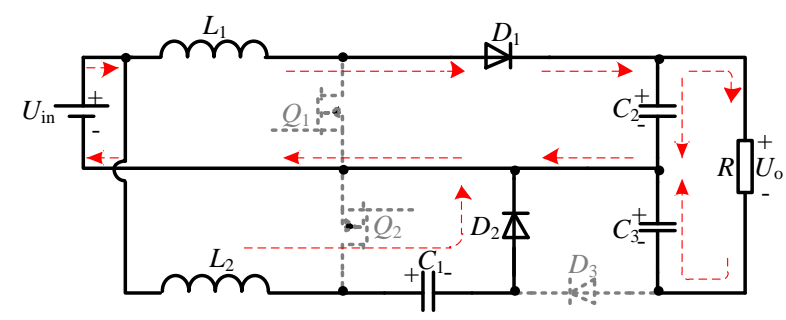

(b) $S_{1} S_{2}=00$

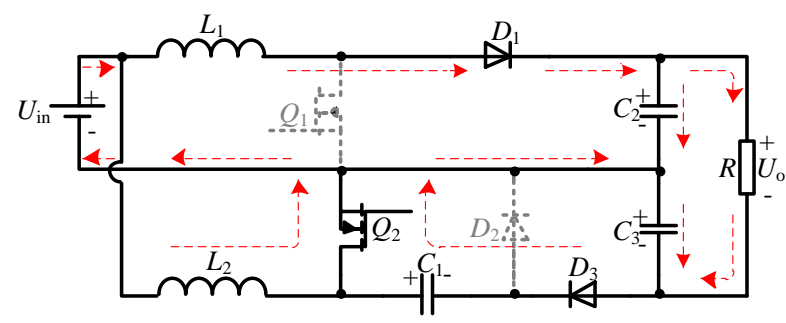

(c) $S_{1} S_{2}=01$

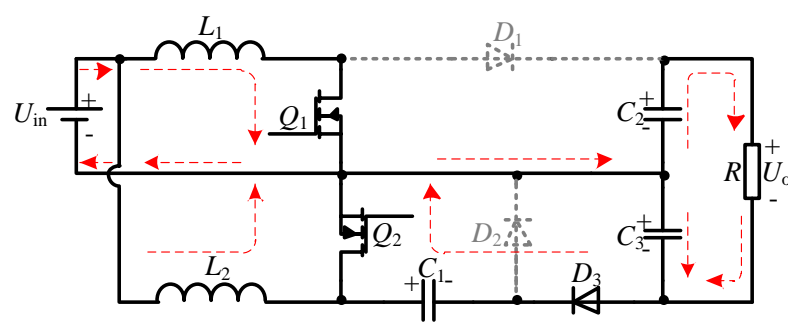

(d) $S_{1} S_{2}=11$

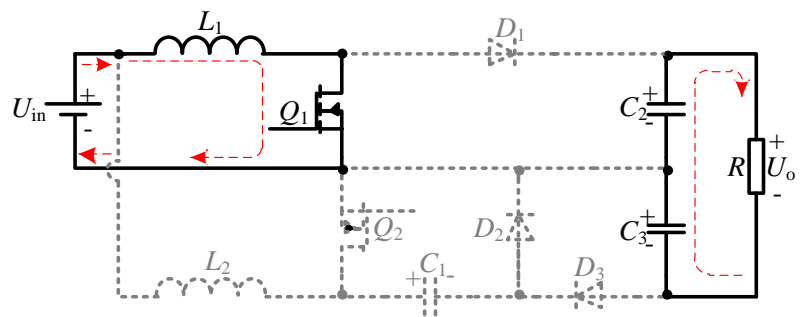

(e) $S_{1} S_{2}=10_{\mathrm{D}}(\mathrm{DCM})$

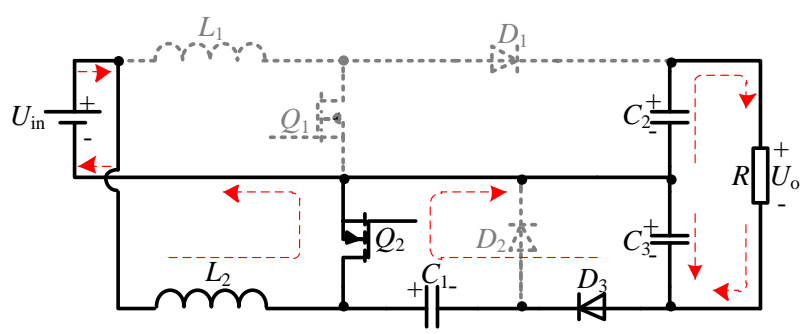

(f) $S_{1} S_{2}=01_{\mathrm{D}}(\mathrm{DCM})$ 


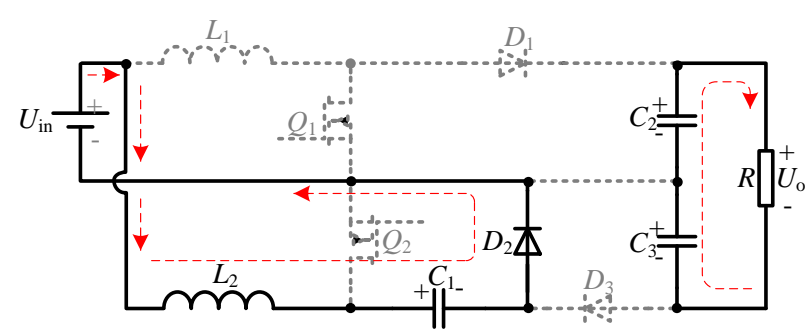

(g) $S_{1} S_{2}=00_{\mathrm{D} 1}(\mathrm{DCM})$

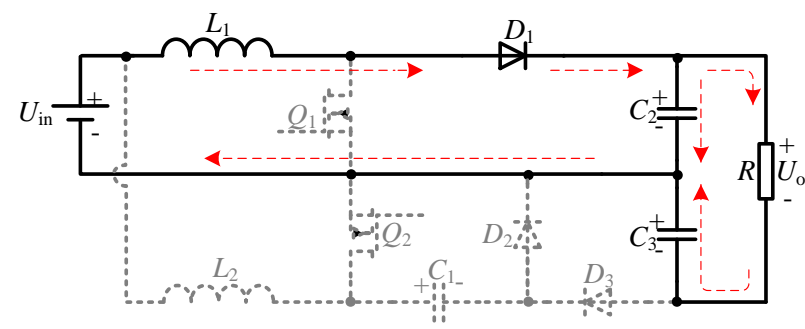

(h) $S_{1} S_{2}=00_{\mathrm{D} 2}(\mathrm{DCM})$

Fig. 2(c). Inductor $L_{1}$ is discharging, and $L_{2}$ is charging from the DC source. At the same time, $C_{2}$ is charging from inductor $L_{1}$, while $C_{1}$ is discharging. In addition, $C_{3}$ is charging from $C_{1}$. The DC source and $L_{1}$ transfer energies to the load.

When $S_{1} S_{2}=11$ : power switches $Q_{1}$ and $Q_{2}$ are turned on. Diodes $D_{1}$ and $D_{2}$ are turned off, while $D_{3}$ is turned on. The energy flow path in this switching state is shown in

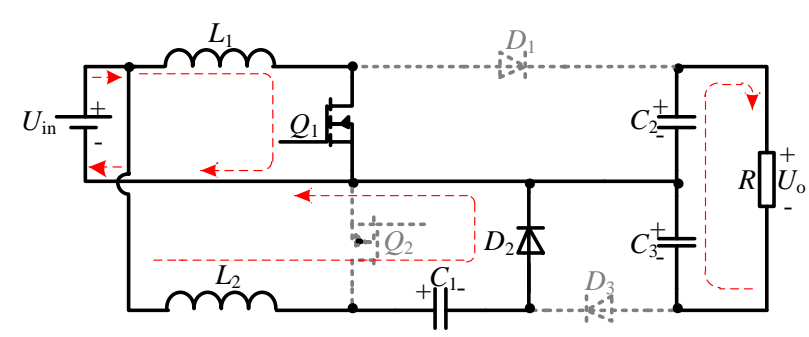

(a) $S_{1} S_{2}=10$

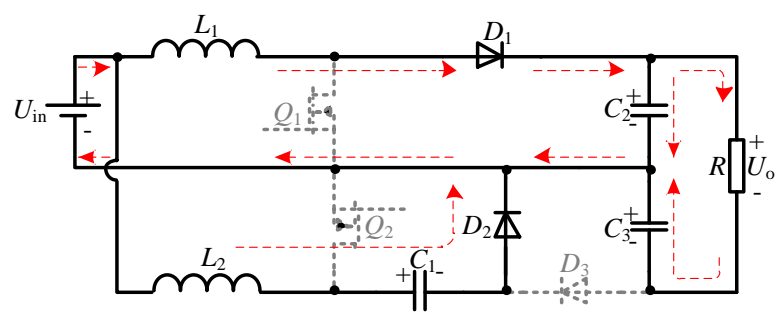

(b) $S_{1} S_{2}=00$

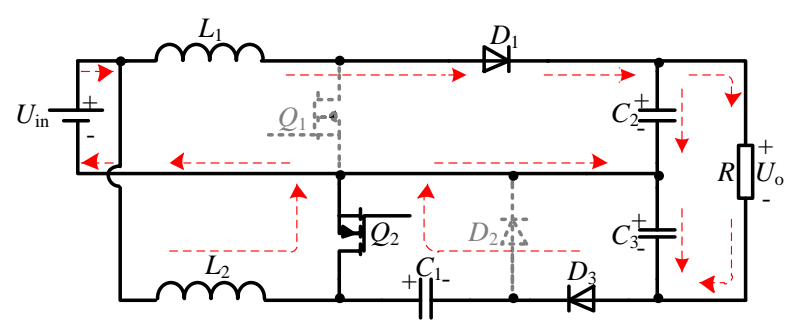

(c) $S_{1} S_{2}=01$

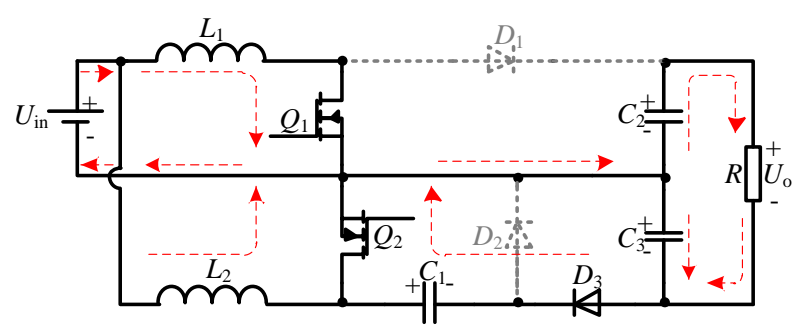

(d) $S_{1} S_{2}=11$

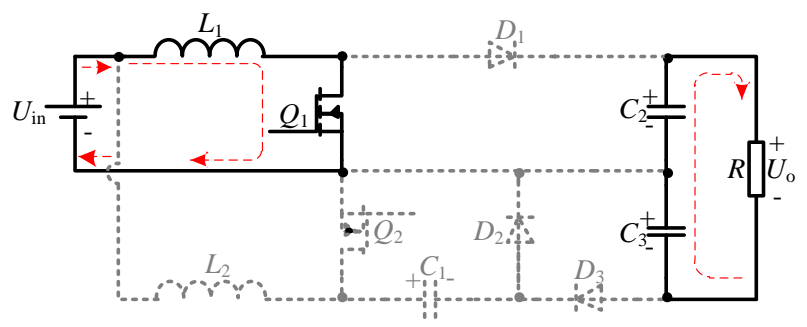

(e) $S_{1} S_{2}=10_{\mathrm{D}}(\mathrm{DCM})$

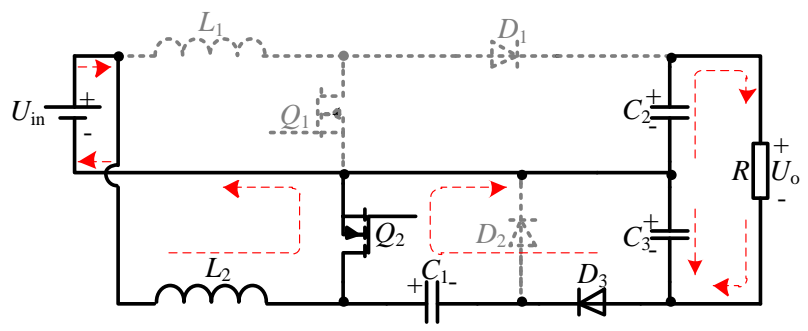

(f) $S_{1} S_{2}=01_{\mathrm{D}}(\mathrm{DCM})$

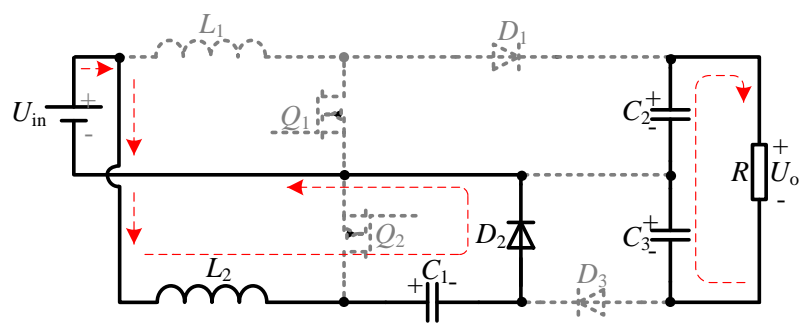

(g) $S_{1} S_{2}=00_{\mathrm{D} 1}(\mathrm{DCM})$

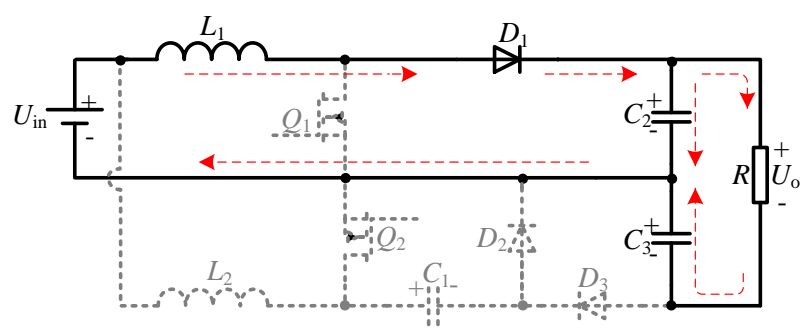

(h) $S_{1} S_{2}=00_{\mathrm{D} 2}(\mathrm{DCM})$

Fig. 2(d). Inductors $L_{1}$ and $L_{2}$ are charging from the DC source. At the same time, $C_{1}$ and $C_{2}$ are discharging. Capacitors $C_{1}$ and $C_{2}$ are series connected to transfer energies to the load.

\section{B. DCM operation}

When $S_{1} S_{2}=10_{\mathrm{D}}, Q_{1}$ is turned on and $Q_{2}$ is turned off. $D_{1}, D_{2}$ and $D_{3}$ are turned off. The energy flow path in 


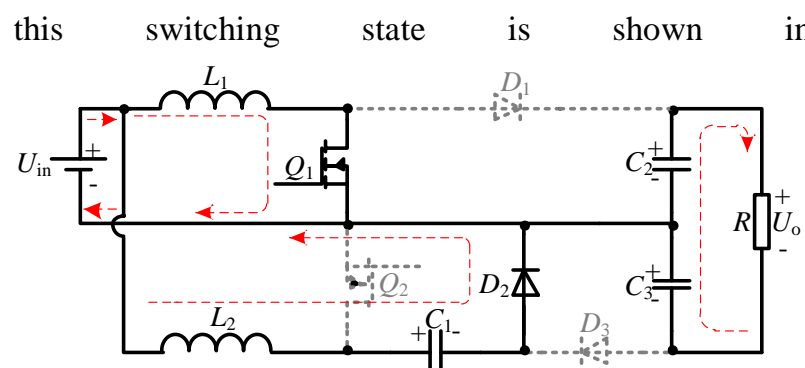

(a) $S_{1} S_{2}=10$

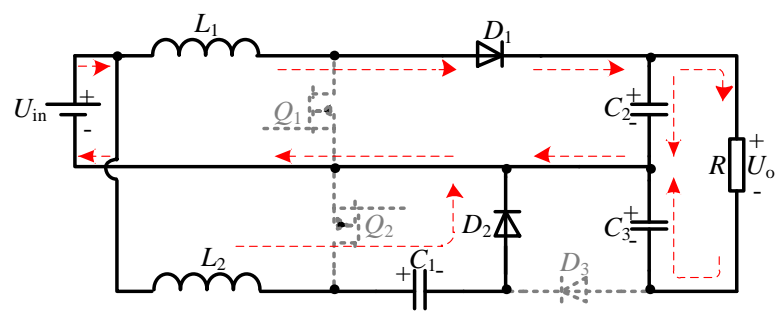

(b) $S_{1} S_{2}=00$

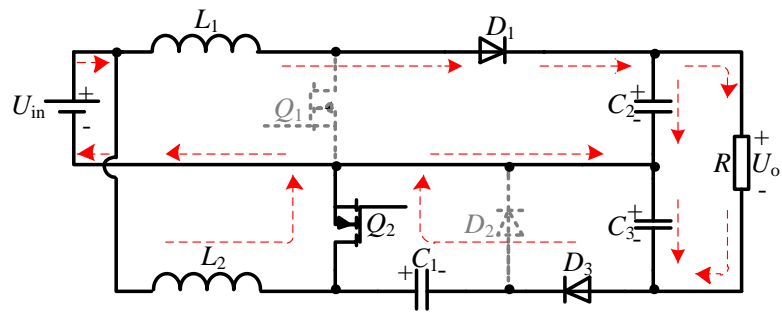

(c) $S_{1} S_{2}=01$

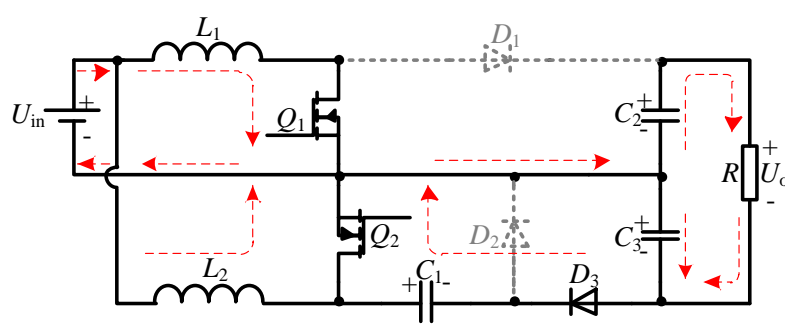

(d) $S_{1} S_{2}=11$

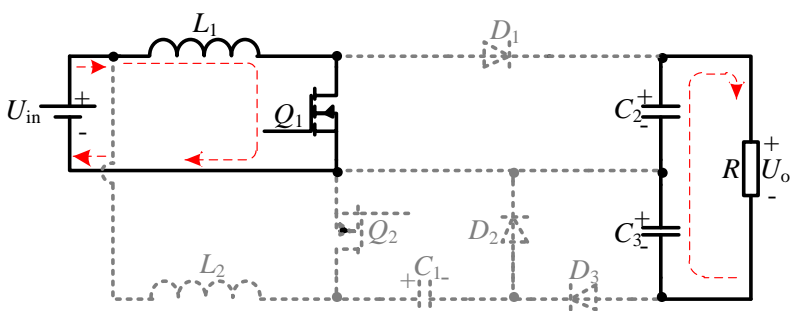

(e) $S_{1} S_{2}=10_{\mathrm{D}}(\mathrm{DCM})$

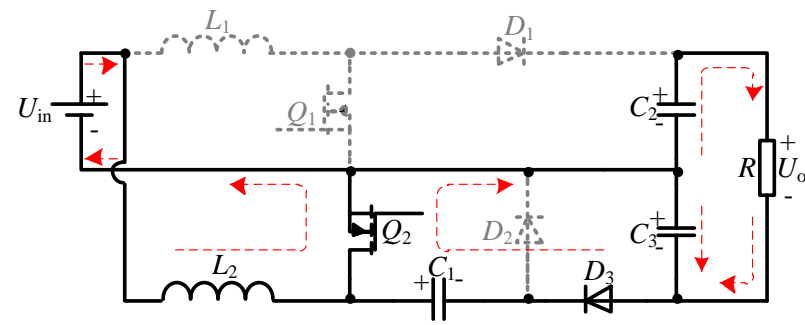

(f) $S_{1} S_{2}=01_{\mathrm{D}}$ (DCM)

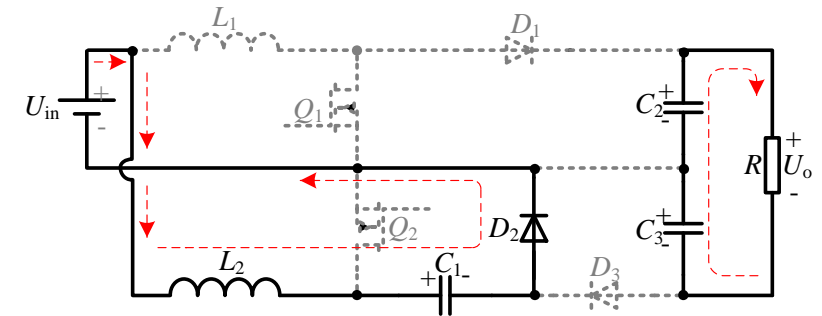

(g) $S_{1} S_{2}=00_{\mathrm{D} 1}(\mathrm{DCM})$

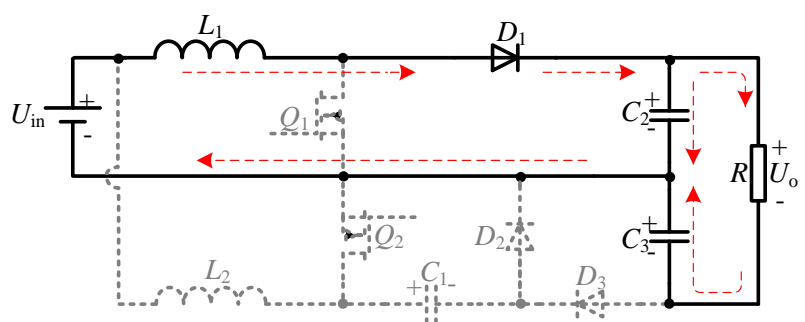

(h) $S_{1} S_{2}=00_{\mathrm{D} 2}$ (DCM)

Fig. 2(e). Inductor $L_{1}$ is charging from the DC source, and inductor current $i_{\mathrm{L} 2}$ is 0 . At the same time, $C_{2}$ and $C_{3}$ are discharging in series to transfer energy to the load.

When $S_{1} S_{2}=01_{\mathrm{D}}, Q_{1}$ is turned off and $Q_{2}$ is turned on. $D_{1}$ and $D_{2}$ are turned off, while $D_{3}$ is turned on. The energy flow path in this switching state is shown in

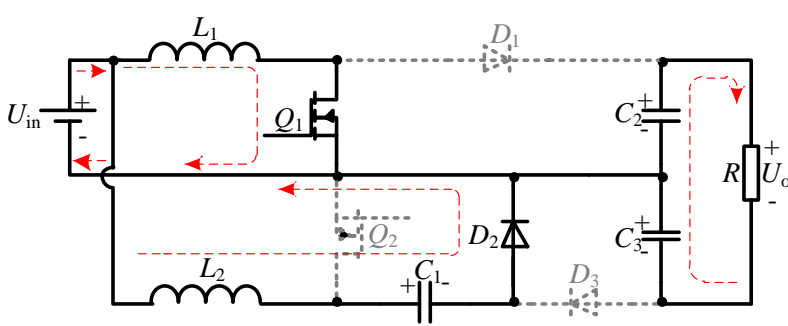

(a) $S_{1} S_{2}=10$

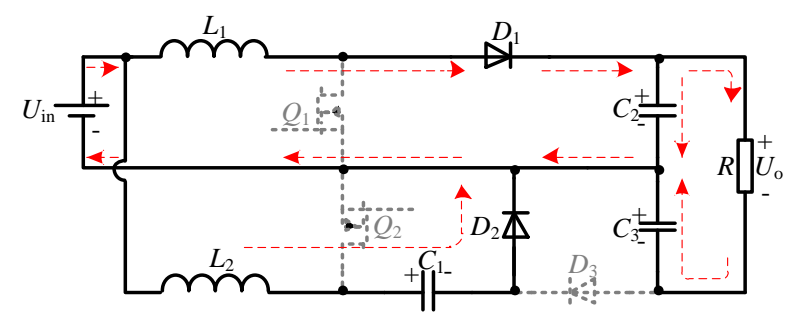

(b) $S_{1} S_{2}=00$

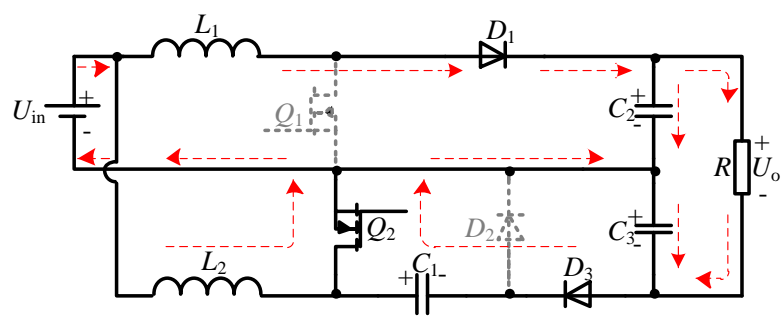

(c) $S_{1} S_{2}=01$ 


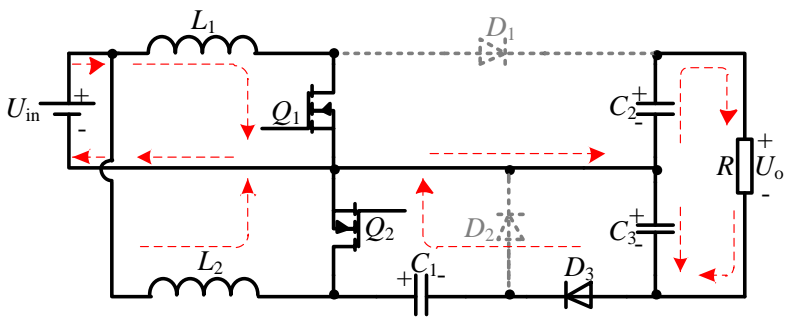

(d) $S_{1} S_{2}=11$

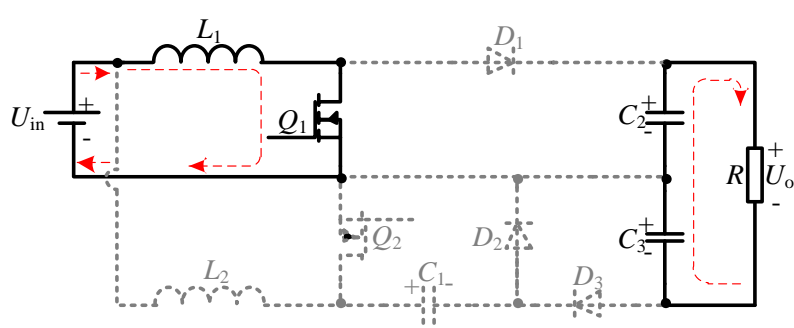

(e) $S_{1} S_{2}=10_{\mathrm{D}}(\mathrm{DCM})$

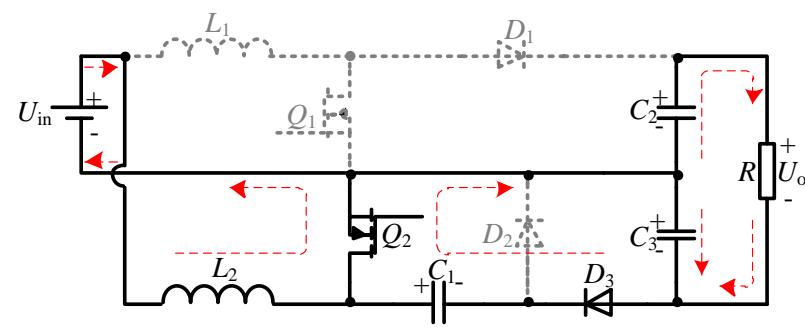

(f) $S_{1} S_{2}=01_{\mathrm{D}}$ (DCM)

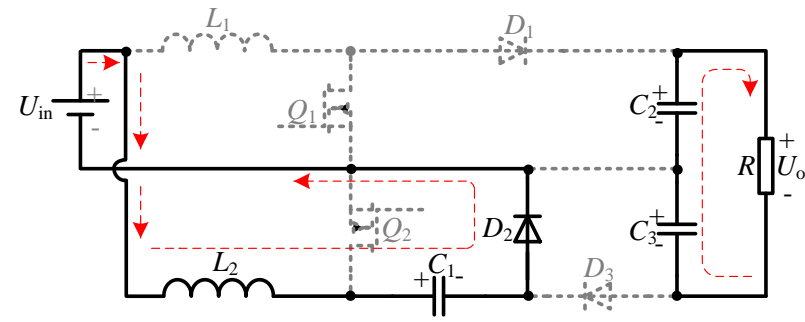

(g) $S_{1} S_{2}=00_{\mathrm{D} 1}(\mathrm{DCM})$

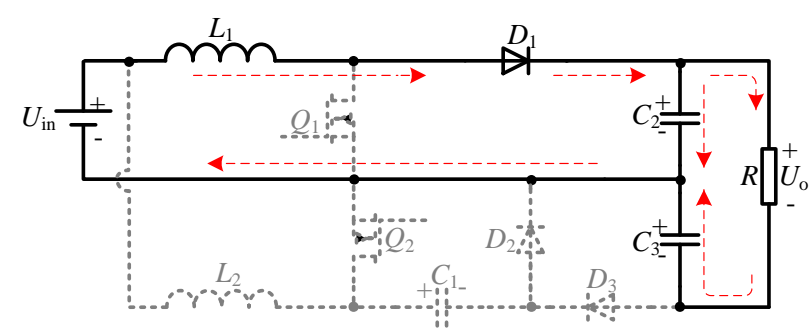

(h) $S_{1} S_{2}=00_{\mathrm{D} 2}(\mathrm{DCM})$

Fig. 2(f). Inductor current $i_{\mathrm{L} 1}$ is 0 and inductor $L_{2}$ is charging from the DC source. At the same time, $C_{1}$ and $C_{2}$ are discharging in series to transfer energy to the load, while $C_{3}$ is charging from $C_{1}$.

When $S_{1} S_{2}=00_{\mathrm{D} 1}, Q_{1}$ and $Q_{2}$ are turned off. $D_{1}$ and $D_{3}$ are turned off, while $D_{2}$ is turned on. The energy flow path in this switching state is shown in

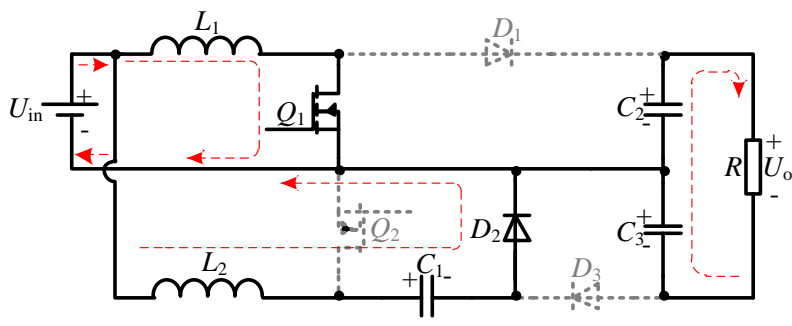

(a) $S_{1} S_{2}=10$

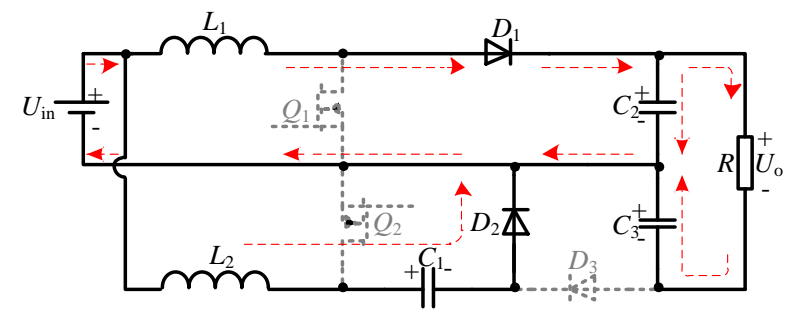

(b) $S_{1} S_{2}=00$

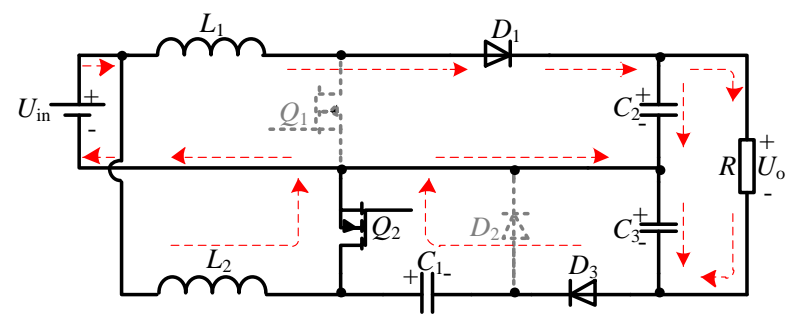

(c) $S_{1} S_{2}=01$

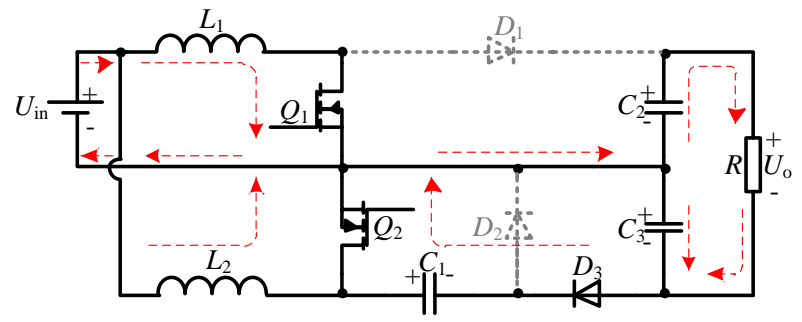

(d) $S_{1} S_{2}=11$

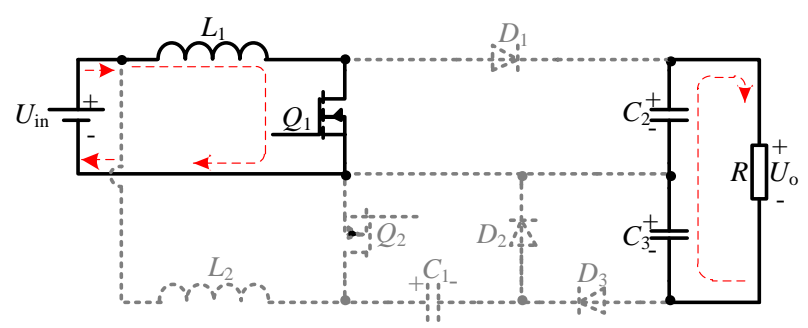

(e) $S_{1} S_{2}=10_{\mathrm{D}}(\mathrm{DCM})$

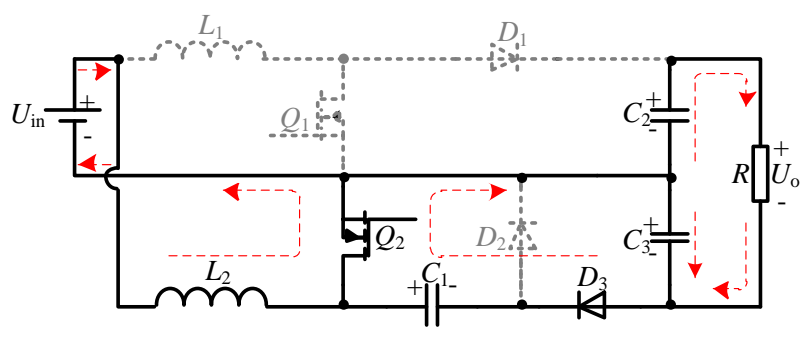

(f) $S_{1} S_{2}=01_{\mathrm{D}}(\mathrm{DCM})$ 


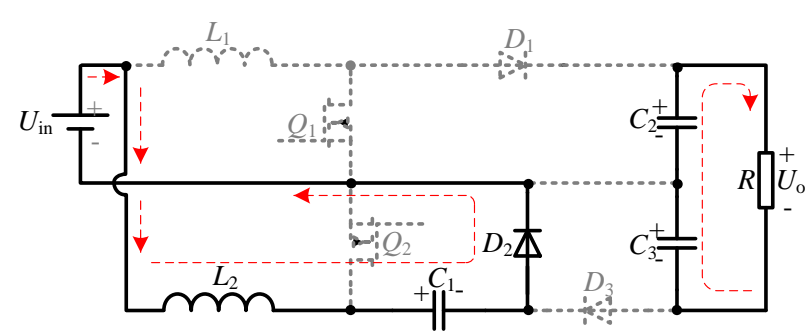

(g) $S_{1} S_{2}=00_{\mathrm{D} 1}(\mathrm{DCM})$

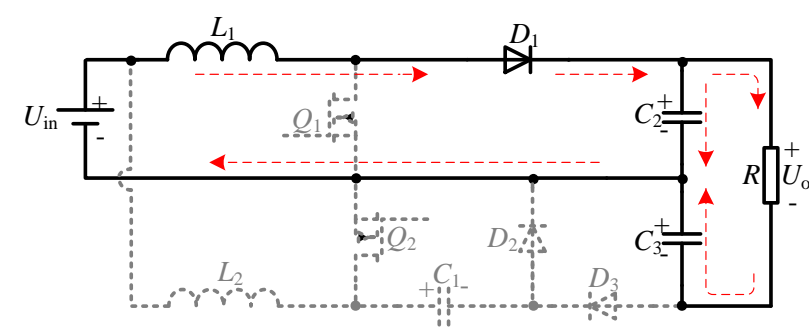

(h) $S_{1} S_{2}=00_{\mathrm{D} 2}(\mathrm{DCM})$

Fig. 2 (g). Inductor current $i_{\mathrm{L} 1}$ is 0 , and inductor $L_{2}$ is discharging. At the same time, $C_{1}$ is charging from the DC source and $L_{2}$, while $C_{2}$ and $C_{3}$ are discharging in series to transfer energy to the load.

When $S_{1} S_{2}=00_{\mathrm{D} 2}, Q_{1}$ and $Q_{2}$ are turned off. $D_{1}$ is turned on, while $D_{2}$ and $D_{3}$ are turned off. The energy flow path in this switching state is shown in

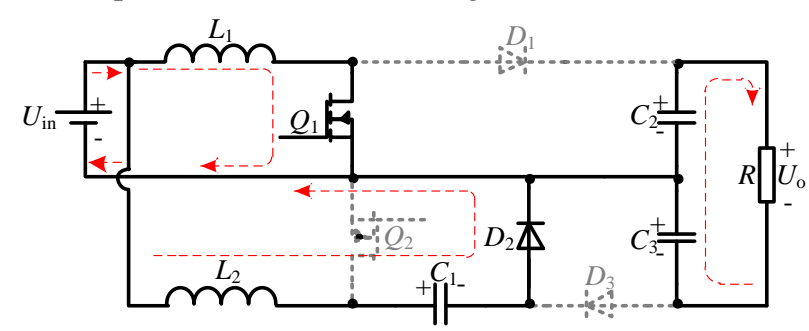

(a) $S_{1} S_{2}=10$

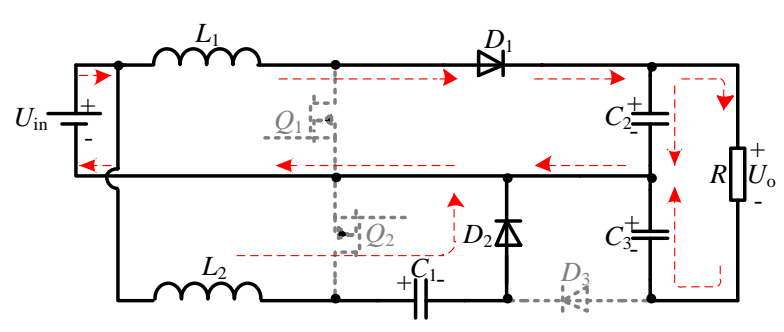

(b) $S_{1} S_{2}=00$

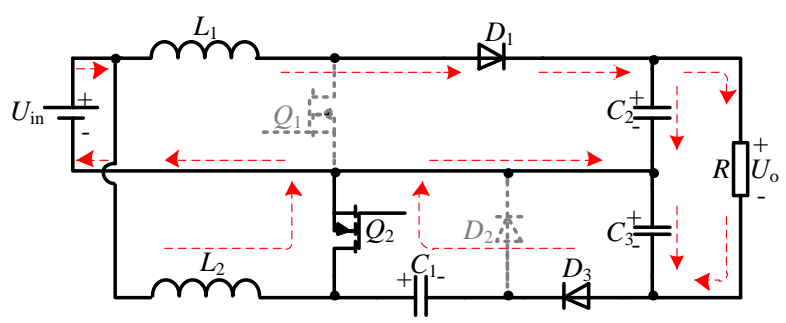

(c) $S_{1} S_{2}=01$

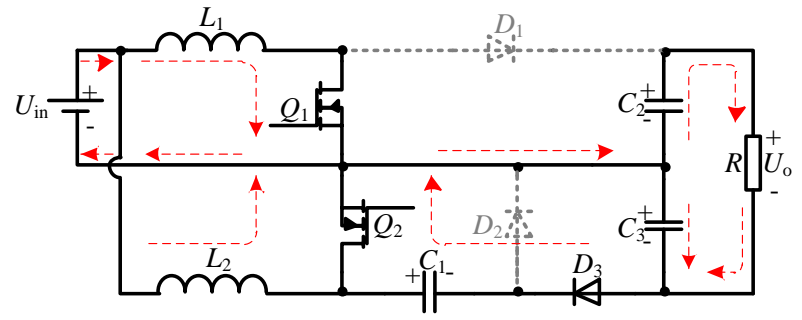

(d) $S_{1} S_{2}=11$

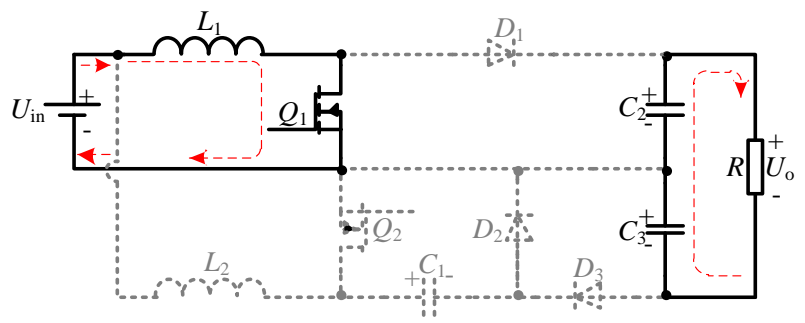

(e) $S_{1} S_{2}=10_{\mathrm{D}}(\mathrm{DCM})$

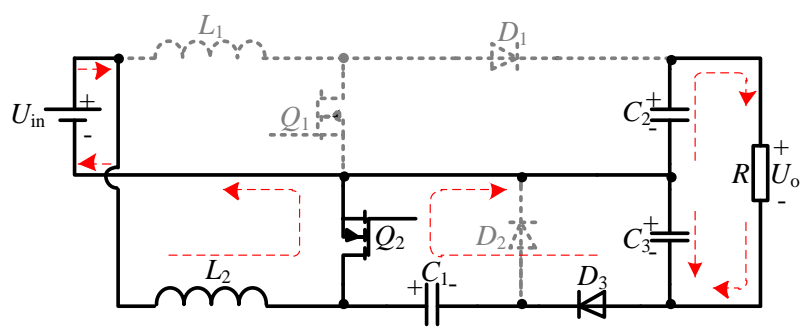

(f) $S_{1} S_{2}=01_{\mathrm{D}}(\mathrm{DCM})$

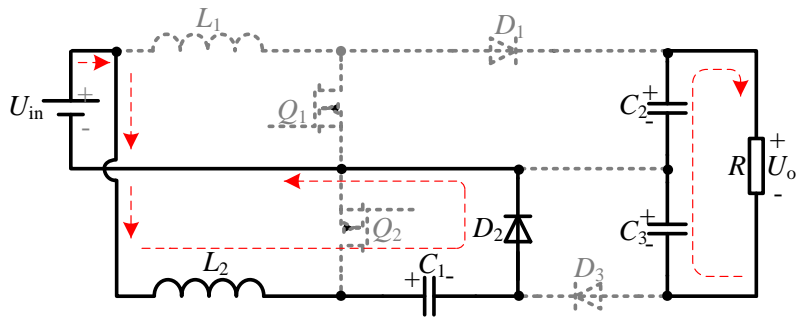

(g) $S_{1} S_{2}=00_{\mathrm{D} 1}(\mathrm{DCM})$

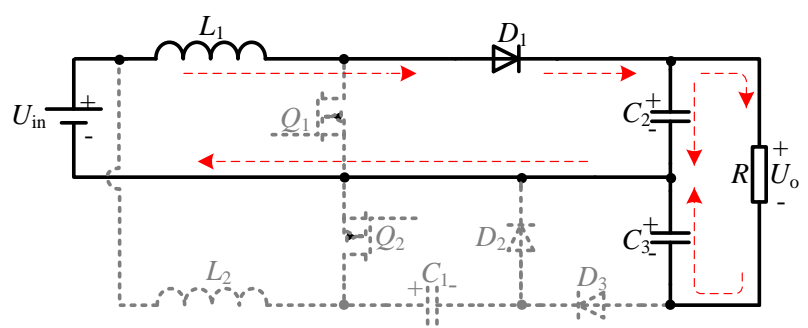

(h) $S_{1} S_{2}=00_{\mathrm{D} 2}(\mathrm{DCM})$

Fig. 2(h). Inductor $L_{1}$ is discharging, and inductor current $i_{\mathrm{L} 2}$ is 0 . At the same time, $C_{2}$ is charging from the DC source and $L_{1}$, while $C_{3}$ is discharging. The DC source, $L_{1}$ and $C_{3}$ transfer energy to the load.

When $S_{1} S_{2}=10,01$, and 11 , the operating principles of the proposed converter in DCM are the same as the ones in CCM.

IV. ANALYSIS OF STEADY-STATE 


\section{CHARACTERISTICS}

\section{A. Voltage-gain in steady-state}

\section{Voltage-gain in CCM operation}

In the range of $0<d<0.5$, according to

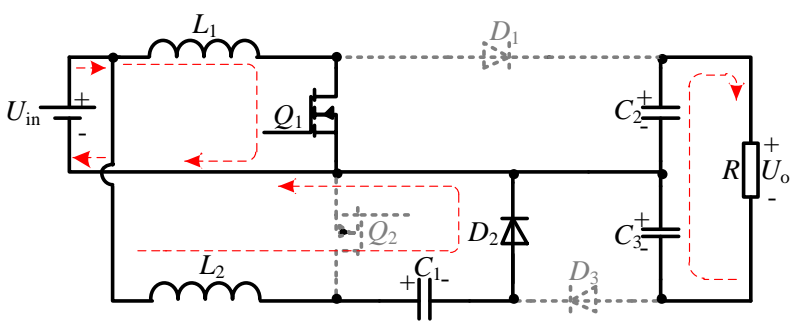

(a) $S_{1} S_{2}=10$

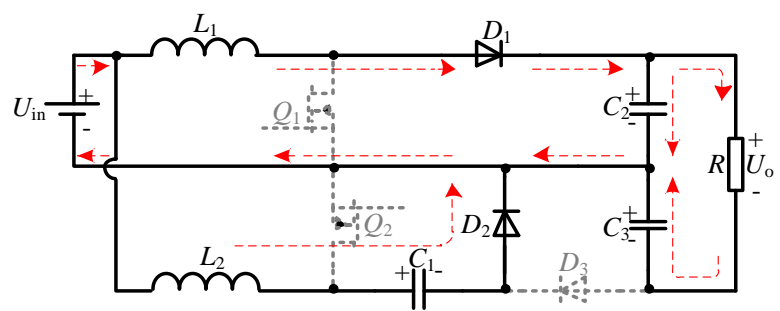

(b) $S_{1} S_{2}=00$

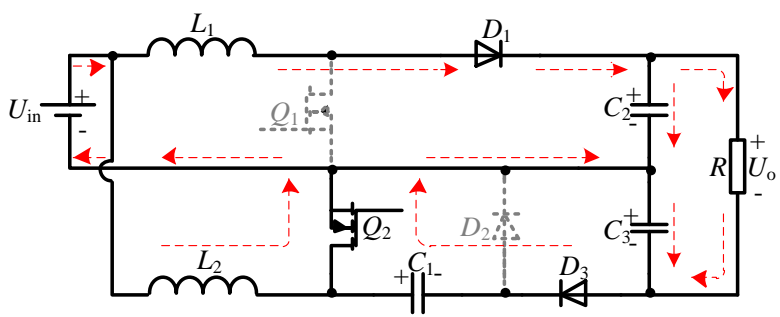

(c) $S_{1} S_{2}=01$

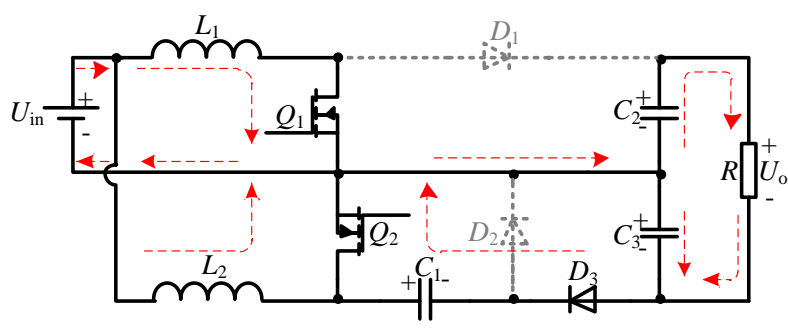

(d) $S_{1} S_{2}=11$

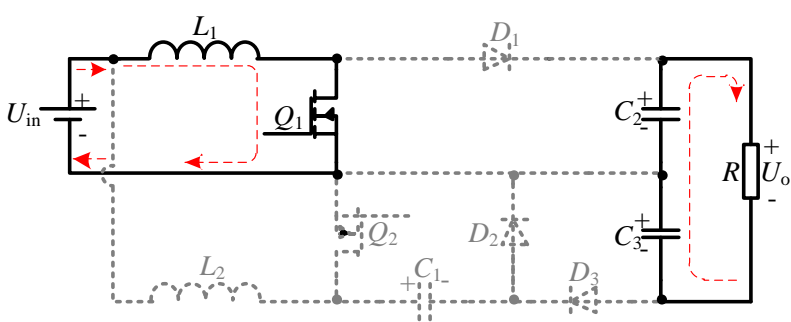

(e) $S_{1} S_{2}=10_{\mathrm{D}}(\mathrm{DCM})$

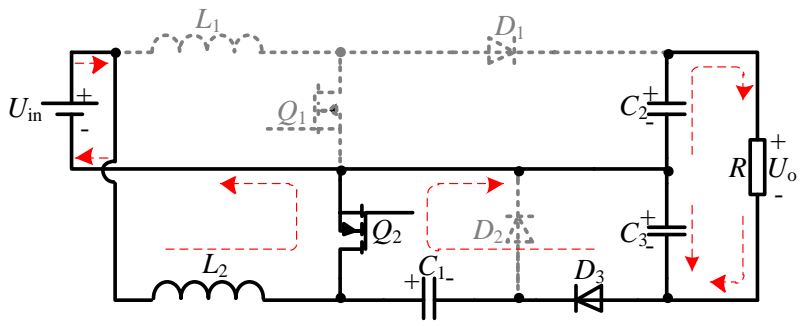

(f) $S_{1} S_{2}=01_{\mathrm{D}}(\mathrm{DCM})$

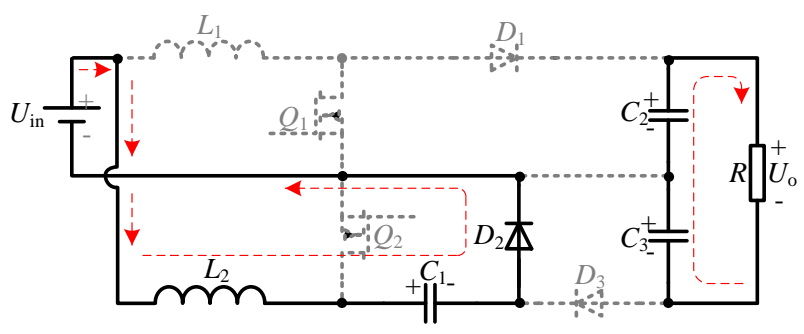

(g) $S_{1} S_{2}=00_{\mathrm{D} 1}(\mathrm{DCM})$

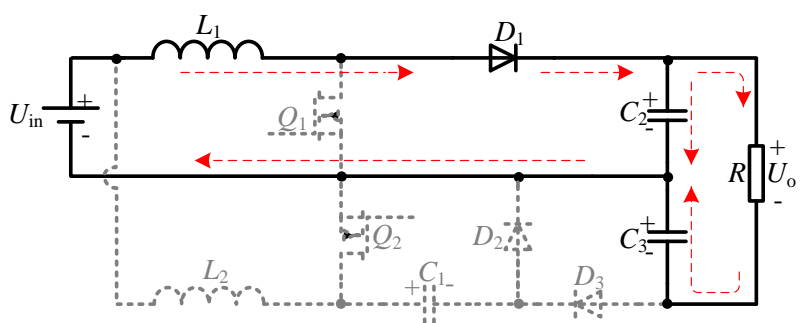

(h) $S_{1} S_{2}=00_{\mathrm{D} 2}$ (DCM)

Fig. 2(c), power switch $Q_{2}$ and diode $D_{3}$ are turned on, so that $C_{1}$ and $C_{3}$ are connected in parallel. Therefore, the voltages of $C_{1}$ and $C_{3}$ are equal. By using the volt-second balance on $L_{1}$ and $L_{2}$, the following equations can be obtained:

$$
\left\{\begin{array}{l}
d \times U_{\text {in }}=(1-d) \times\left(U_{\mathrm{C} 2}-U_{\text {in }}\right) \\
d \times U_{\text {in }}=(1-d) \times\left(U_{\mathrm{Cl}}-U_{\text {in }}\right) \\
U_{\mathrm{C} 1}=U_{\mathrm{C} 3}
\end{array}\right.
$$

Simplifying (1), the capacitor voltages and the output voltage are obtained as:

$$
\left\{\begin{array}{l}
U_{\mathrm{C} 1}=U_{\mathrm{C} 2}=U_{\mathrm{C} 3}=\frac{1}{1-d} U_{\text {in }} \\
U_{\mathrm{o}}=\frac{2}{1-d} U_{\text {in }}
\end{array}\right.
$$

By using the amp-second balance on $C_{2}$, the following equations can be obtained:

$$
\left\{\begin{array}{l}
d \times I_{\mathrm{o}}=(1-d) \times\left(I_{\mathrm{L} 1}-I_{\mathrm{o}}\right) \\
I_{\text {in }} \times U_{\mathrm{in}}=U_{\mathrm{o}} \times I_{\mathrm{o}} \\
I_{\mathrm{in}}=I_{\mathrm{L} 1}+I_{\mathrm{L} 2}
\end{array}\right.
$$

where $I_{\text {in }}, I_{\mathrm{L} 1}$ and $I_{\mathrm{L} 2}$ are the average currents of $i_{\mathrm{in}}, i_{\mathrm{L} 1}$ and $i_{\mathrm{L} 2}$ respectively. Simplifying (3), $I_{\mathrm{in}}, I_{\mathrm{L} 1}$ and $I_{\mathrm{L} 2}$ can be derived as: 


$$
\left\{\begin{array}{l}
I_{\text {in }}=\frac{2}{1-d} I_{\mathrm{o}} \\
I_{\mathrm{L} 1}=I_{\mathrm{L} 2}=\frac{1}{1-d} I_{\mathrm{o}}
\end{array}\right.
$$

According to (2) and (4), the voltage-gain of the proposed converter is $2 /(1-d)$, which is twice the voltage-gain of a conventional interleaved DC-DC Boost converter. In addition, the voltage stress of capacitors $C_{1}$, $C_{2}$ and $C_{3}$ can be reduced to half of the output voltage. Inductor currents $i_{\mathrm{L} 1}$ and $i_{\mathrm{L} 2}$ are both half of the input

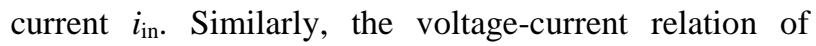
components within the range of $0.5<d<1$ can be obtained, which is the same as that within the range of $0<d<0.5$.

\section{Voltage-gain in DCM operation}

In the range of $0<d<0.5$, according to

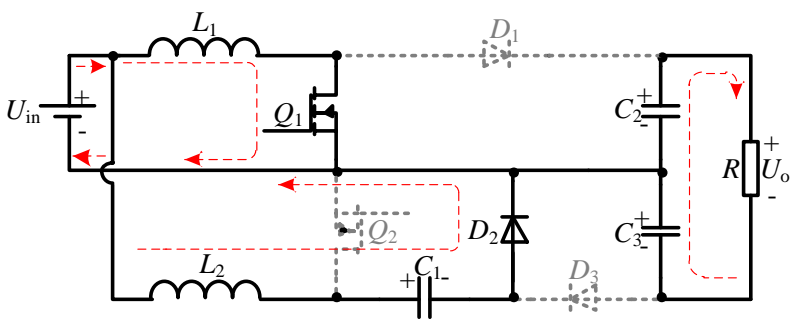

(a) $S_{1} S_{2}=10$

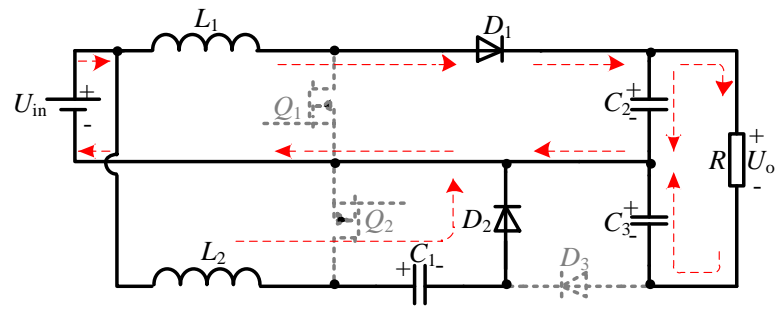

(b) $S_{1} S_{2}=00$

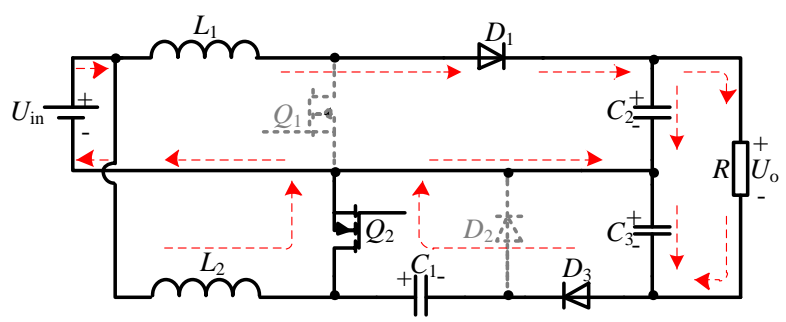

(c) $S_{1} S_{2}=01$

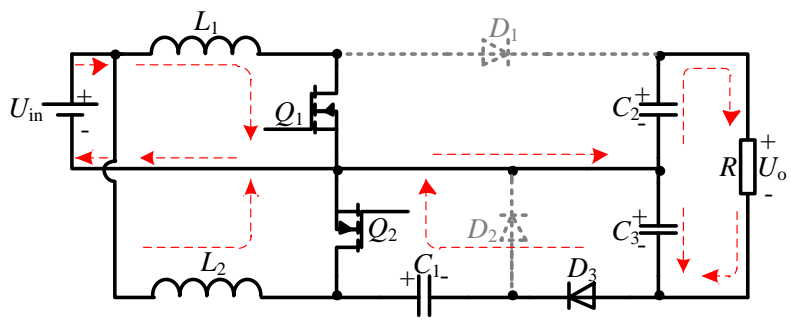

(d) $S_{1} S_{2}=11$

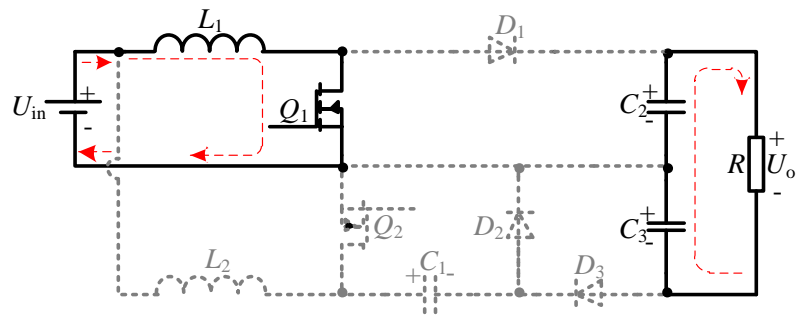

(e) $S_{1} S_{2}=10_{\mathrm{D}}(\mathrm{DCM})$

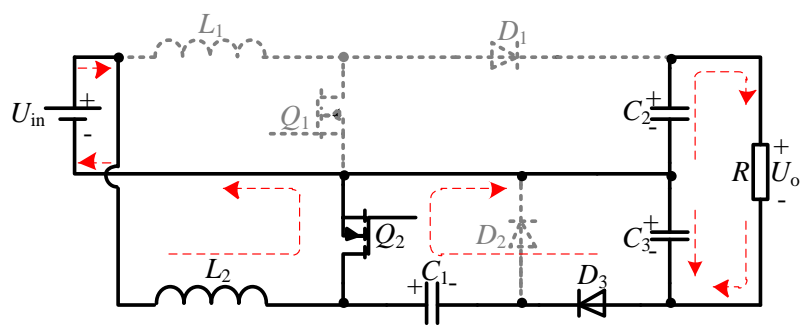

(f) $S_{1} S_{2}=01_{\mathrm{D}}(\mathrm{DCM})$

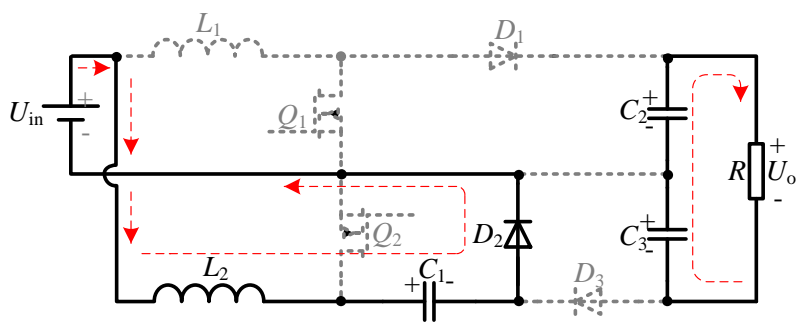

(g) $S_{1} S_{2}=00_{\text {D } 1}$ (DCM)

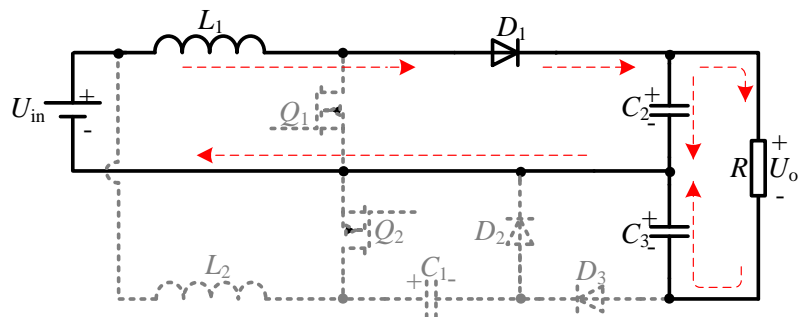

(h) $S_{1} S_{2}=00_{\mathrm{D} 2}(\mathrm{DCM})$

Fig. 2(a, e) and Fig. 3(c), when $L_{1}$ is charging from the DC source, the peak current $I_{\mathrm{L} 1 \mathrm{p}}$ can be obtained as

$$
I_{\mathrm{Llp}}=\frac{d \times T_{\mathrm{s}} \times U_{\text {in }}}{L}
$$

According

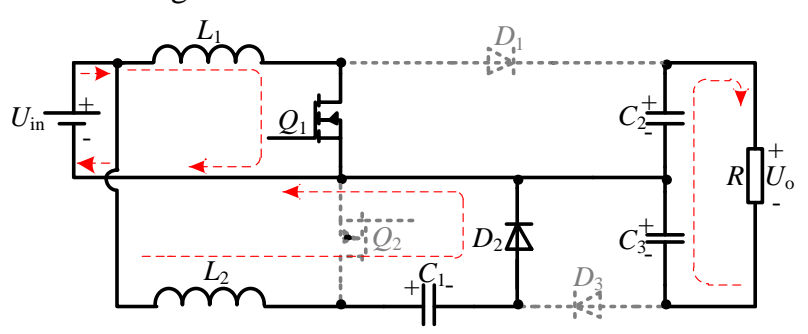

(a) $S_{1} S_{2}=10$ 


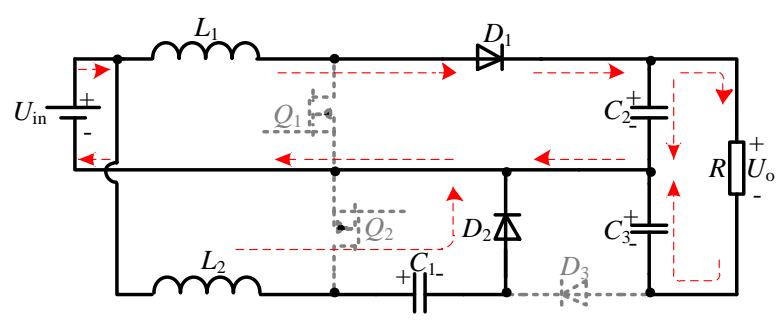

(b) $S_{1} S_{2}=00$

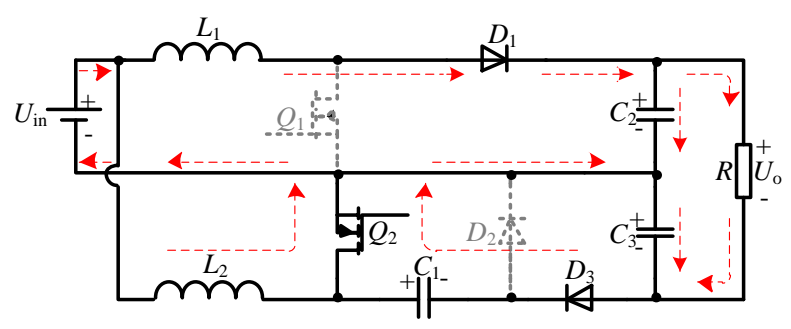

(c) $S_{1} S_{2}=01$

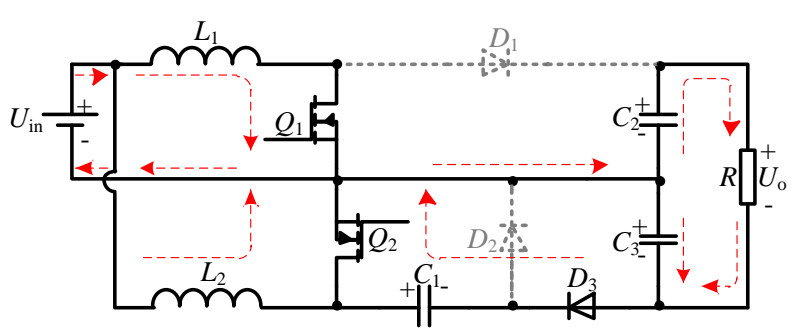

(d) $S_{1} S_{2}=11$

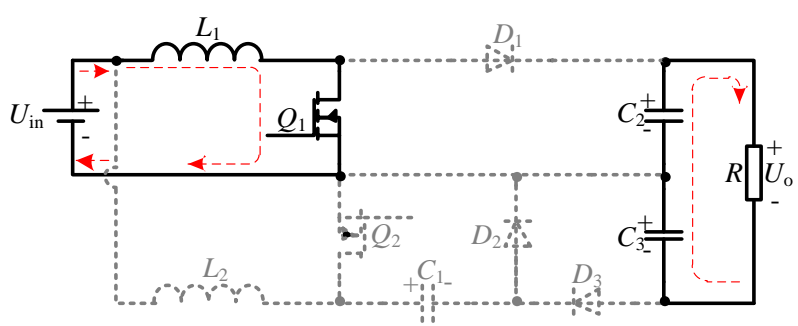

(e) $S_{1} S_{2}=10_{\mathrm{D}}(\mathrm{DCM})$

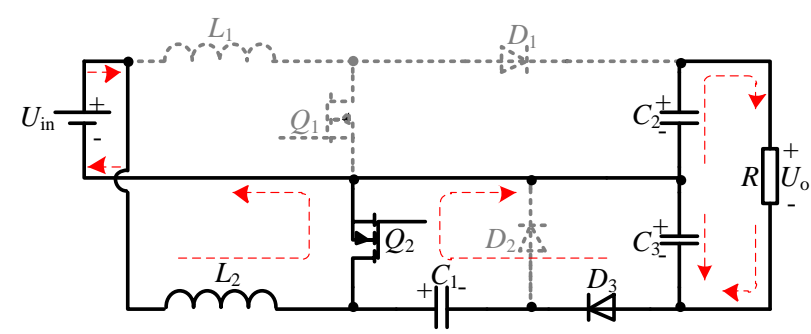

(f) $S_{1} S_{2}=01_{\mathrm{D}}(\mathrm{DCM})$

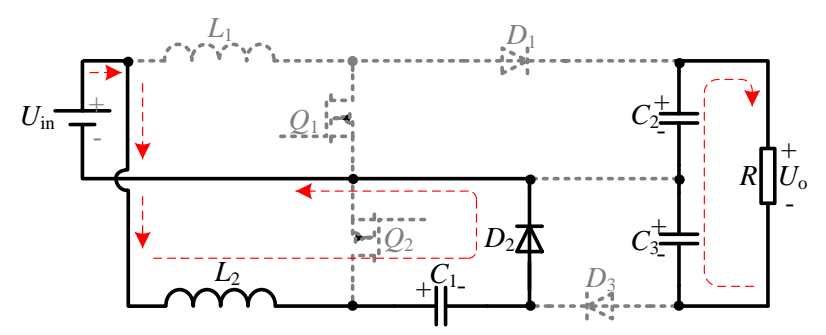

(g) $S_{1} S_{2}=00_{\mathrm{D} 1}(\mathrm{DCM})$

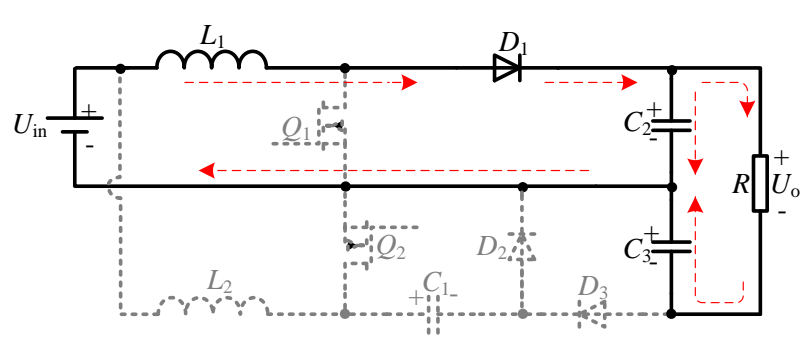

(h) $S_{1} S_{2}=00_{\mathrm{D} 2}(\mathrm{DCM})$

Fig. 2(h, c) and Fig. 3(c), when $L_{1}$ is discharging, the peak current $I_{\mathrm{L} 1 \mathrm{p}}$ can also be obtained as

$$
I_{\mathrm{L} 1 \mathrm{p}}=\frac{d_{2} \times T_{\mathrm{s}} \times\left(U_{\mathrm{C} 2}-U_{\mathrm{in}}\right)}{L}
$$

According to (5) and (6), $d_{2}$ can be derived as

$$
d_{2}=\frac{d \times U_{\text {in }}}{U_{\mathrm{C} 2}-U_{\text {in }}}
$$

By

$$
\text { means }
$$

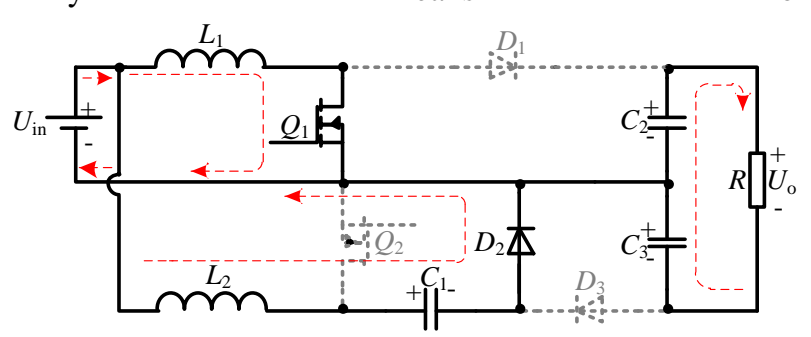

(a) $S_{1} S_{2}=10$

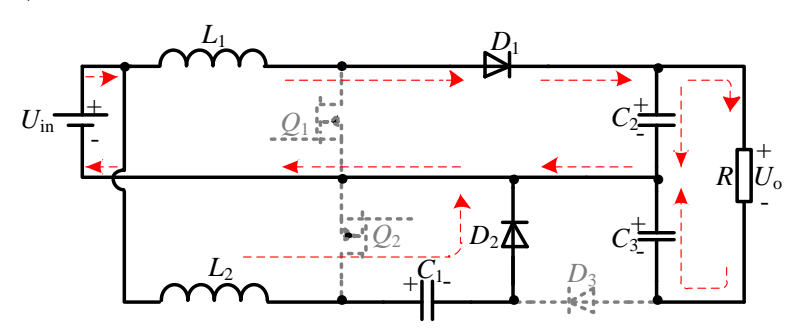

(b) $S_{1} S_{2}=00$

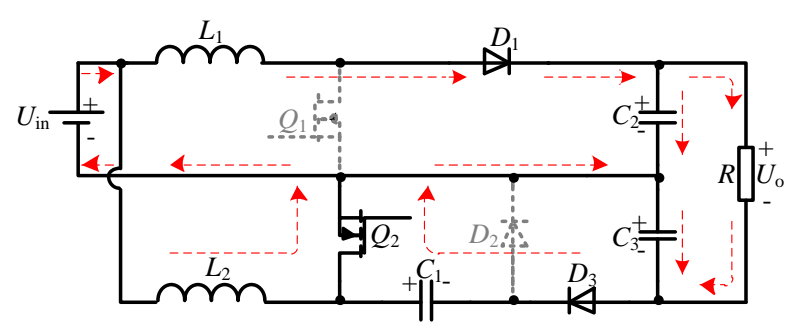

(c) $S_{1} S_{2}=01$

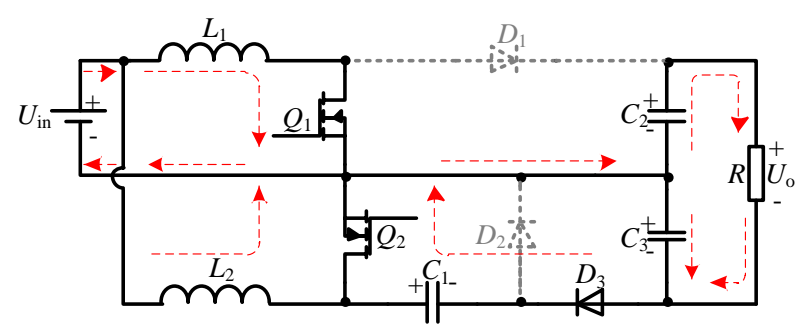

(d) $S_{1} S_{2}=11$ 


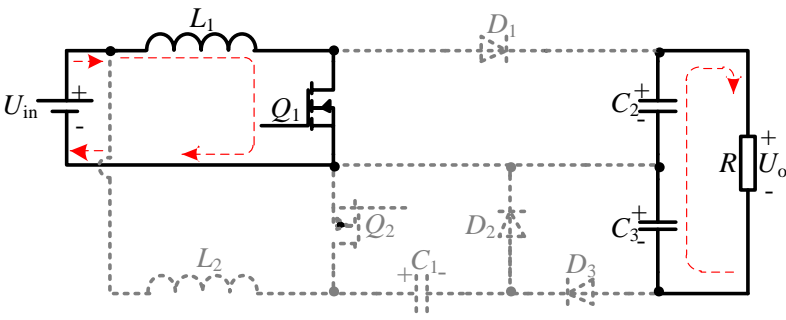

(e) $S_{1} S_{2}=10_{\mathrm{D}}(\mathrm{DCM})$

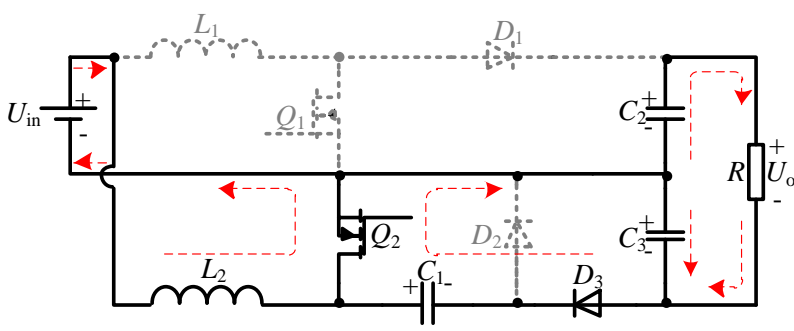

(f) $S_{1} S_{2}=01_{\mathrm{D}}(\mathrm{DCM})$

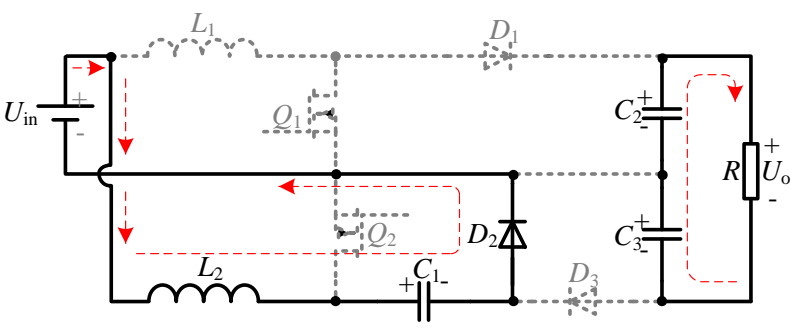

(g) $S_{1} S_{2}=00_{\mathrm{D} 1}$ (DCM)

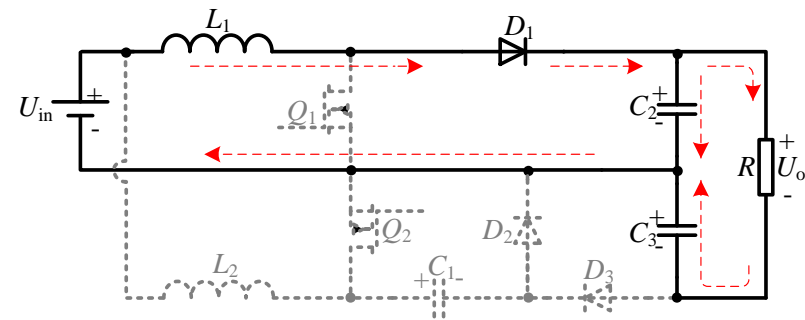

(h) $S_{1} S_{2}=00_{\mathrm{D} 2}(\mathrm{DCM})$

Fig. 2(c), $Q_{1}$ is turned off and $Q_{2}$ is turned on, so that $C_{1}$ and $C_{3}$ are connected in parallel. Therefore, the voltages across $C_{1}$ and $C_{3}$ are equal. By using the voltage-second balance principle on $L_{1}$ and $L_{2}$, the following equations can be obtained

$$
\left\{\begin{array}{l}
d U_{\text {in }}=d_{2}\left(U_{\mathrm{C} 2}-U_{\text {in }}\right) \\
d U_{\text {in }}=d_{2}\left(U_{\mathrm{C} 1}-U_{\text {in }}\right) \\
U_{\mathrm{C} 1}=U_{\mathrm{C} 3} \\
U_{\mathrm{o}}=U_{\mathrm{C} 2}+U_{\mathrm{C} 3}
\end{array}\right.
$$

Simplifying (8), $U_{\mathrm{C} 1}, U_{\mathrm{C} 2}$ and $U_{\mathrm{C} 3}$ can be derived as

$$
U_{\mathrm{C} 1}=U_{\mathrm{C} 2}=U_{\mathrm{C} 3}=\frac{U_{\mathrm{o}}}{2}
$$

By using the ampere-second balance principle on $C_{2}$, the following equations can be obtained

$$
\left(1-d_{2}\right) \times I_{\mathrm{o}}=d_{2} \times\left(\frac{I_{\mathrm{Llp}}}{2}-I_{\mathrm{o}}\right)
$$

According to (5), (7), (9) and (10), the following equation can be obtained as

$$
\frac{d^{2} U_{\text {in }}^{2} T_{\mathrm{s}}}{2 L\left(\frac{U_{\mathrm{o}}}{2}-U_{\mathrm{in}}\right)}=\frac{U_{\mathrm{o}}}{R}
$$

The normalized inductor time constant $\tau_{\mathrm{L}}$ is defined as

$$
\tau_{\mathrm{L}}=\frac{L \times f_{\mathrm{s}}}{R}
$$

where $f_{\mathrm{s}}$ is the switching frequency $\left(f_{\mathrm{s}}=1 / T_{\mathrm{s}}\right)$, and $R$ is the load resistance.

Substituting (12) into (11), the voltage-gain of the proposed converter in DCM is given by

$$
U_{\mathrm{o}}=U_{\text {in }} \times\left(1+\sqrt{1+\frac{d^{2}}{\tau_{\mathrm{L}}}}\right)
$$

Similarly, the voltage-gain within the range of $0.5<d<1$ can be obtained, which is the same as the one within the range of $0<d<0.5$.

\section{Boundary operating condition between CCM and DCM}

When the proposed converter operates in the boundary conduction mode (BCM), the voltage-gain of the CCM operation is equal to the voltage-gain of the DCM operation. According to (2) and (13), the boundary normalized inductor time constant $\tau_{\mathrm{LB}}$ can be derived as

$$
\tau_{\mathrm{LB}}=\frac{d \times(1-d)^{2}}{4}
$$

The relationship between $\tau_{\mathrm{LB}}$ and $d$ is shown in Fig. 4 . If $\tau_{\mathrm{L}}>\tau_{\mathrm{LB}}$, then the proposed converter is operating in CCM.

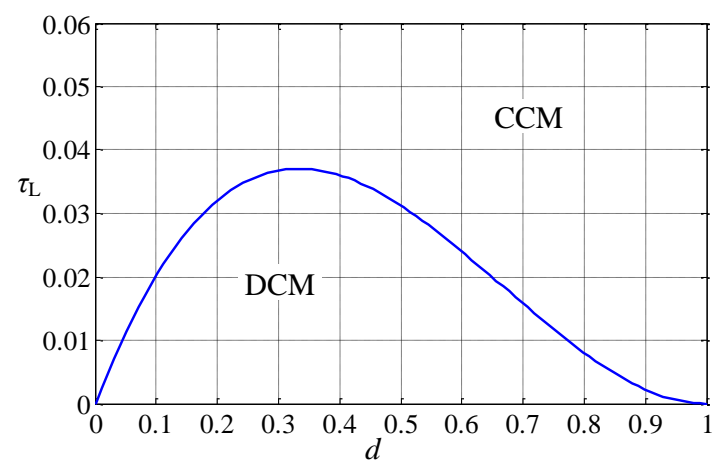

Fig. 4 Boundary condition of the proposed converter.

B. Voltage stress and current stress of the power 
semiconductors

By

means

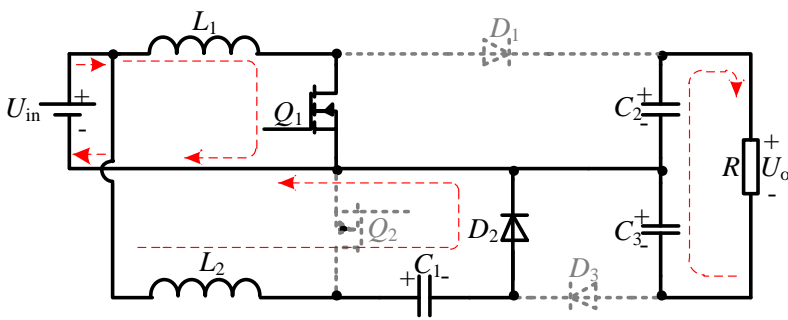

(a) $S_{1} S_{2}=10$

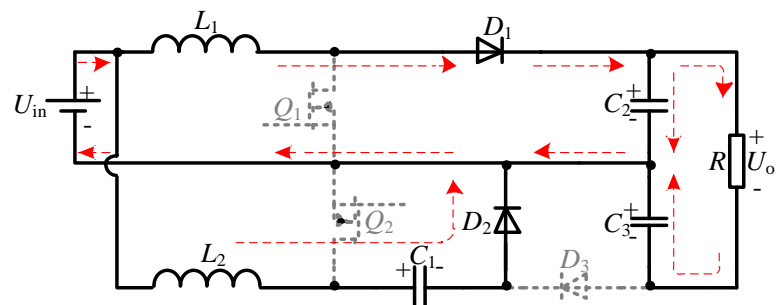

(b) $S_{1} S_{2}=00$

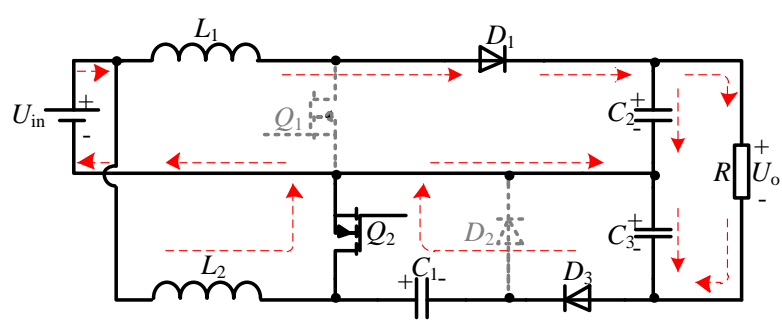

(c) $S_{1} S_{2}=01$

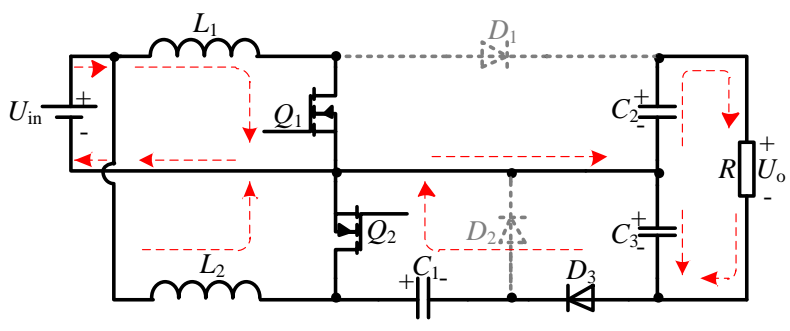

(d) $S_{1} S_{2}=11$

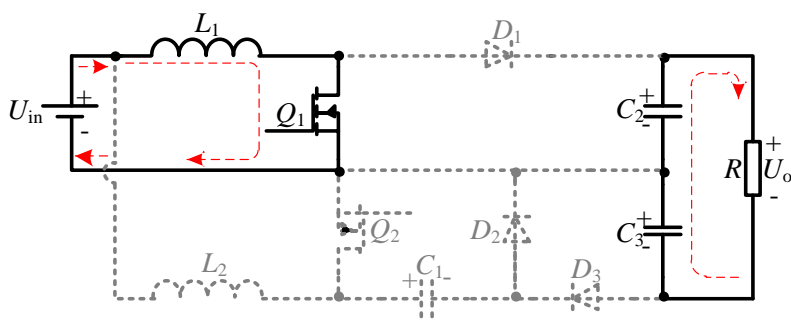

(e) $S_{1} S_{2}=10_{\mathrm{D}}(\mathrm{DCM})$

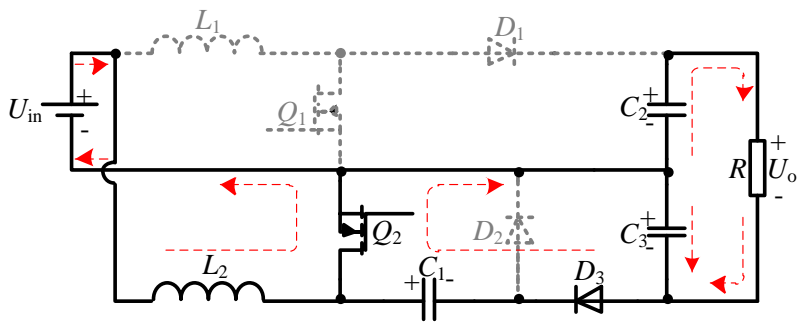

(f) $S_{1} S_{2}=01_{\mathrm{D}}(\mathrm{DCM})$

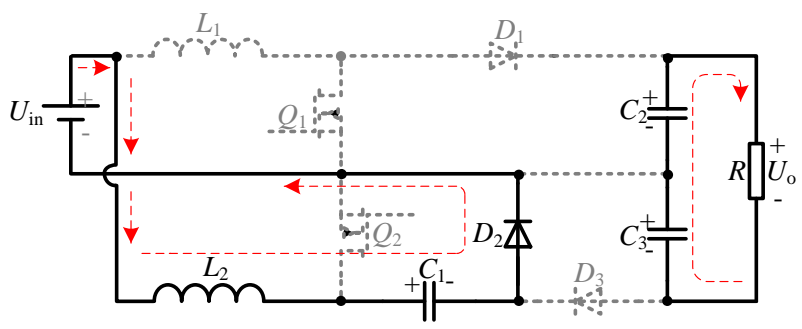

(g) $S_{1} S_{2}=00_{\mathrm{D} 1}(\mathrm{DCM})$

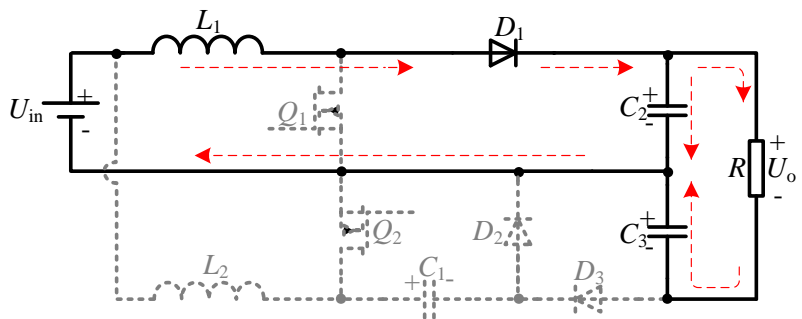

(h) $S_{1} S_{2}=00_{\mathrm{D} 2}(\mathrm{DCM})$

Fig. 2(b, c), power switch $Q_{1}$ is turned off and diode $D_{1}$ is turned on, so that $Q_{1}$ and $C_{2}$ are connected in parallel. Therefore, the voltages of $Q_{1}$ and $C_{2}$ are equal. Symmetrically, the voltages of the other power semiconductors can be obtained. The voltage stress for the power semiconductors can be written as follows:

$$
\left\{\begin{array}{l}
U_{\mathrm{Q} 1}=U_{\mathrm{D} 1}=U_{\mathrm{C} 2}=\frac{U_{\mathrm{o}}}{2} \\
U_{\mathrm{Q} 2}=U_{\mathrm{D} 2}=U_{\mathrm{C} 1}=\frac{U_{\mathrm{o}}}{2} \\
U_{\mathrm{D} 3}=U_{\mathrm{C} 3}=\frac{U_{\mathrm{o}}}{2}
\end{array}\right.
$$

Based on (15), the voltage stress for all of the power semiconductors is half of the output voltage.

The comparisons between the proposed topology and the four topologies which include the conventional interleaved DC-DC Boost converter, the three-level DC-DC Boost converter and the topology of the converter in [23] are shown in

Tab. 2.

Tab. 2 The comparisons between the proposed typology and the other four typologies

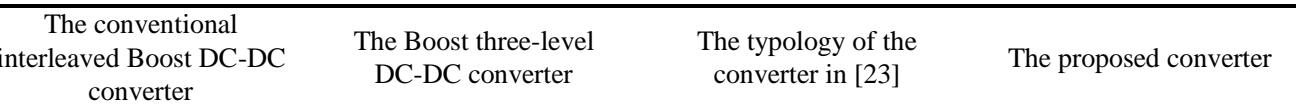




\begin{tabular}{|c|c|c|c|c|}
\hline Voltage-gain & $1 /(1-d)$ & $1 /(1-d)$ & $2 /(1-d)$ & $2 /(1-d)$ \\
\hline $\begin{array}{l}\text { Voltage stress for power } \\
\text { switches }\end{array}$ & $U_{\mathrm{o}}$ & $U_{\mathrm{d}} / 2$ & $U_{\mathrm{o}} / 2$ & $U_{\mathrm{o}} / 2$ \\
\hline Voltage stress for diodes & $U_{\mathrm{o}}$ & $U_{\mathrm{o}} / 2$ & $U_{\mathrm{o}}, \quad U_{\mathrm{o}} / 2$ & $U_{\mathrm{o}} / 2$ \\
\hline $\begin{array}{l}\text { Input current } \\
\text { ripple }(d<0.5)\end{array}$ & $\frac{d(1-2 d) U_{\mathrm{o}} T_{\mathrm{s}}}{L}$ & $\frac{d(1-2 d) U_{\mathrm{o}} T_{\mathrm{s}}}{2 L}$ & High & $\frac{d(1-2 d) T_{\mathrm{s}} U_{\mathrm{o}}}{2 L}$ \\
\hline $\begin{array}{l}\text { Ripple rate of the input } \\
\text { current }(d<0.5)\end{array}$ & $\frac{d(1-d)(1-2 d) R T_{\mathrm{s}}}{L}$ & $\frac{d(1-d)(1-2 d) R T_{\mathrm{s}}}{2 L}$ & High & $\frac{d(1-d)(1-2 d) R T_{\mathrm{s}}}{4 L}$ \\
\hline $\begin{array}{l}\text { Input current } \\
\text { ripple }(d>0.5)\end{array}$ & $\frac{(2 d-1)(1-d) U_{\mathrm{o}} T_{\mathrm{s}}}{L}$ & $\frac{(2 d-1)(1-d) U_{\mathrm{o}} T_{\mathrm{s}}}{2 L}$ & High & $\frac{(2 d-1)(1-d) T_{\mathrm{s}} U_{\mathrm{o}}}{2 L}$ \\
\hline $\begin{array}{l}\text { Ripple rate of the input } \\
\quad \text { current }(d>0.5)\end{array}$ & $\frac{(2 d-1)(1-d)^{2} R T_{\mathrm{s}}}{L}$ & $\frac{(2 d-1)(1-d)^{2} R T_{\mathrm{s}}}{2 L}$ & High & $\frac{(2 d-1)(1-d)^{2} R T_{\mathrm{s}}}{4 L}$ \\
\hline The number of inductors & 2 & 1 & 2 & 2 \\
\hline $\begin{array}{c}\text { The number of power } \\
\text { switches }\end{array}$ & 2 & 2 & 2 & 2 \\
\hline The number of diodes & 2 & 2 & 2 & 3 \\
\hline
\end{tabular}

According to

Tab. 2, compared with the conventional interleaved

DC-DC Boost converter, the proposed converter benefits from higher voltage-gain and lower voltage stress for the power semiconductors. The proposed topology can also achieve a higher voltage-gain than the voltage-gain of the three-level DC-DC Boost converter. In addition, compared with the topology in [23], the voltage stress for each power semiconductor of the proposed topology is half of the output voltage. Regarding the input current ripple, the converter in [23] suffers the highest input current ripple among these converters, because its input current is a pulse current which is discontinuous. According to Error! Reference source not found., when these converters have the same parameters, such as the output voltage $U_{\mathrm{o}}$, the duty cycle $d$, the switching period $T_{\mathrm{s}}$, the inductance $L$ and the load resistance $R$, the input current ripple of the proposed converter is lower than the one of the conventional interleaved Boost DC-DC converter. The ripple rate of the input current for the proposed converter is half of the one for the Boost three-level DC-DC converter, which means the proposed converter has the lowest ripple rate of the input current among these converters.

According

to

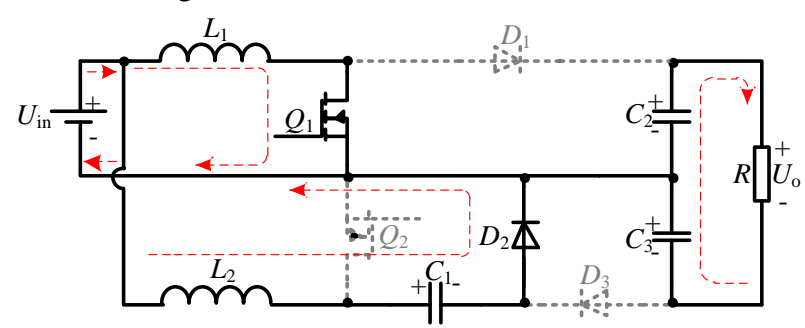

(a) $S_{1} S_{2}=10$

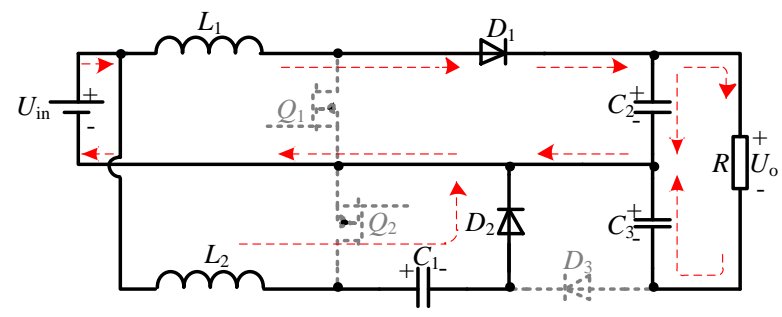

(b) $S_{1} S_{2}=00$

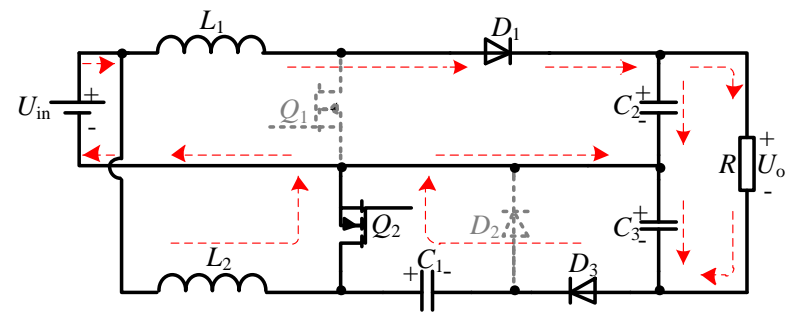

(c) $S_{1} S_{2}=01$

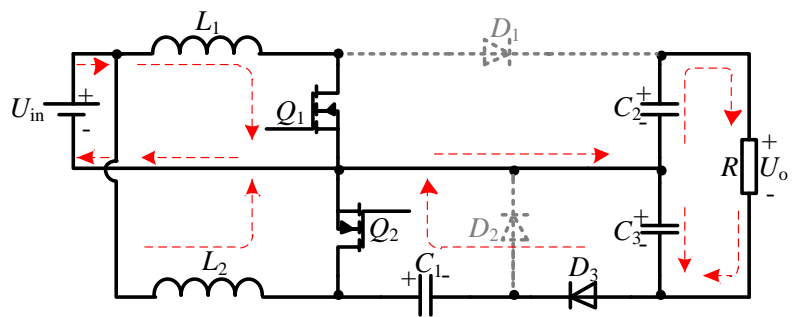

(d) $S_{1} S_{2}=11$

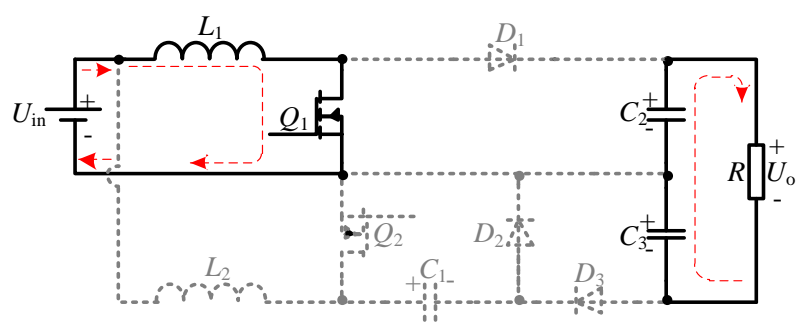

(e) $S_{1} S_{2}=10_{\mathrm{D}}(\mathrm{DCM})$ 


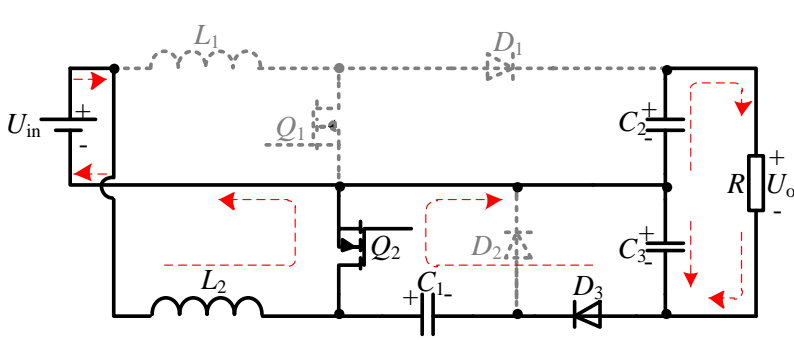

(f) $S_{1} S_{2}=01_{\mathrm{D}}(\mathrm{DCM})$

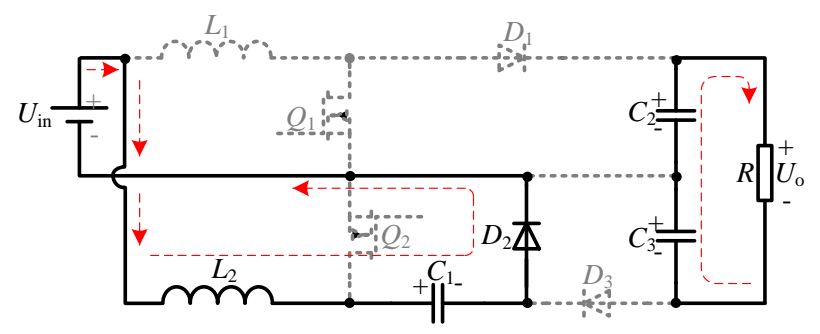

(g) $S_{1} S_{2}=00_{\mathrm{D} 1}(\mathrm{DCM})$

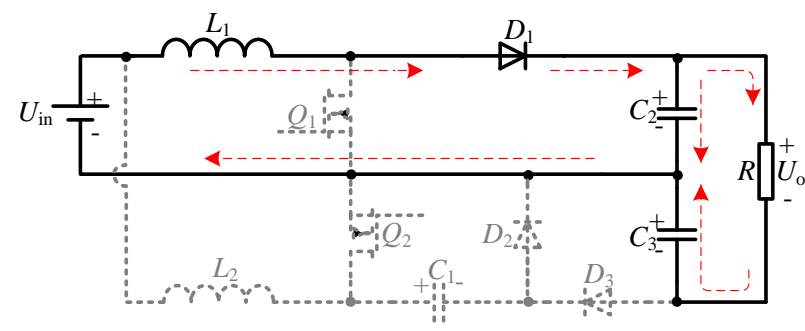

(h) $S_{1} S_{2}=00_{\mathrm{D} 2}(\mathrm{DCM})$

Fig. 2 and (4), the current stress of the power semiconductors can be obtained by using the voltage-balance on capacitors $C_{1}, C_{2}$ and $C_{3}$ as given in (16).

$$
\left\{\begin{array}{l}
I_{\mathrm{Q} 1}=\frac{1}{1-d} I_{\mathrm{o}} \\
I_{\mathrm{Q} 2}=\left(\frac{1}{1-d}+\frac{1}{d}\right) I_{\mathrm{o}} \\
I_{\mathrm{D} 1}=I_{\mathrm{D} 2}=\frac{1}{1-d} I_{\mathrm{o}} \\
I_{\mathrm{D} 3}=\frac{1}{d} I_{\mathrm{o}}
\end{array}\right.
$$

Simplifying (16), the current stress of $Q_{2}$ is higher than that of $Q_{1}$, but it is easier (and cheaper) to choose a MOSFET with a higher rated current than the one with a higher rated voltage. The proposed converter can also obtain a high voltage-gain while the duty cycle is in the range of $0.5<d<1$. In this case, the difference of the current stress between $Q_{1}$ and $Q_{2}$ is small. Therefore, the type of power switch $Q_{1}$ can be the same as the type of $Q_{2}$, which means the difference of the current stress between $Q_{1}$ and $Q_{2}$ does not affect the selection of power switches.

The converters in [24] and [25] have the similar structures comparing with the proposed converter. The comparisons between the proposed converter and the other two similar converters are shown in Error! Reference source not found.. The converters in [24] and [25] employ coupled inductors. To simplify the analysis, it is assumed that each coupled inductor has the same turn ratio $N$.

Tab. 3 The comparisons between the proposed converter and the other two similar converters

\begin{tabular}{|c|c|c|c|}
\hline & The converter in [24] & The converter in [25] & The proposed converter \\
\hline Voltage-gain & $2(N+1) /(1-d)$ & $(2 N+3+d) /(1-d)$ & $2 /(1-d)$ \\
\hline $\begin{array}{c}\text { Voltage stress for power } \\
\text { switches }\end{array}$ & $U_{\mathrm{o}} / 2(N+1)$ & $U_{\mathrm{o}} /(2 N+3+d)$ & $U_{\mathrm{o}} / 2$ \\
\hline $\begin{array}{l}\text { The maximum voltage } \\
\text { stress for diodes }\end{array}$ & $N U_{\mathrm{o}} /(N+1)$ & $(N+1) U_{\mathrm{o}} /(2 N+3+d)$ & $U_{\mathrm{o}} / 2$ \\
\hline Input current & $(1-k)(1-d)(2 d-1) U_{\mathrm{o}} T_{\mathrm{s}}$ & $\underline{(1-k)(1-d)(2 d-1) U_{\mathrm{o}} T_{\mathrm{s}}}$ & $\underline{(2 d-1)(1-d) T_{\mathrm{s}} U_{\mathrm{o}}}$ \\
\hline $\operatorname{ripple}(d>0.5)$ & $2 L_{\mathrm{k}}(N+1)$ & $(2 N+3+d) L_{\mathrm{k}}$ & $2 L$ \\
\hline $\begin{array}{c}\text { The number of } \\
\text { inductors/coupled } \\
\text { inductors }\end{array}$ & 2 & 2 & 2 \\
\hline $\begin{array}{c}\text { The number of power } \\
\text { switches }\end{array}$ & 2 & 2 & 2 \\
\hline The number of diodes & 4 & 6 & 3 \\
\hline The number of capacitors & 4 & 6 & 3 \\
\hline
\end{tabular}

The input current ripple calculations of converters in Error! Reference source not found. and [25] are approximate ones, even though the practical input current ripple is still quite lower. According to Error!

Reference source not found., the converters in [24] and
[25] both obtain a higher voltage-gain and lower input current ripple. The voltage stress for power switches of the two converters is lower than that of the proposed converter. But the voltage stress for diodes of the proposed converter is lower than that of the converter in 
[24] (when $N>1$ ). The converter in [25] benefits the lowest voltage stress for diodes among these converters. But, both the potential differences between the output and the input side grounds of the converters in [24] and [25] are high frequency PWM voltages (i.e. without a common ground), which may cause more EMI. In addition, the number of components for the proposed converter is the smallest one among these converters.

Regarding the voltage-gain of converters for fuel cell vehicles, a wide range of voltage-gain is really required because the output voltage of the fuel cell varies within a wide range when the load power varies widely. Therefore, sometimes the converters need to operate with a lower voltage-gain (i.e. the duty cycle is lower due to the higher output voltage of the fuel cell). According to Tab. 3, when these converters need to achieve the required lower voltage-gain, the duty cycle of the proposed converter is proper, i.e. a wider voltage-gain range can be realized.

\section{Analysis of the input current ripple}

Within the range of $0<d<0.5$, the input current ripple $\Delta i_{\text {in }}$ can be obtained as follows according to Fig. 3(a)

$$
\begin{aligned}
\Delta i_{\text {in }} & =\left(I_{\mathrm{L} 1 \mathrm{~m}}+I_{\mathrm{L} 2 \mathrm{a}}\right)-\left(I_{\mathrm{L} 1 \mathrm{a}}+I_{\mathrm{L} 2 \mathrm{~m}}\right) \\
& =\left(I_{\mathrm{L} 1 \mathrm{~m}}-I_{\mathrm{L} 1 \mathrm{a}}\right)+\left(I_{\mathrm{L} 2 \mathrm{a}}-I_{\mathrm{L} 2 \mathrm{~m}}\right)
\end{aligned}
$$

When $S_{1} S_{2}=00\left(t_{1} \sim t_{2}\right)$, the following equations can be obtained as follows according to

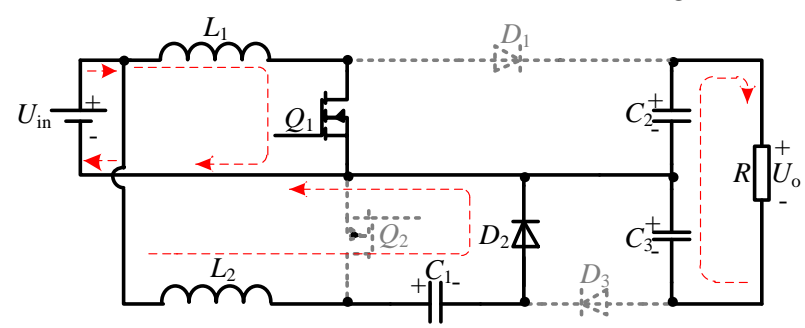

(a) $S_{1} S_{2}=10$

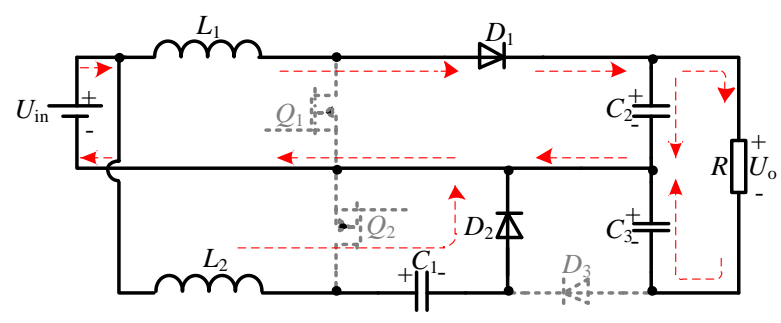

(b) $S_{1} S_{2}=00$

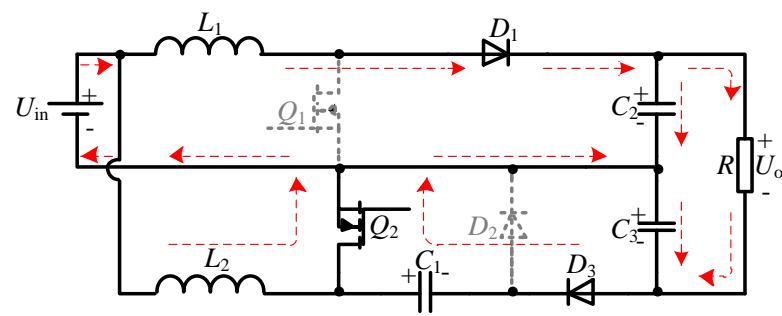

(c) $S_{1} S_{2}=01$

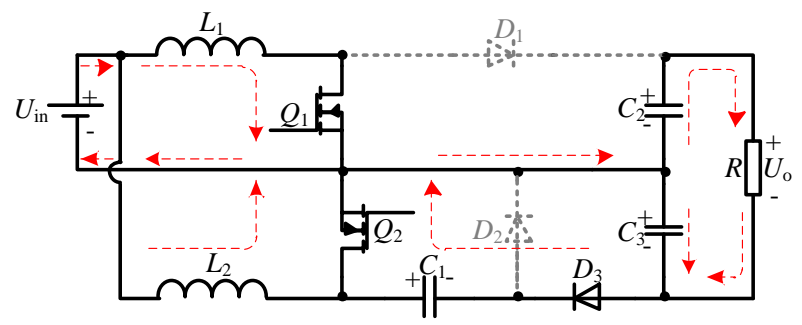

(d) $S_{1} S_{2}=11$

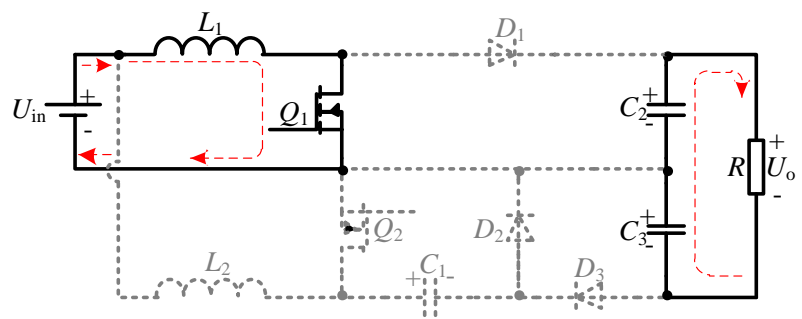

(e) $S_{1} S_{2}=10_{\mathrm{D}}(\mathrm{DCM})$

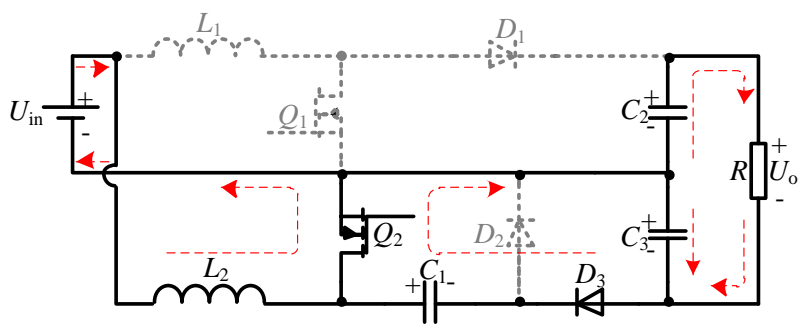

(f) $S_{1} S_{2}=01_{\mathrm{D}}(\mathrm{DCM})$

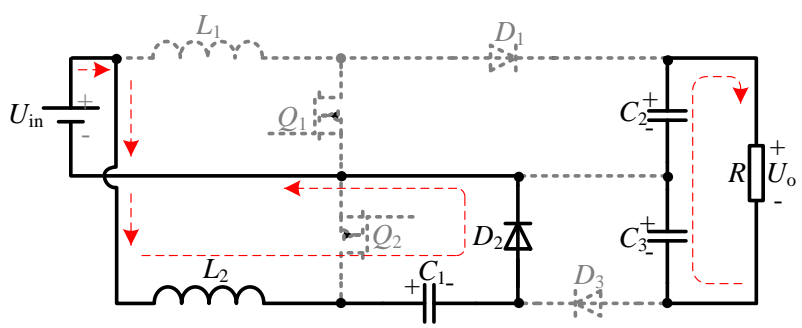

(g) $S_{1} S_{2}=00_{\mathrm{D} 1}(\mathrm{DCM})$

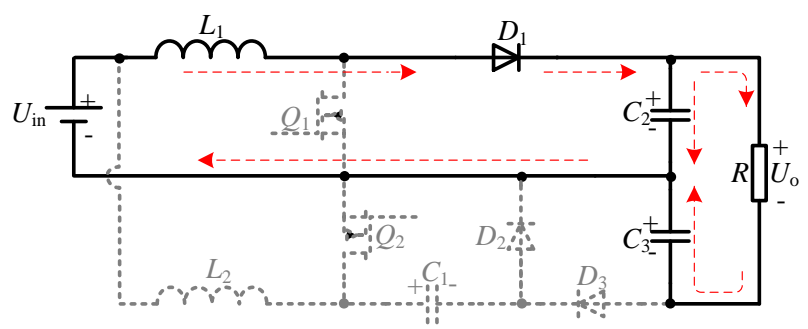

(h) $S_{1} S_{2}=00_{\mathrm{D} 2}(\mathrm{DCM})$

Fig. 2(b) and Fig. 3(a), 


$$
\left\{\begin{array}{l}
I_{\mathrm{L} 1 \mathrm{~m}}-I_{\mathrm{L} 1 \mathrm{a}}=\frac{\left(U_{\mathrm{c} 2}-U_{\mathrm{in}}\right)(1-2 d) T_{\mathrm{s}}}{2 L} \\
I_{\mathrm{L} 2 \mathrm{a}}-I_{\mathrm{L} 2 \mathrm{~m}}=\frac{\left(U_{\mathrm{c} 1}-U_{\mathrm{in}}\right)(1-2 d) T_{\mathrm{s}}}{2 L}
\end{array}\right.
$$

In terms of (2), (17) and (18), $\Delta i_{\text {in }}$ can be derived as

$$
\Delta i_{\text {in }}=\frac{d \times(1-2 d) \times T_{\mathrm{s}} \times U_{\text {in }}}{(1-d) \times L}=\frac{d \times(1-2 d) \times T_{\mathrm{s}} \times U_{\mathrm{o}}}{2 L}
$$

Then, the ripple of $i_{\mathrm{L} 1}, i_{\mathrm{L} 2}$ and $i_{\text {in }}$ within the range of $0<d<0.5$ can be described as follows

$$
\left\{\begin{array}{l}
\Delta i_{\mathrm{L} 1}=\Delta i_{\mathrm{L} 2}=\frac{d \times T_{\mathrm{s}} \times U_{\text {in }}}{L}=\frac{d \times(1-d) \times T_{\mathrm{s}} \times U_{\mathrm{o}}}{2 L} \\
\Delta i_{\mathrm{in}}=\frac{d \times(1-2 d) \times T_{\mathrm{s}} \times U_{\text {in }}}{(1-d) \times L}=\frac{d \times(1-2 d) \times T_{\mathrm{s}} \times U_{\mathrm{o}}}{2 L}
\end{array}\right.
$$

where $\Delta i_{\mathrm{L} 1}, \Delta i_{\mathrm{L} 2}$ and $\Delta i_{\text {in }}$ are the ripple of $i_{\mathrm{L} 1}, i_{\mathrm{L} 2}$ and $i_{\text {in }}$.

Within the range of $0.5<d<1$, according to Fig. 3(b), the input current ripple $\Delta \dot{i}_{\text {in }}$ can be obtained as

$$
\begin{aligned}
\Delta i_{\mathrm{in}} & =\left(I_{\mathrm{L} 1 \mathrm{n}}+I_{\mathrm{L} 2 \mathrm{~b}}\right)-\left(I_{\mathrm{L} 1 \mathrm{~b}}+I_{\mathrm{L} 2 \mathrm{n}}\right) \\
& =\left(I_{\mathrm{L} 1 \mathrm{n}}-I_{\mathrm{L} 1 \mathrm{~b}}\right)+\left(I_{\mathrm{L} 2 \mathrm{~b}}-I_{\mathrm{L} 2 \mathrm{n}}\right)
\end{aligned}
$$

When $S_{1} S_{2}=11\left(t_{2} \sim t_{3}\right)$, the following equations can be obtained as follows according to

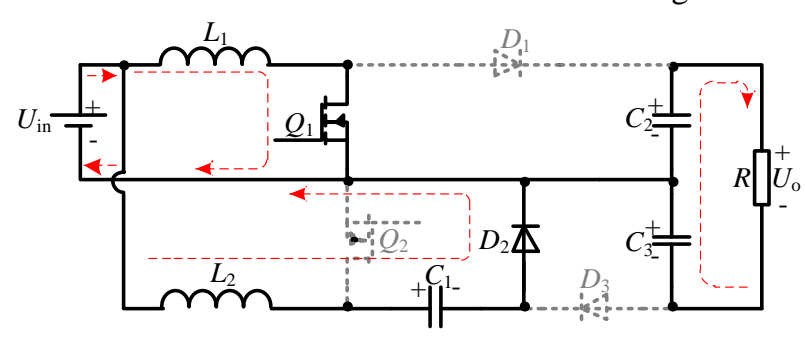

(a) $S_{1} S_{2}=10$

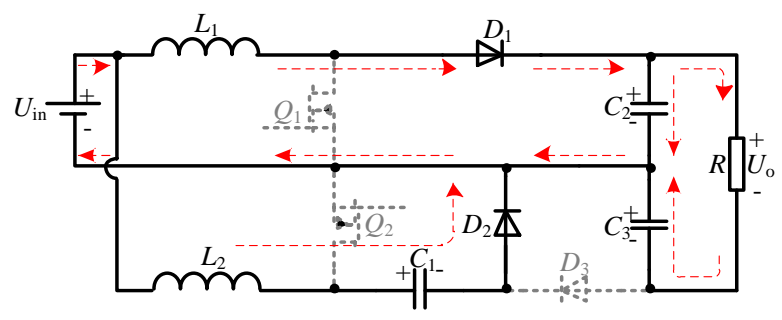

(b) $S_{1} S_{2}=00$

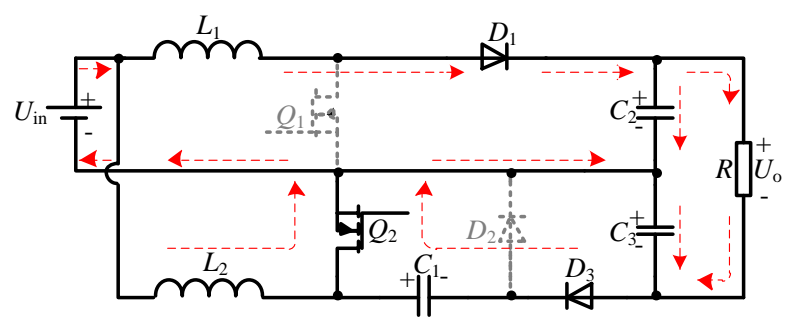

(c) $S_{1} S_{2}=01$

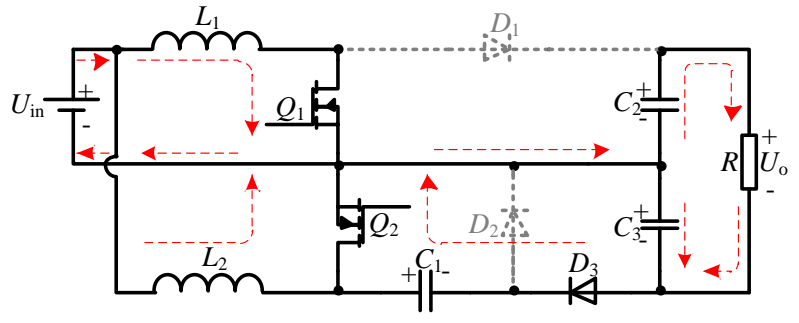

(d) $S_{1} S_{2}=11$

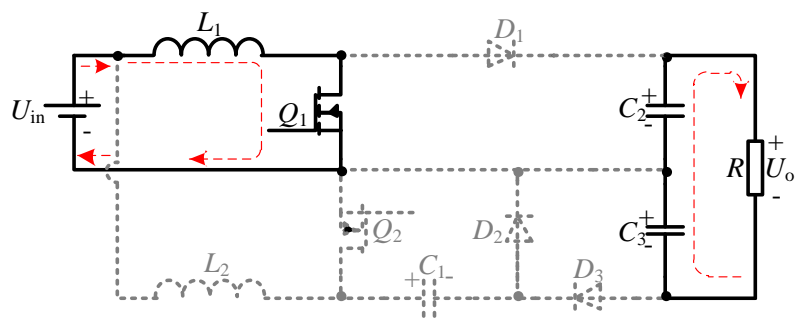

(e) $S_{1} S_{2}=10_{\mathrm{D}}(\mathrm{DCM})$

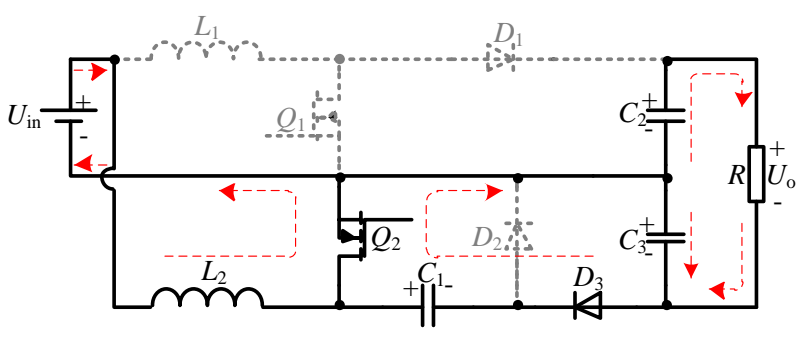

(f) $S_{1} S_{2}=01_{\mathrm{D}}(\mathrm{DCM})$

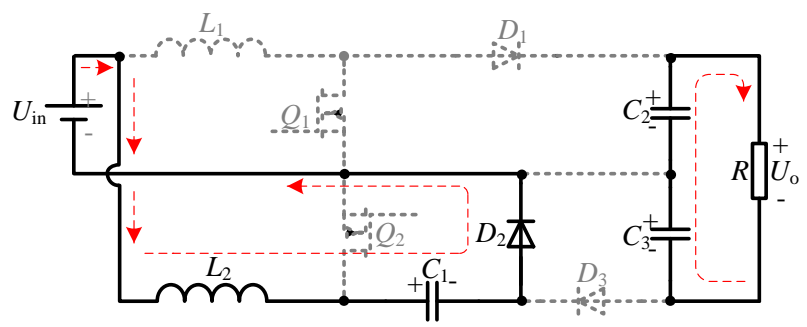

(g) $S_{1} S_{2}=00_{\mathrm{D} 1}(\mathrm{DCM})$

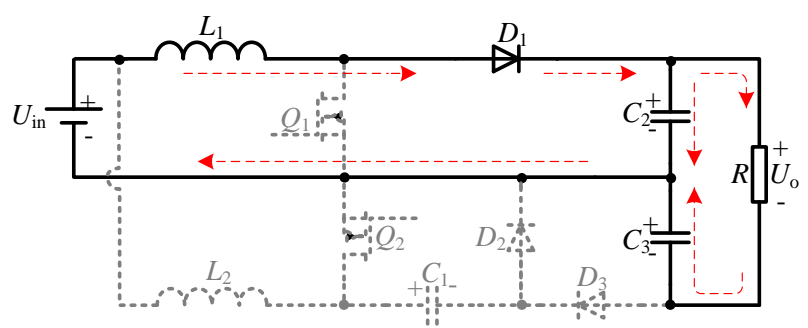

(h) $S_{1} S_{2}=00_{\mathrm{D} 2}$ (DCM)

Fig. 2(d) and Fig. 3(b)

$$
\left\{\begin{array}{l}
I_{\mathrm{L} 1 \mathrm{n}}-I_{\mathrm{L} 1 \mathrm{~b}}=\frac{(2 d-1) U_{\mathrm{in}} T_{\mathrm{S}}}{2 L} \\
I_{\mathrm{L} 2 \mathrm{~b}}-I_{\mathrm{L} 2 \mathrm{n}}=\frac{(2 d-1) U_{\mathrm{in}} T_{\mathrm{S}}}{2 L}
\end{array}\right.
$$

By means of (2), (21) and (22), $\Delta i_{\text {in }}$ can be derived as 


$$
\Delta i_{\text {in }}=\frac{(2 d-1) \times T_{\mathrm{s}} \times U_{\text {in }}}{L}=\frac{(2 d-1) \times(1-d) \times T_{\mathrm{s}} \times U_{\mathrm{o}}}{2 L}
$$

Then, the ripple of $i_{\mathrm{L} 1}, i_{\mathrm{L} 2}$ and $i_{\text {in }}$ within the range of $0.5<d<1$ can be obtained as follows

$$
\left\{\begin{array}{l}
\Delta i_{\mathrm{L} 1}=\Delta i_{\mathrm{L} 2}=\frac{d \times T \times \times_{\mathrm{s}} U_{\text {in }}}{L}=\frac{d \times(1-d) \times T_{\mathrm{s}} \times U_{\mathrm{o}}}{2 L} \\
\Delta i_{\text {in }}=\frac{(2 d-1) \times T_{\mathrm{s}} \times U_{\text {in }}}{L}=\frac{(2 d-1) \times(1-d) \times T_{\mathrm{s}} \times U_{\mathrm{o}}}{2 L}
\end{array}\right.
$$

For the case when $U_{\mathrm{o}}=400 \mathrm{~V}, L=226 \mu \mathrm{H}, f_{\mathrm{s}}=20 \mathrm{kHz}$ and $R=100 \Omega$, using (20) and (24), the current ripple rate of $i_{\mathrm{L} 1}, i_{\mathrm{L} 2}$ and $i_{\text {in }}$ can be calculated and is shown in Fig. 5, where $\Delta i / I$ is the current ripple rate. According to Fig. 5, the ripple rate of the input current is lower than the ripple rate of $i_{\mathrm{L} 1}$ and $i_{\mathrm{L} 2}$. When the DC source is in the range of $U_{\mathrm{in}}=50 \mathrm{~V} \sim 120 \mathrm{~V}$, the duty cycle varies in the range of $0.4<\mathrm{d}<0.75$. In this case, the minimum ripple rate of the input current is zero, while the duty cycle $d=0.5$. In the range of $0.4 \leq d<0.5$, the maximum ripple rate of the input current is $27 \%$, when the duty cycle is $d=0.4$. In addition, the maximum ripple rate of the input current is $20.5 \%$, when the duty cycle is $d=0.67$ within the range of $0.5<d<0.75$

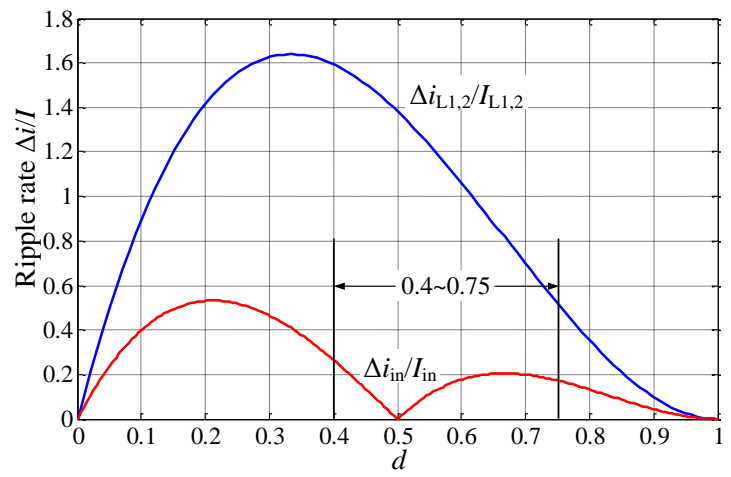

Fig. 5 The ripple rate of $i_{\mathrm{L} 1}, i_{\mathrm{L} 2}$ and $i_{\text {in }}$

\section{Parameters design of the converter}

\section{Power switches and diodes}

When the output voltage is $U_{\mathrm{o}}=400 \mathrm{~V}$, the voltage stress for each power semiconductor is $200 \mathrm{~V}$ based on (15). When the voltage-gain is $8(d=0.75)$ and the load resistance is $R=100 \Omega$, the current stress (namely average currents in the $O N$ state) for power semiconductors can be obtained as: $I_{\mathrm{Q} 1}=16 \mathrm{~A}, I_{\mathrm{Q} 2}=21.3 \mathrm{~A}$, $I_{\mathrm{D} 1}=I_{\mathrm{D} 2}=16 \mathrm{~A}, \quad$ and $\quad I_{\mathrm{D} 3}=5.3 \mathrm{~A} \quad$ according to Error! Reference source not found. The power switches and diodes can be selected by these referenced voltage and current stresses.

\section{Inductors and capacitors}

According to (24), the inductances of $L_{1}$ and $L_{2}$ can be obtained as

$$
\left\{\begin{array}{l}
L_{1}=\frac{d \times U_{\text {in }} \times T_{\mathrm{s}}}{\Delta i_{\mathrm{L} 1}} \\
L_{2}=\frac{d \times U_{\text {in }} \times T_{\mathrm{s}}}{\Delta i_{\mathrm{L} 2}}
\end{array}\right.
$$

In

terms

of

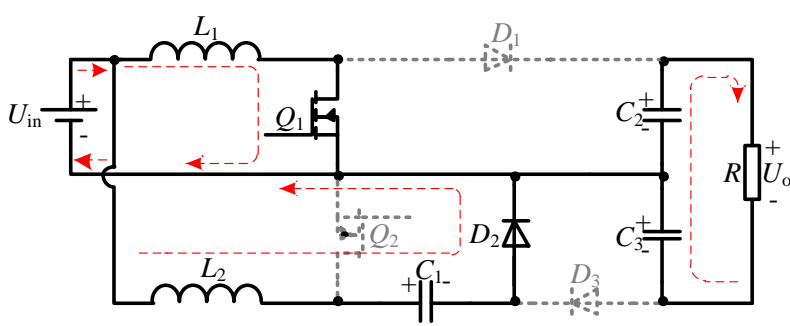

(a) $S_{1} S_{2}=10$

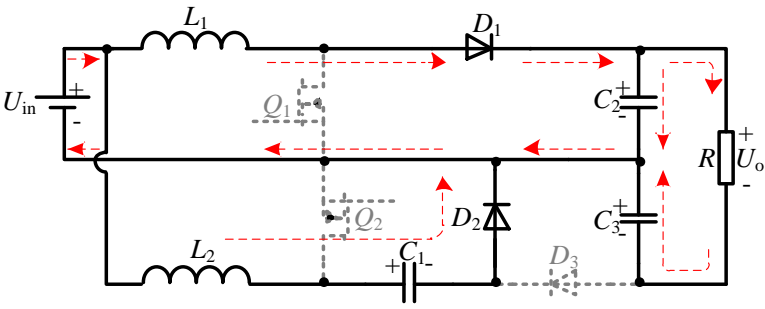

(b) $S_{1} S_{2}=00$

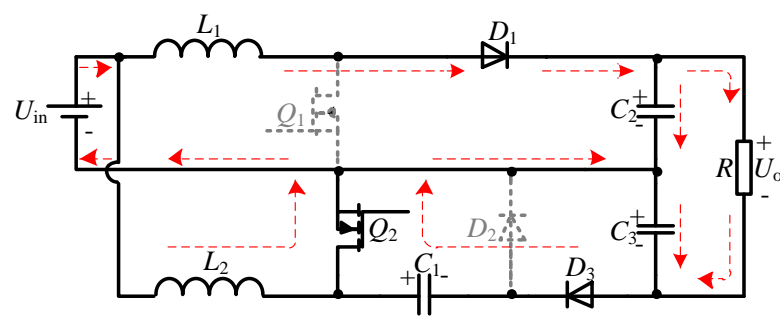

(c) $S_{1} S_{2}=01$

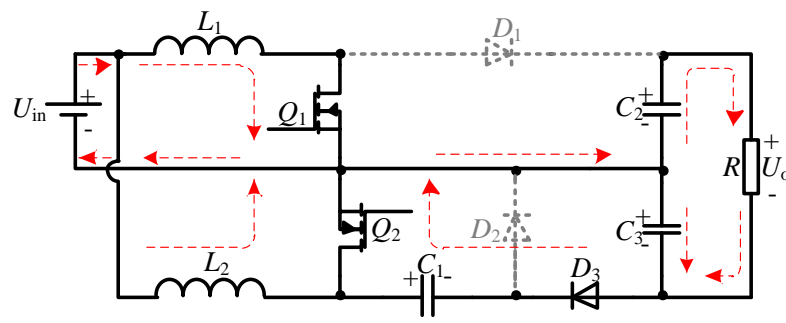

(d) $S_{1} S_{2}=11$

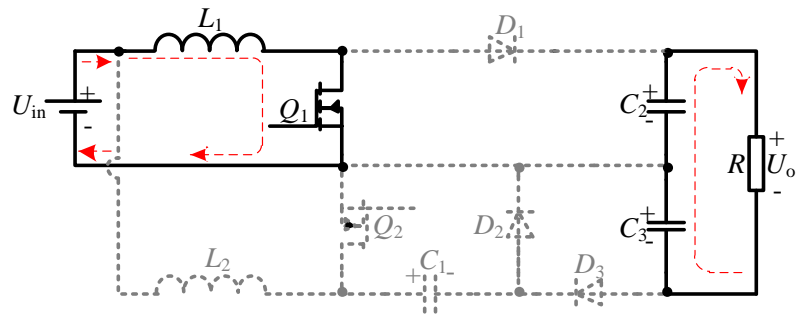

(e) $S_{1} S_{2}=10_{\mathrm{D}}(\mathrm{DCM})$ 


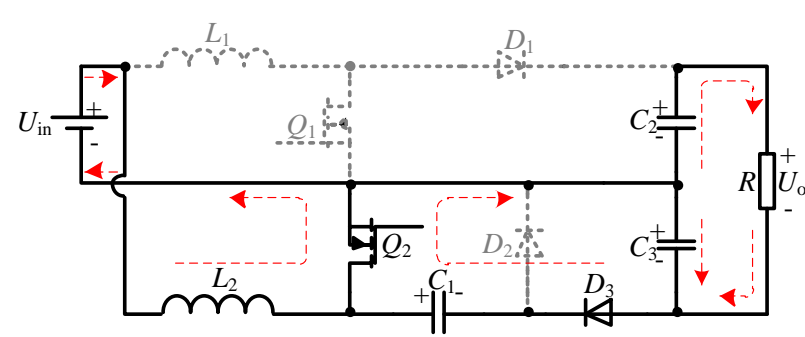

(f) $S_{1} S_{2}=01_{\mathrm{D}}(\mathrm{DCM})$

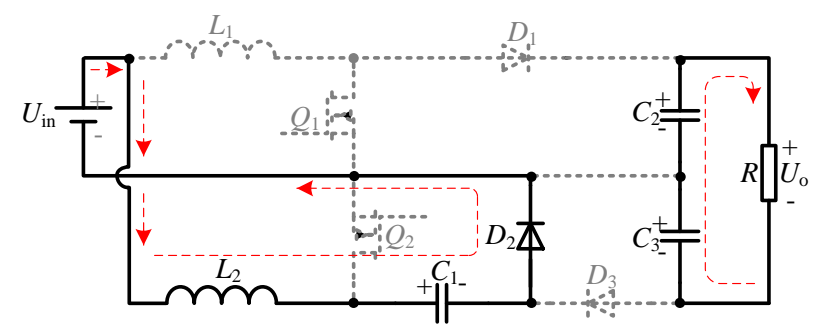

(g) $S_{1} S_{2}=00_{\mathrm{D} 1}$ (DCM)

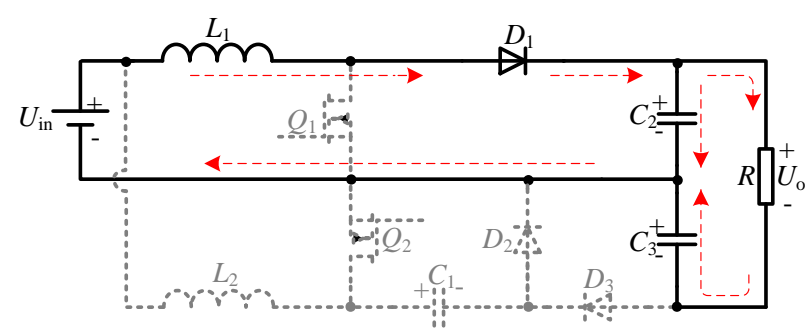

(h) $S_{1} S_{2}=00_{\mathrm{D} 2}$ (DCM)

Fig. 2(a, b), when the power switch $Q_{2}$ is turned off, $C_{1}$ is charging from inductor $L_{2}$ and the DC source. Then, the capacitance of $C_{1}$ can be obtained as

$$
C_{1}=\frac{(1-d) I_{\mathrm{L} 2} T_{\mathrm{s}}}{\Delta U_{\mathrm{C} 1}}
$$

where $\Delta U_{\mathrm{C} 1}$ is the capacitor voltage fluctuation.

By

$$
\text { means }
$$

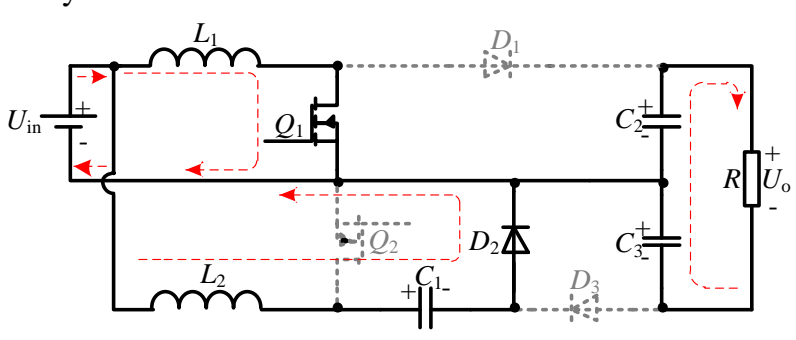

(a) $S_{1} S_{2}=10$

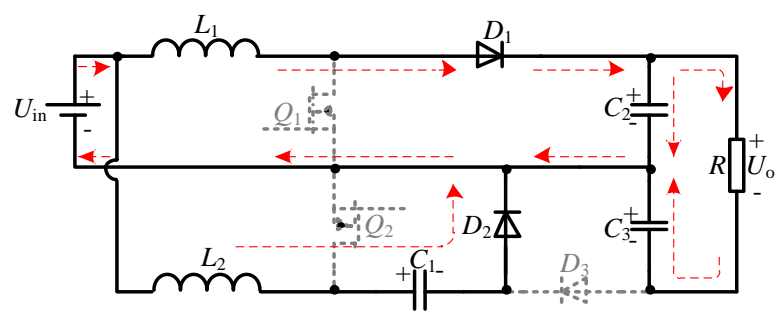

(b) $S_{1} S_{2}=00$

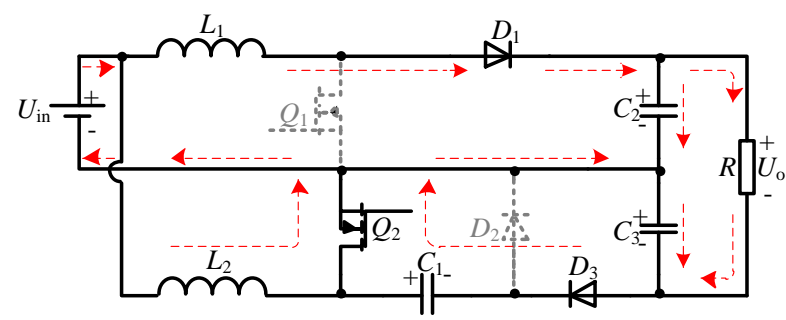

(c) $S_{1} S_{2}=01$

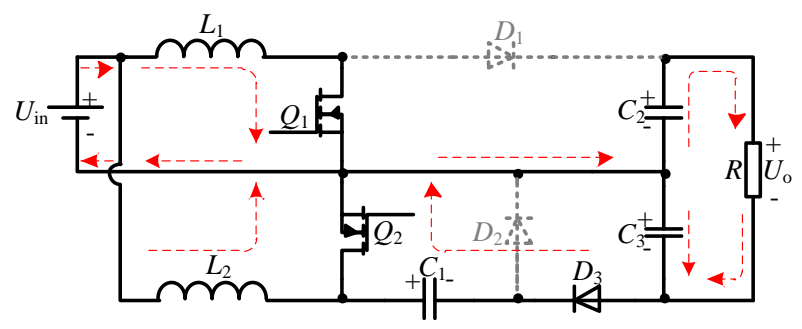

(d) $S_{1} S_{2}=11$

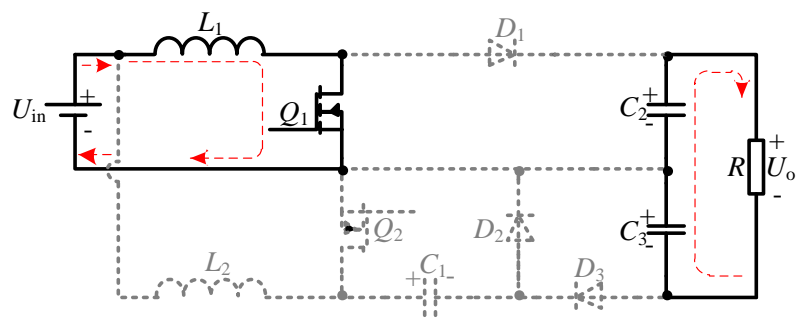

(e) $S_{1} S_{2}=10_{\mathrm{D}}$ (DCM)

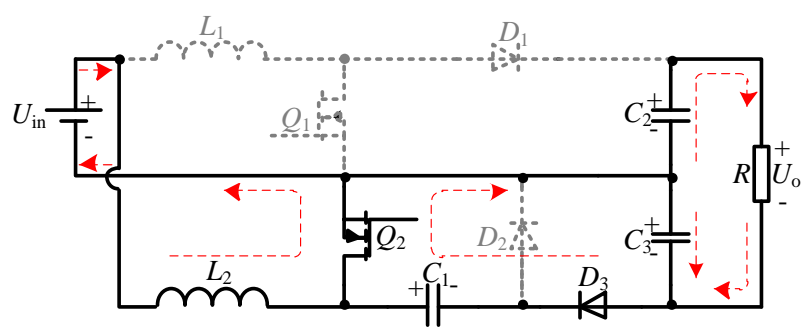

(f) $S_{1} S_{2}=01_{\mathrm{D}}(\mathrm{DCM})$

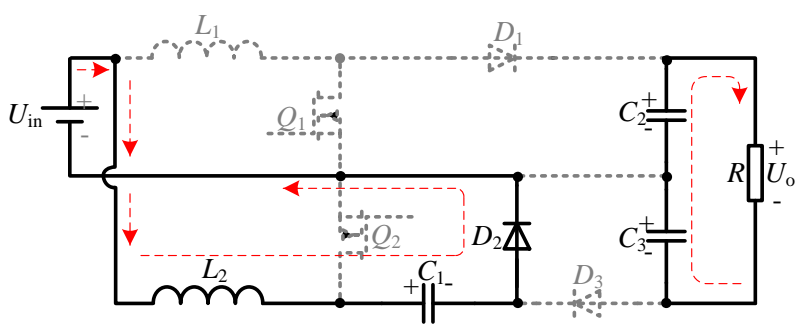

(g) $S_{1} S_{2}=00_{\mathrm{D} 1}$ (DCM)

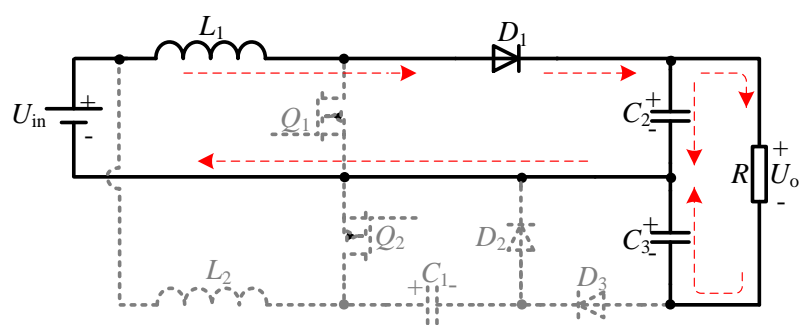

(h) $S_{1} S_{2}=00_{\mathrm{D} 2}(\mathrm{DCM})$

Fig. 2(a, d), when the $Q_{1}$ is turned on, $C_{2}$ is discharging. 


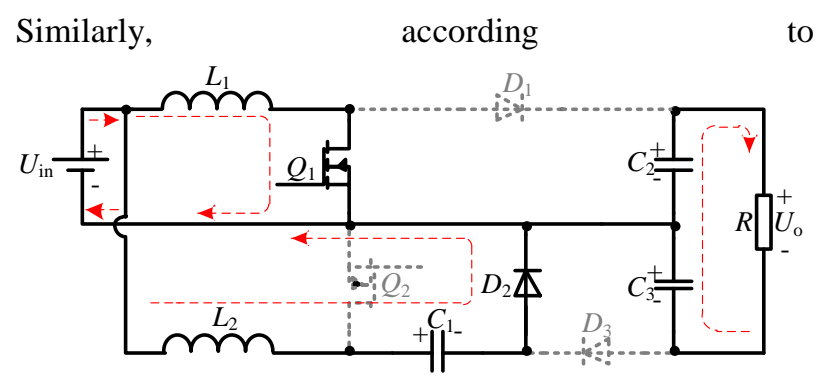

(a) $S_{1} S_{2}=10$

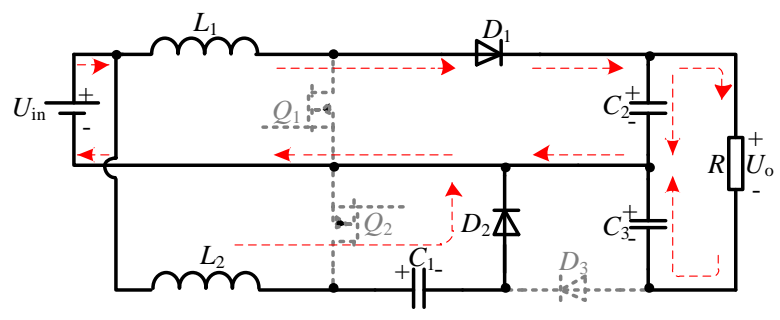

(b) $S_{1} S_{2}=00$

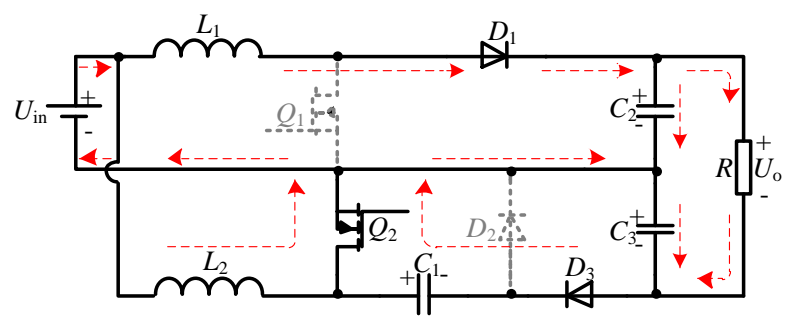

(c) $S_{1} S_{2}=01$

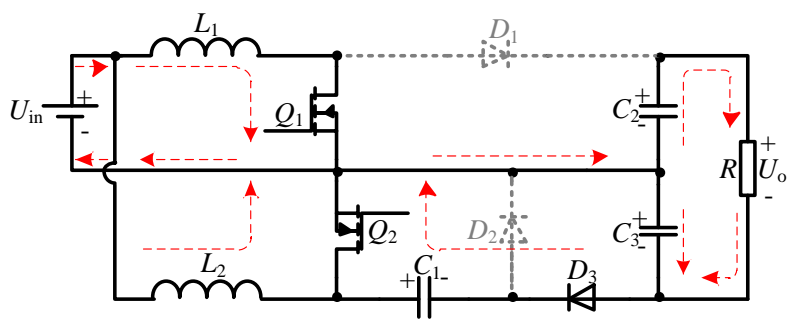

(d) $S_{1} S_{2}=11$

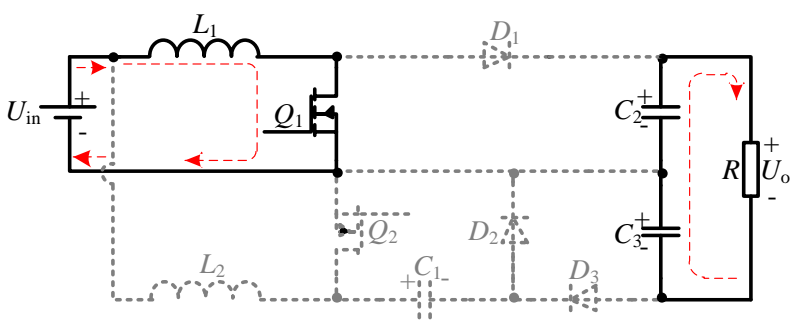

(e) $S_{1} S_{2}=10_{\mathrm{D}}(\mathrm{DCM})$

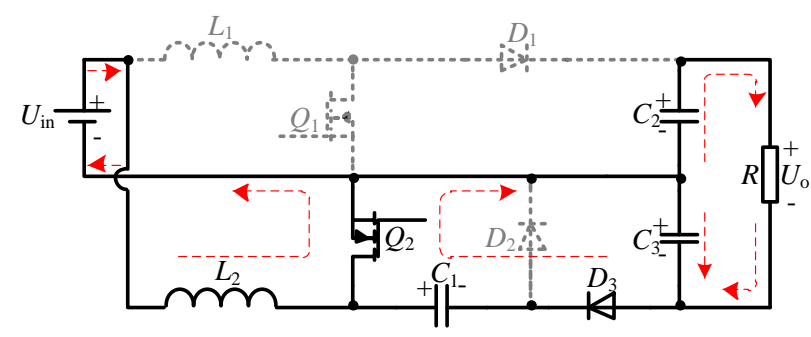

(f) $S_{1} S_{2}=01_{\mathrm{D}}(\mathrm{DCM})$

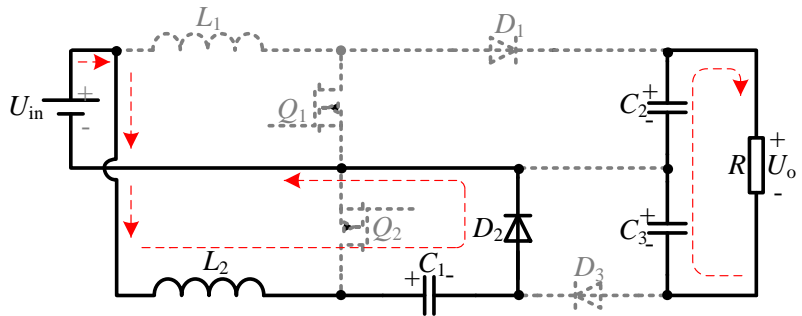

(g) $S_{1} S_{2}=00_{\mathrm{D} 1}(\mathrm{DCM})$

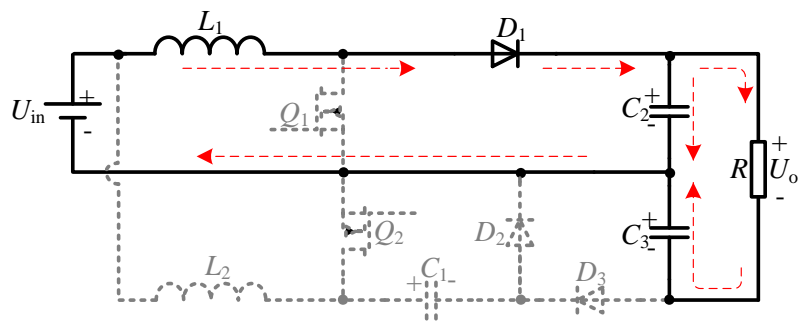

(h) $S_{1} S_{2}=00_{\mathrm{D} 2}(\mathrm{DCM})$

Fig. 2(a, b), when $Q_{2}$ is turned off, $C_{3}$ is discharging. Therefore, the capacitances of $C_{2}$ and $C_{3}$ can be obtained as

$$
\left\{\begin{array}{l}
C_{2}=\frac{d \times I_{\mathrm{o}} \times T_{\mathrm{s}}}{\Delta U_{\mathrm{C} 2}} \\
C_{3}=\frac{(1-d) \times I_{\mathrm{o}} \times T_{\mathrm{s}}}{\Delta U_{\mathrm{C} 3}}
\end{array}\right.
$$

where $\Delta U_{\mathrm{C} 2}$ and $\Delta U_{\mathrm{C} 3}$ are the capacitor voltage fluctuations of $C_{1}$ and $C_{2}$.

In terms of (25), (26) and (27), the inductances of inductors $L_{1}$ and $L_{2}$, and the capacitances of capacitors $C_{1}, C_{2}$ and $C_{3}$ can be designed in this paper.

\section{EXPERIMENT RESULTS AND ANALYSIS}

In order to validate the feasibility and effectiveness of the proposed converter, an input-parallel output-series Boost DC-DC converter was constructed which uses an adjustable DC source with a range of $U_{\text {in }}=50 \mathrm{~V} \sim 120 \mathrm{~V}$ to replace the fuel cell stack source. The converter voltage loop is controlled by a TMS320F28335 DSP. The power circuit uses IXTK102N30P MOSFETs (which has a rated voltage of $300 \mathrm{~V}$ and a rated current of $102 \mathrm{~A}$, while the output voltage of the converter is $400 \mathrm{~V}$ ), and also uses DPG60C300HB Schottky Barrier Diodes. The switching frequency is $20 \mathrm{kHz}$, The inductors are $L_{1}=227 \mu \mathrm{H}$ and $L_{2}=225 \mu \mathrm{H}$ respectively and the capacitances are $C_{1}=C_{2}=C_{3}=470 \mu \mathrm{F}$. The reference output voltage is $400 \mathrm{~V}$, and the load resistance is $R=100 \Omega$.

When the input voltage is $U_{\text {in }}=50 \mathrm{~V}$, the voltage of each power semiconductor is shown in Fig. 6. Fig. 6(a) 
shows the voltages of power switches $Q_{1}$ and $Q_{2}$, and Fig. 6(b) shows the voltages of diodes $D_{1}$ and $D_{2}$. The voltages of $D_{2}$ and $D_{3}$ are shown in Fig. 6(c). The voltage of each power semiconductor is $200 \mathrm{~V}$, i.e. half of the output voltage, as shown in Fig. 6.

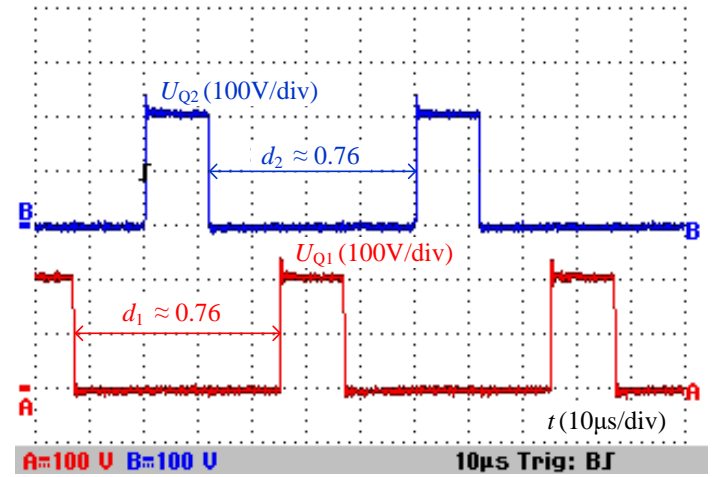

(a) The voltages of power switches $Q_{1}$ and $Q_{2}$

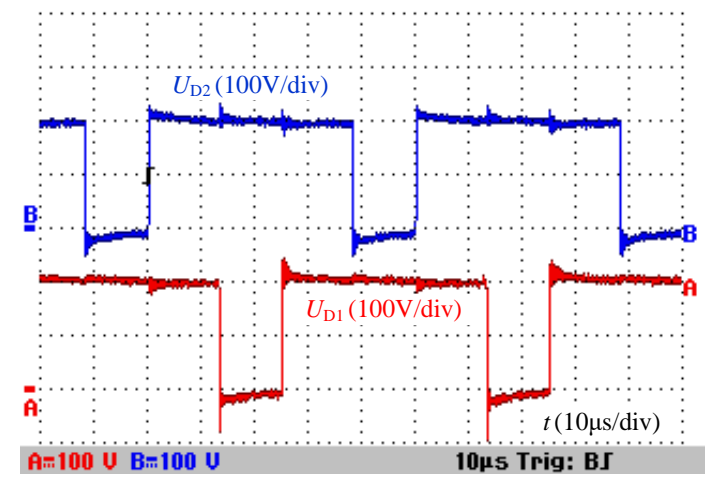

(b) The voltages of diodes $D_{1}$ and $D_{2}$

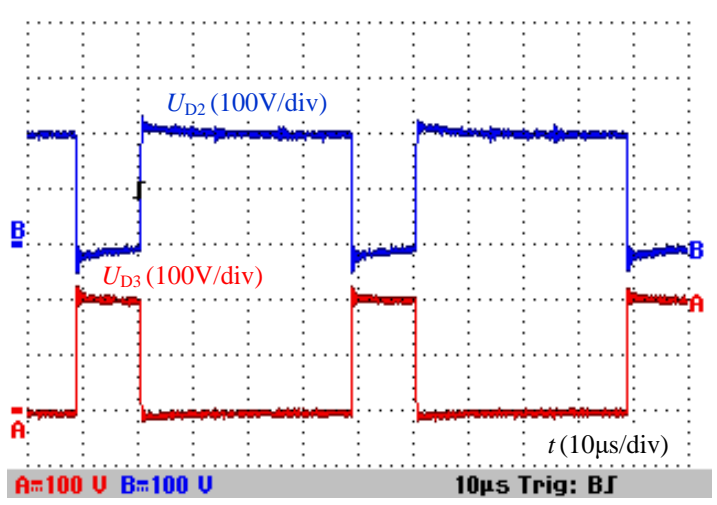

(c) The voltages of $D_{2}$ and $D_{3}$

Fig. 6 The voltage of each power semiconductor when the input voltage is $U_{\text {in }}=50 \mathrm{~V}$.

When the input voltage is $U_{\text {in }}=50 \mathrm{~V}$, the voltages of capacitors $C_{2}$ and $C_{3}$ are shown in Fig. 7. According to Fig. 7 , the voltages of $C_{2}$ and $C_{3}$ are both $200 \mathrm{~V}$, i.e. half of the output voltage. The potential difference between the output and input sides of this converter is the voltage across $C_{3}$, whose ripple is quite low.

When the input voltage is $U_{\text {in }}=50 \mathrm{~V}$, the input current $i_{\text {in }}$, and inductor currents $i_{\mathrm{L} 1}$ and $i_{\mathrm{L} 2}$ are shown in Fig. 8 . Inductor currents $i_{\mathrm{L} 1}$ and $i_{\mathrm{L} 2}$ are shown in Fig. 8(a). Fig. 8(b) shows the input current $i_{\text {in }}$ and inductor current $i_{\mathrm{L} 1}$. According to Fig. 7, the ripple rate of $i_{\mathrm{L} 1}$ is $53.13 \%$, and the ripple rate of $i_{\mathrm{L} 2}$ is $56.25 \%$. In addition, the ripple rate of the input current is $17.65 \%$. The conclusion here is that the current ripple of $i_{\text {in }}$ is much lower than the current ripple of $i_{\mathrm{L} 1}$ and $i_{\mathrm{L} 2}$. According to (24), the ripple rate of $i_{\mathrm{L} 1}$ and $i_{\mathrm{L} 2}$ is $51.81 \%$, and the ripple rate of $i_{\text {in }}$ is $17.28 \%$ theoretically. These results are very similar to the theoretical results.

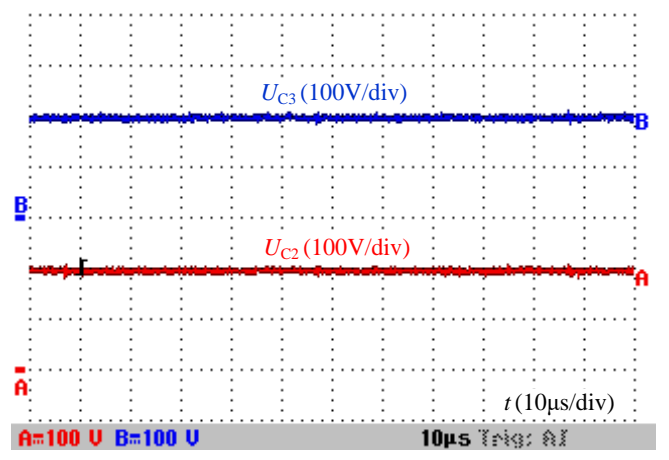

Fig. 7 The voltages of capacitors $C_{2}$ and $C_{3}$ when the input voltage is $U_{\text {in }}=50 \mathrm{~V}$.

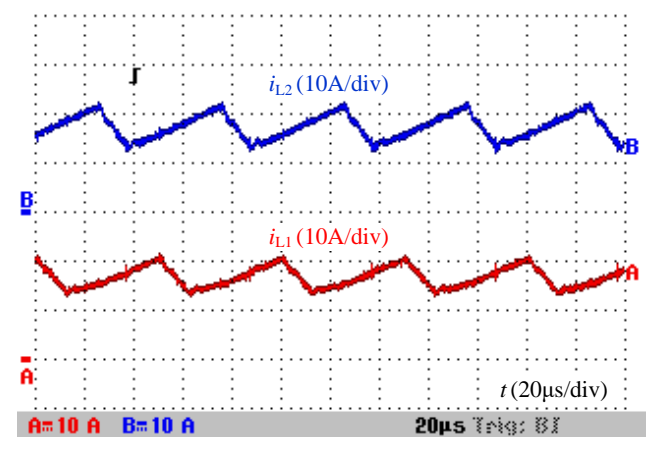

(a) Inductor currents $i_{\mathrm{L} 1}$ and $i_{\mathrm{L} 2}$

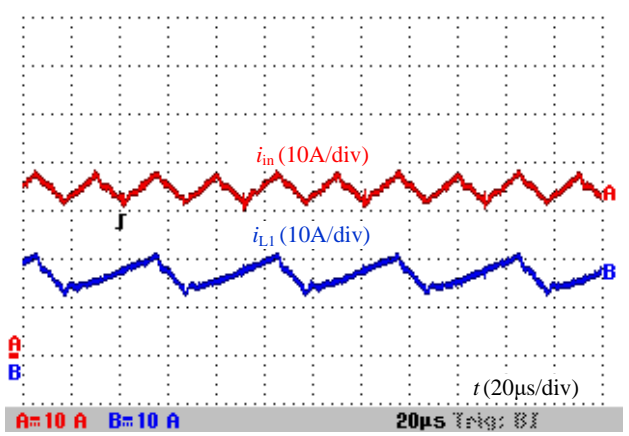

(b) The input current $i_{\text {in }}$ and the inductor current $i_{\mathrm{L} 1}$ 
Fig. 8 The input current $i_{\text {in }}$, inductor currents $i_{\mathrm{L} 1}$ and $i_{\mathrm{L} 2}$ when the input voltage is $U_{\text {in }}=50 \mathrm{~V}$.

The output voltage remains close to the reference voltage $400 \mathrm{~V}$ under the action of the voltage control loop. Fig. 9 shows the dynamic response of the output voltage and the input current when the input voltage was changed from $120 \mathrm{~V}$ to $50 \mathrm{~V}$. Fig. 9(a) shows the output and input voltages, while Fig. 9(b) shows the input current and voltage. According to Fig. 9(a), when the input voltage $U_{\text {in }}$ is changed gradually from $120 \mathrm{~V}$ to $50 \mathrm{~V}$, the output voltage stays around $400 \mathrm{~V}$, which means the proposed converter has a wide voltage gain range varying from 3.3 to 8 . Correspondingly, the input current increases gradually (from $13 \mathrm{~A}$ to $34 \mathrm{~A}$ ) with this large reduction of input voltage (from $120 \mathrm{~V}$ to $50 \mathrm{~V}$ ), as shown in Fig. 9(b).

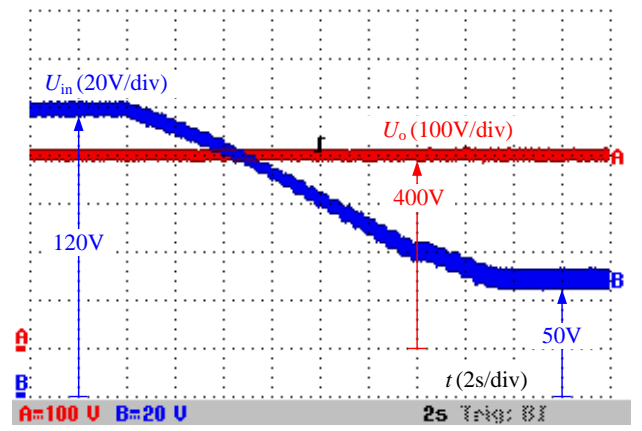

(a) The output and input voltages

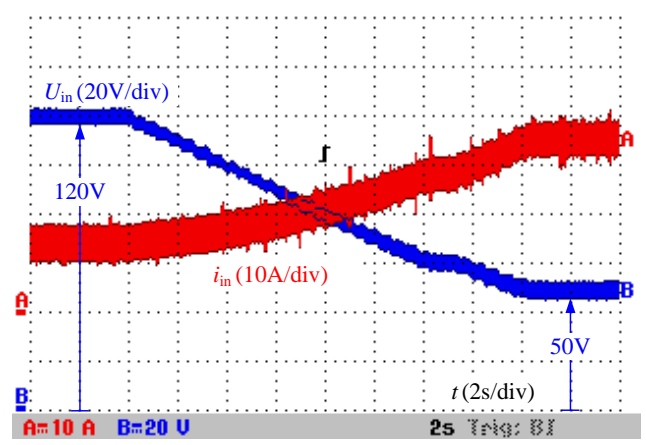

(b) The input current and voltage

Fig. 9 The output voltage and the input current with the wide-range changed input voltage from $120 \mathrm{~V}$ to $50 \mathrm{~V}$ in dynamical state.

When the output voltage is $U_{\mathrm{o}}=400 \mathrm{~V}$ and the load resistance is $R=100 \Omega$, the ripple rate of the input current within the wide input voltage range from $50 \mathrm{~V}$ to $120 \mathrm{~V}$ is shown in Fig. 10, where $\Delta i_{\text {in } 1} / I_{\text {in } 1}$ is the experimental ripple rate of the input current, and $\Delta i_{\text {in } 2} / I_{\text {in } 2}$ is the ripple rate of the input current which is calculated by (4), (19) and (23). According to Fig. 10, the theoretical results are similar to the experiment results.

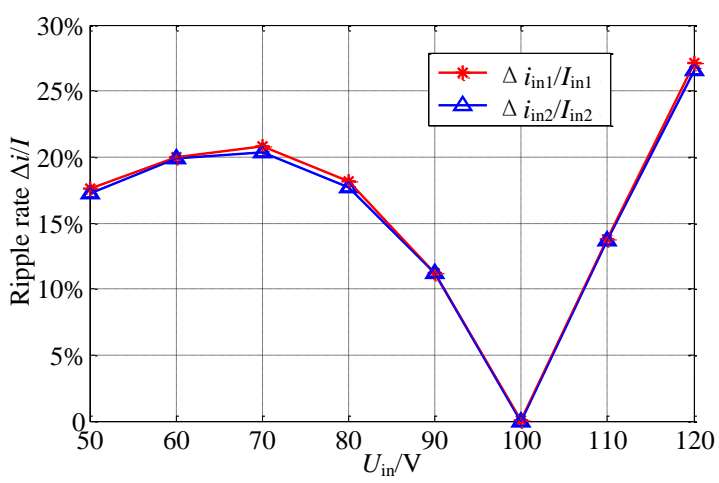

Fig. 10 The ripple rate of input current within the wide input voltage range from $50 \mathrm{~V}$ to $120 \mathrm{~V}$.

When the output voltage is $U_{\mathrm{o}}=400 \mathrm{~V}$ and the load resistance is $R=100 \Omega$, the efficiency $\eta_{\mathrm{e}}$ measured by a Power Analyzer (Yokogawa-WT3000) for different input voltages ranging from $120 \mathrm{~V}$ to $50 \mathrm{~V}$ is shown in Fig. 11. The maximum efficiency is $96.62 \%$, when the voltage-gain is $3.3\left(U_{\text {in }}=120 \mathrm{~V}\right)$. The minimum efficiency is $94.14 \%$, when the voltage-gain is $8\left(U_{\mathrm{in}}=50 \mathrm{~V}\right)$. The input current increases when the voltage gain changes from 3.3 to 8 , and this effect decreases the efficiency of the proposed converter.

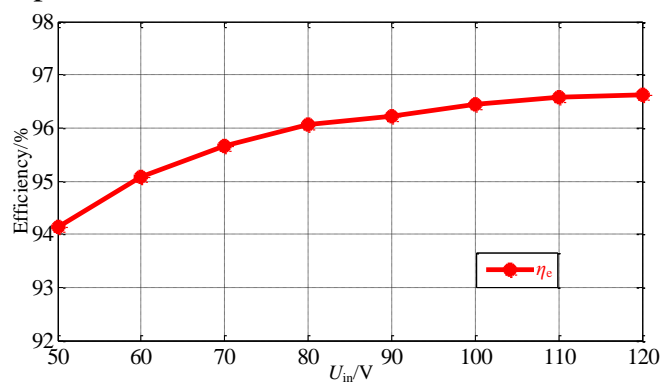

Fig. 11 The efficiency with the wide-range changed input voltage from $120 \mathrm{~V}$ to $50 \mathrm{~V}$ when the output voltage is $U_{\mathrm{o}}=400 \mathrm{~V}$ and the load resistance is $R=100 \Omega$.

\section{CONCLUSION}

In this paper, an input-parallel output-series DC-DC Boost converter with a wide input voltage range is presented. The converter can obtain a wide range of voltage-gain. The voltage stress of each power semiconductor is half of the output voltage. The input current ripple is low, which can prevent accelerated reductions of the life time of a fuel cell. In addition, the potential difference between output and input grounds of the proposed converter is a constant capacitor voltage 
rather than a high frequency PWM voltage. Therefore, it is suitable for fuel cell vehicles.

\section{REFERENCES}

[1] B. K. Bose, "Global Warming: Energy, Environmental Pollution, and the Impact of Power Electronics," IEEE Ind. Electron. Mag., vol. 4, no. 1, pp. 6-17, Mar. 2010.

[2] H. Rudnick, "Evolution of Energy: Global Developments and Challenges," IEEE Power Energy Mag., vol. 10, no.3, pp. 12-19, May 2012.

[3] H. Liu, X. Huang, L. Tan, J. Guo, and W. Wei, "Switching Control Optimization Strategy of Segmented Transmitting Coils for On-road Charging of Electrical Vehicles," IET Power Electron., vol. 9, no. 11, pp. 2282-2288, Jun. 2016.

[4] T. Kin, H. Oh, H. Kin, and B. D. Youn, “An Online-Applicable Model for Predicting Health Degradation of PEM Fuel Cells with Root Cause Analysis," IEEE Trans. Ind. Electron., vol. 63, no. 11, pp. 7091-7103, Nov. 2016.

[5] M. Vasirani, R. Kota, R. L. G. Cavalcante, S. Ossowski, and N. R. Jennings, "An Agent-Based Approach to Virtual Power Plants of Wind Power Generators and Electric Vehicles," IEEE Trans. Smart Grid, vol. 4, no. 3, pp. 1314-1322, Sep. 2013.

[6] F. Yang, Q. Sun, Q. Han, and Z. Wu, "Cooperative Model Predictive Control for Distributed Photovoltaic Power Generation Systems," IEEE Journal of Emerging and Selected Topics in Power Electronics, vol. 4, no. 2, pp. 414-420, Jun. 2016.

[7] A. Chiba, K. Kiyota, N. Hoshi, M. Takemoto, and S. Ogasawara, "Development of a Rare-Earth-Free SR Motor With High Torque Density for Hybrid Vehicles," IEEE Trans. Energy Convers., vol. 30, no. 1 , pp. 175-182, Mar. 2015.

[8] K. Li, T. Chen, Y. Luo, and J. Wang, "Intelligent environment-friendly vehicles: concept and case studies," IEEE Trans. Intell. Transp. Syst., vol. 13, no.1, pp. 318 - 328, Jul. 2011.

[9] K. Tomoda, N. Hoshi, J. Haruna, M. Cao, A. Yoshizaki, and K. Hirata, "Hydrolysis Rate Improvement in Hydrogen Generation System Fueled by Powdery Sodium Borohydride for Fuel-Cell Vehicle," IEEE Trans. Ind. Appl., vol. 50, no. 4, pp. 2741-2748, Jul./Aug. 2014.

[10] M. Jang, and V. G. Agelidis, "A Boost-Inverter-Based, Battery-Supported, Fuel-Cell Sourced Three-Phase Stand-Alone Power Supply," IEEE Trans. Power Electron., vol. 29, no. 12, pp. 6472-6480, Dec. 2014.

[11] U. R. Prasanna, and A. K. Rathore, "Dual three-pulse modulation-based high-frequency pulsating DC link two-stage three-phase inverter for electric/hybrid/fuel cell vehicles applications," IEEE Journal of Emerging and Selected Topics in Power Electronics, vol. 2, no. 3, pp. 477-486, Oct. 2014

[12] C. Liu, and J. Lai, "Low Frequency Current Ripple Reduction Technique With Active Control in a Fuel Cell Power System With Inverter Load," IEEE Trans. Power Electron., vol. 22, no. 4, pp. 1429-1436, 2007

[13] X. Ruan, B. Li, Q. Chen, S. Tan, and C. K. Tse, "Fundamental considerations of three-level DC-DC converters: topologies, analyses, and control," IEEE Trans. Circuits Syst. I, Reg. Papers, vol. 55, no. 11, pp. 3733-3743, Dec. 2008.

[14] K. Jin, X. Ruan, M. Yang, and M. Xu, "A. Hybrid Fuel Cell Power System,” IEEE Trans. Ind. Electron., vol. 56, no. 4, pp. 1212-1222, Apr. 2009.

[15] F. Z. Peng, F. Zhang, and Z. Qian, "A magnetic-less dc-dc converter fordual-voltage automotive systems," IEEE Trans. Ind. Appl., vol. 39, no. 2, pp. 511-518, Mar./Apr. 2003.

[16] S. J. Amodeo, H. G. Chiacchiarini, and A. R. Oliva, "High-performance control of a DC-DC Z-source converter used for an excitation field driver," IEEE Trans. Power Electron., vol. 27, no. 6, pp 2947-2957, Jun. 2012.

[17] K. Patidar, and A. C. Umarikar, "High step-up pulse-width modulation DC-DC converter based on quasi-Z-source topology," IET Power Electron., vol. 8, no. 4, pp. 477-488, 2015.

[18] Y. Tang, D. Fu, T. Wang, and Z. Xu, "Hybrid Switched-Inductor Converters for High Step-Up Conversion," IEEE Trans. Ind. Electron., vol. 62, no. 3, pp. 1480-1490, Oct. 2015.

[19] R. Wai and R. Duan, "High Step-Up Converter With Coupled-Inductor," IEEE Trans. Power Electron., vol. 20, no. 5, pp. 1025-1035, Sep. 2005.

[20] W. Li and X. He, "Review of Nonisolated High-Step-Up DC/DC Converters in Photovoltaic Grid-Connected Applications," IEEE Trans. Ind. Electron, vol. 58, no. 4, pp. 1239-1250, Apr. 2011.

[21] H. Liu, H. Hu, H. Wu, Y. Xing and I. Batarseh, "Overview of High-Step-Up Coupled-Inductor Boost Converters," IEEE Journal of Emerging and Selected Topics in Power Electronics, vol. 4, no. 2, pp. 689-704, Jun. 2016.

[22] F. L. Tofoli, D. d. C. Pereira, W. Josias de Paula and D. d. S. Oliveira Júnior, "Survey on non-isolated high-voltage step-up dc-dc topologies based on the boost converter," IET Power Electron, vol. 8, no. 10, pp. 2044-2057, Apr. 2015.

[23] L. Yang, T. Liang, and J. Chen, "Transformerless DC-DC Converters With High Step-up Voltage Gain," IEEE Trans. Ind. 
Electron., vol. 56, no. 8, pp. 3144-3152, Aug. 2009.

[24] X. Hu and C. Gong, "A High Gain Input-Parallel Output-Series DC/DC Converter With Dual Coupled Inductors," IEEE Trans. Power Electron., vol. 30, no. 3, pp. 1306-1317, Mar. 2015.

[25] X. Hu, L. Li, Y. Li and G. Wu, "Input-parallel output-series DC-DC converter for non-isolated high step-up applications," Electronics Letters, vol. 52, no. 20, pp. 1715-1717, Sep. 2016. 